\title{
Bioactive Iridoid Glycosides from the Whole Plants of Rehmannia chingii
}

Yan-Fei Liu, Guo-Ru Shi, Xin Wang, Chun-Lei Zhang, Yan Wang, Ruo-Yun Chen, and De-Quan $\mathrm{Yu}^{*}$

State Key Laboratory of Bioactive Substance and Function of Natural Medicines,

Institute of Materia Medica, Chinese Academy of Medical Sciences and Peking Union

Medical College, Beijing 100050, People's Republic of China

\section{Supporting Information}




\section{List of Supporting Information}

S1. IR Spectrum of compound 1

S2. ${ }^{1} \mathrm{H}$ NMR Spectrum of compound $1\left(600 \mathrm{MHz}\right.$, Methanol- $\left.d_{4}\right)$

S3. ${ }^{13} \mathrm{C}$ NMR Spectrum of compound 1 (150 MHz, Methanol- $d_{4}$ )

S4. ${ }^{1} \mathrm{H}-{ }^{1} \mathrm{H}$ COSY Spectrum of compound $\mathbf{1}$

S5. HSQC Spectrum of compound 1

S6. HMBC Spectrum of compound 1

S7. NOESY Spectrum of compound 1

S8. HRESIMS Spectrum of compound $\mathbf{1}$

S9. CD Spectrum of compound $1\left(\mathrm{CH}_{3} \mathrm{OH}\right)$

S10. IR Spectrum of compound 2

S11. ${ }^{1} \mathrm{H}$ NMR Spectrum of compound $2\left(600 \mathrm{MHz}\right.$, Methanol- $\left.d_{4}\right)$

S12. ${ }^{13} \mathrm{C}$ NMR Spectrum of compound 2 (150 MHz, Methanol- $\left.d_{4}\right)$

S13. ${ }^{1} \mathrm{H}-{ }^{1} \mathrm{H}$ COSY Spectrum of compound 2

S14. HSQC Spectrum of compound 2

S15. HMBC Spectrum of compound 2

S16. ROESY Spectrum of compound 2

S17. HRESIMS Spectrum of compound 2

S18. CD Spectrum of compound $2\left(\mathrm{CH}_{3} \mathrm{OH}\right)$

S19. IR Spectrum of compound 3

S20. ${ }^{1} \mathrm{H}$ NMR Spectrum of compound $3\left(500 \mathrm{MHz}\right.$, Methanol- $\left.d_{4}\right)$

S21. ${ }^{13} \mathrm{C}$ NMR Spectrum of compound 3 (125 MHz, Methanol- $\left.d_{4}\right)$

S22. ${ }^{1} \mathrm{H}-{ }^{1} \mathrm{H}$ COSY Spectrum of compound 3

S23. HSQC Spectrum of compound $\mathbf{3}$

S24. HMBC Spectrum of compound 3

S25. ROESY Spectrum of compound 3

S26. HRESIMS Spectrum of compound 3

S27. CD Spectrum of compound $3\left(\mathrm{CH}_{3} \mathrm{OH}\right)$

S28. IR Spectrum of compound 4

S29. ${ }^{1} \mathrm{H}$ NMR Spectrum of compound 4 (500 MHz, Methanol- $d_{4}$ )

S30. ${ }^{13} \mathrm{C}$ NMR Spectrum of compound 4 (125 MHz, Methanol- $\left.d_{4}\right)$

S31. ${ }^{1} \mathrm{H}-{ }^{1} \mathrm{H}$ COSY Spectrum of compound 4

S32. HSQC Spectrum of compound 4

S33. HMBC Spectrum of compound 4

S34. ROESY Spectrum of compound 4

S35. HRESIMS Spectrum of compound 4

S36. CD Spectrum of compound $4\left(\mathrm{CH}_{3} \mathrm{OH}\right)$

S37. IR Spectrum of compound 5

S38. ${ }^{1} \mathrm{H}$ NMR Spectrum of compound $5\left(600 \mathrm{MHz}\right.$, Methanol- $\left.d_{4}\right)$

S39. ${ }^{13} \mathrm{C}$ NMR Spectrum of compound 5 (150 MHz, Methanol- $\left.d_{4}\right)$

S40. ${ }^{1} \mathrm{H}-{ }^{1} \mathrm{H}$ COSY Spectrum of compound 5

S41. HSQC Spectrum of compound $\mathbf{5}$

S42. HMBC Spectrum of compound 5 
S43. ROESY Spectrum of compound 5

S44. HRESIMS Spectrum of compound 5

S45. CD Spectrum of compound $\mathbf{5}\left(\mathrm{CH}_{3} \mathrm{OH}\right)$

S46. IR Spectrum of compound 6

S47. ${ }^{1} \mathrm{H}$ NMR Spectrum of compound 6 (600MHz, Methanol- $\left.d_{4}\right)$

S48. ${ }^{13} \mathrm{C}$ NMR Spectrum of compound 6 (150 MHz, Methanol- $\left.d_{4}\right)$

S49. ${ }^{1} \mathrm{H}-{ }^{1} \mathrm{H}$ COSY Spectrum of compound 6

S50. HSQC Spectrum of compound 6

S51. HMBC Spectrum of compound 6

S52. NOESY Spectrum of compound 6

S53. HRESIMS Spectrum of compound 6

S54. CD Spectrum of compound $6\left(\mathrm{CH}_{3} \mathrm{OH}\right)$

S55. IR Spectrum of compound 7

S56. ${ }^{1} \mathrm{H}$ NMR Spectrum of compound 7 (500MHz, Methanol- $\left.d_{4}\right)$

S57. ${ }^{13} \mathrm{C}$ NMR Spectrum of compound 7 (125 MHz, Methanol- $\left.d_{4}\right)$

S58. ${ }^{1} \mathrm{H}-{ }^{1} \mathrm{H}$ COSY Spectrum of compound 7

S59. HSQC Spectrum of compound 7

S60. HMBC Spectrum of compound 7

S61. ROESY Spectrum of compound 7

S62. HRESIMS Spectrum of compound 7

S63. CD Spectrum of compound $7\left(\mathrm{CH}_{3} \mathrm{OH}\right)$

S64. IR Spectrum of compound $\mathbf{8}$

S65. ${ }^{1} \mathrm{H}$ NMR Spectrum of compound $8\left(500 \mathrm{MHz}\right.$, Methanol- $\left.d_{4}\right)$

S66. ${ }^{13} \mathrm{C}$ NMR spectrum of compound $8\left(125 \mathrm{MHz}\right.$, Methanol- $\left.d_{4}\right)$

S67. ${ }^{1} \mathrm{H}-{ }^{1} \mathrm{H}$ COSY Spectrum of compound 8

S68. HSQC Spectrum of compound $\mathbf{8}$

S69. HMBC Spectrum of compound 8

S70. ROESY Spectrum of compound 8

S71. HRESIMS Spectrum of compound $\mathbf{8}$

S72. CD Spectrum of compound $8\left(\mathrm{CH}_{3} \mathrm{OH}\right)$

S73. IR Spectrum of compound 9

S74. ${ }^{1} \mathrm{H}$ NMR Spectrum of compound $9\left(500 \mathrm{MHz}\right.$, Methanol- $\left.d_{4}\right)$

S75. ${ }^{13} \mathrm{C}$ NMR Spectrum of compound $9\left(125 \mathrm{MHz}\right.$, Methanol- $\left.d_{4}\right)$

S76. ${ }^{1} \mathrm{H}-{ }^{1} \mathrm{H}$ COSY Spectrum of compound 9

S77. HSQC Spectrum of compound 9

S78. HMBC Spectrum of compound 9

S79. ROESY Spectrum of compound 9

S80. HRESIMS Spectrum of compound 9

S81. CD Spectrum of compound $9\left(\mathrm{CH}_{3} \mathrm{OH}\right)$ 


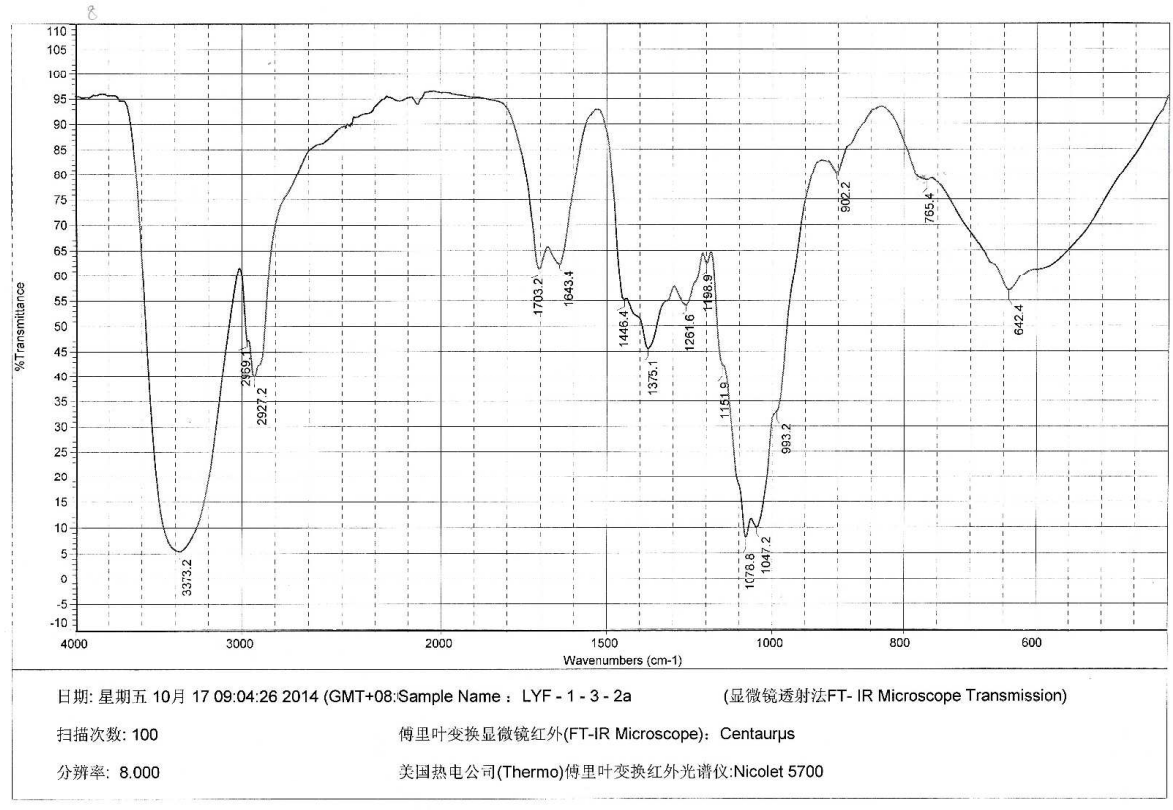

S1. IR Spectrum of compound 1

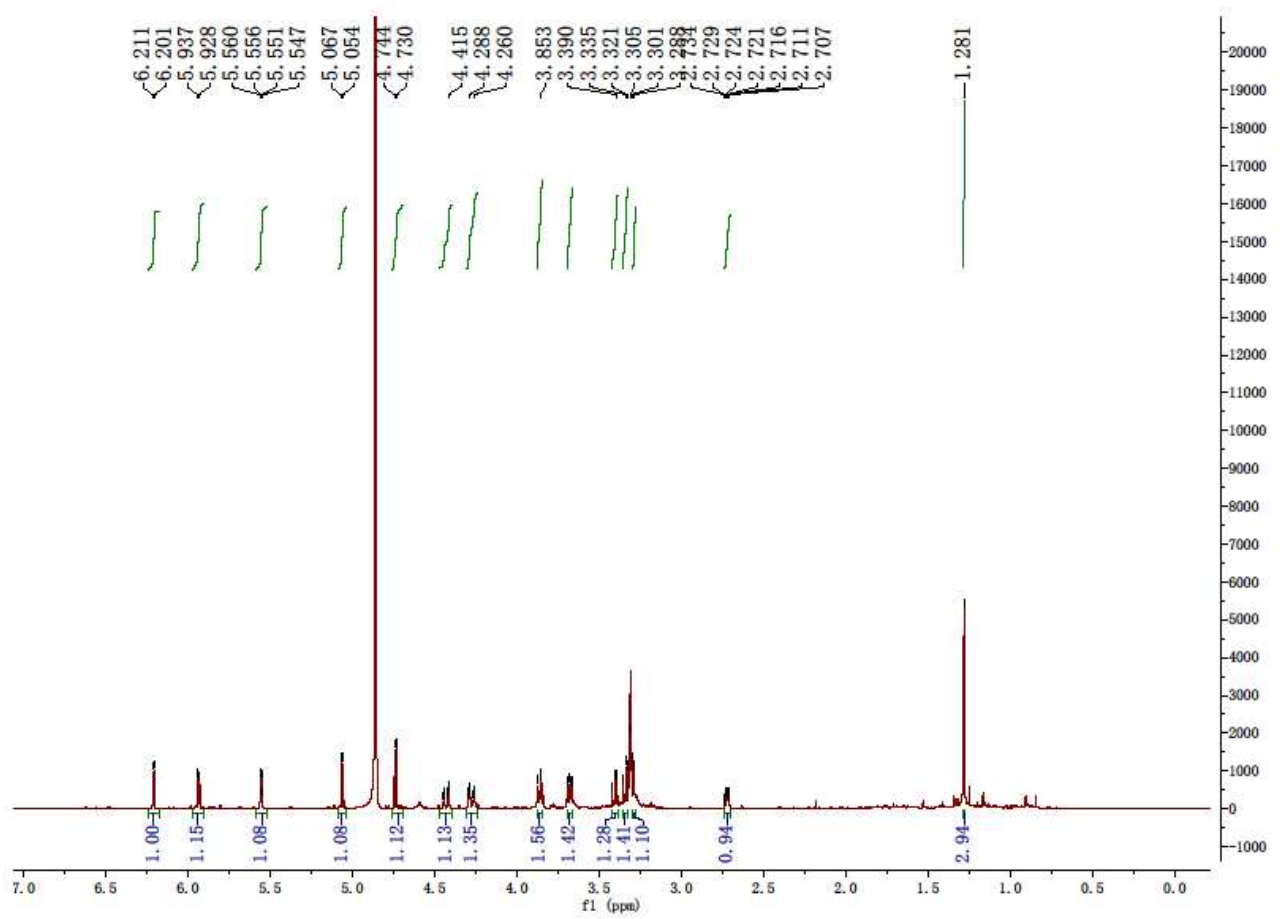

S2. ${ }^{1} \mathrm{H}$ NMR Spectrum of compound 1 (600MHz, Methanol- $\left.d_{4}\right)$ 


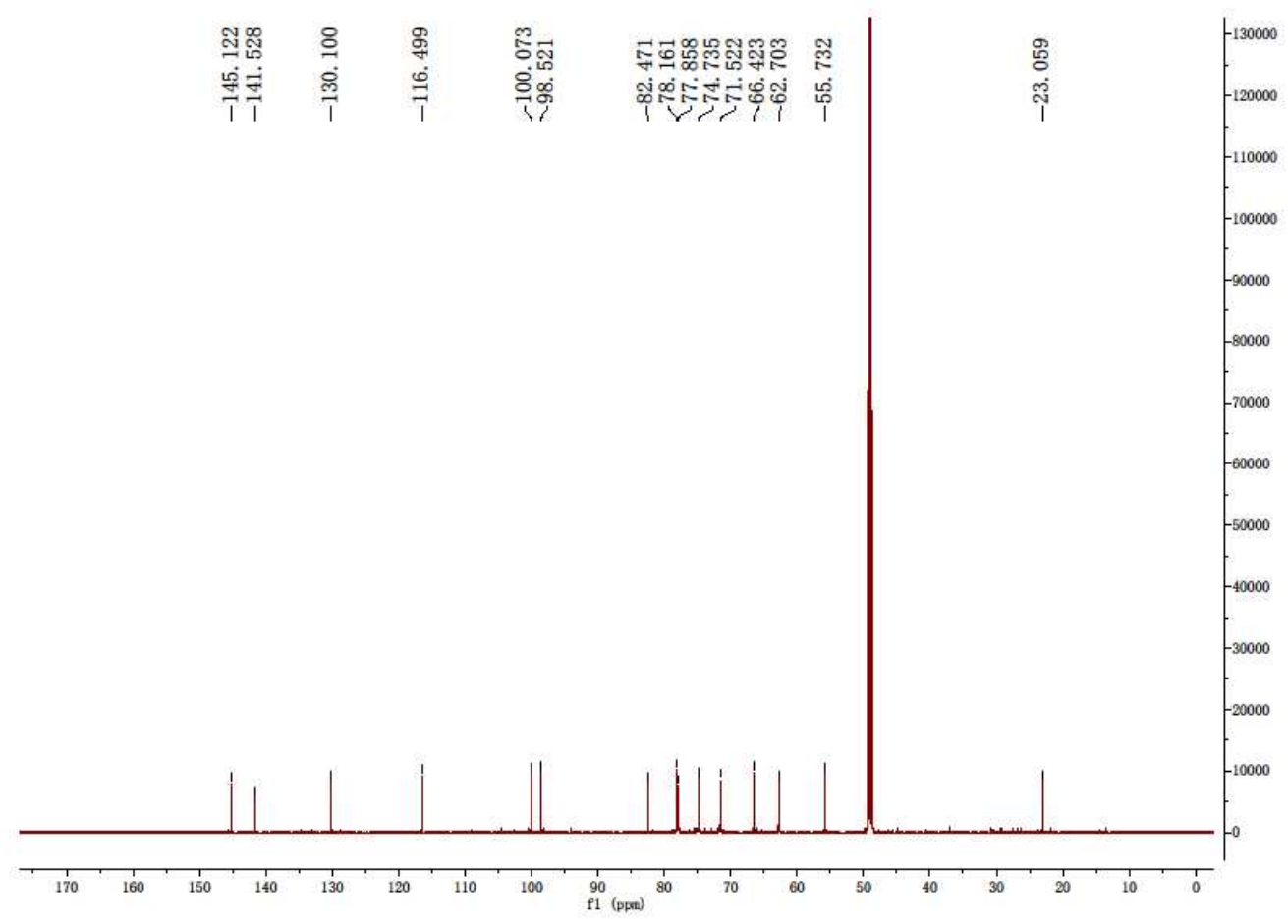

S3. ${ }^{13} \mathrm{C}$ NMR Spectrum of compound 1 (150 MHz, Methanol- $\left.d_{4}\right)$

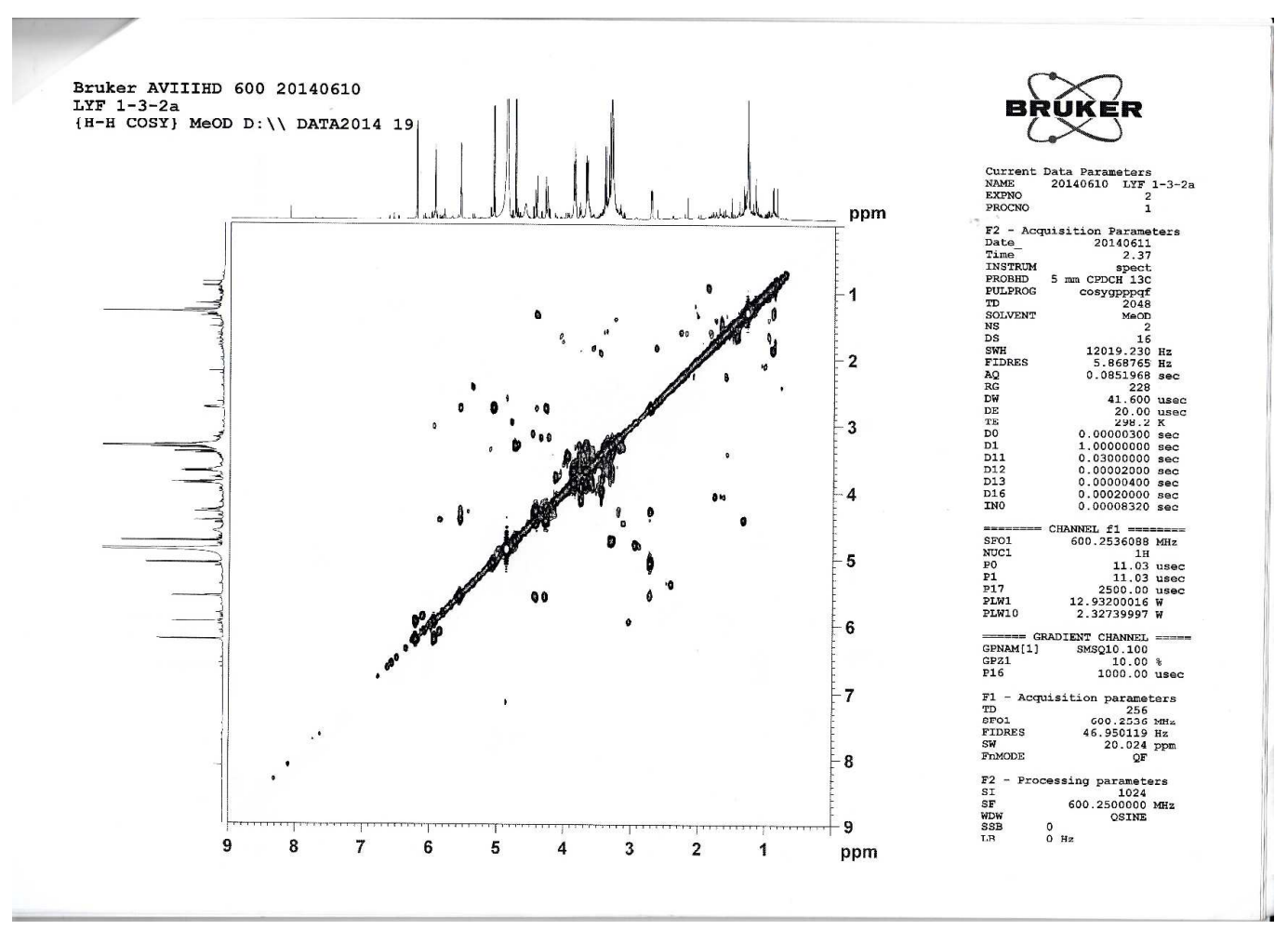

S4. ${ }^{1} \mathrm{H}-{ }^{1} \mathrm{H}$ COSY Spectrum of compound $\mathbf{1}$ 


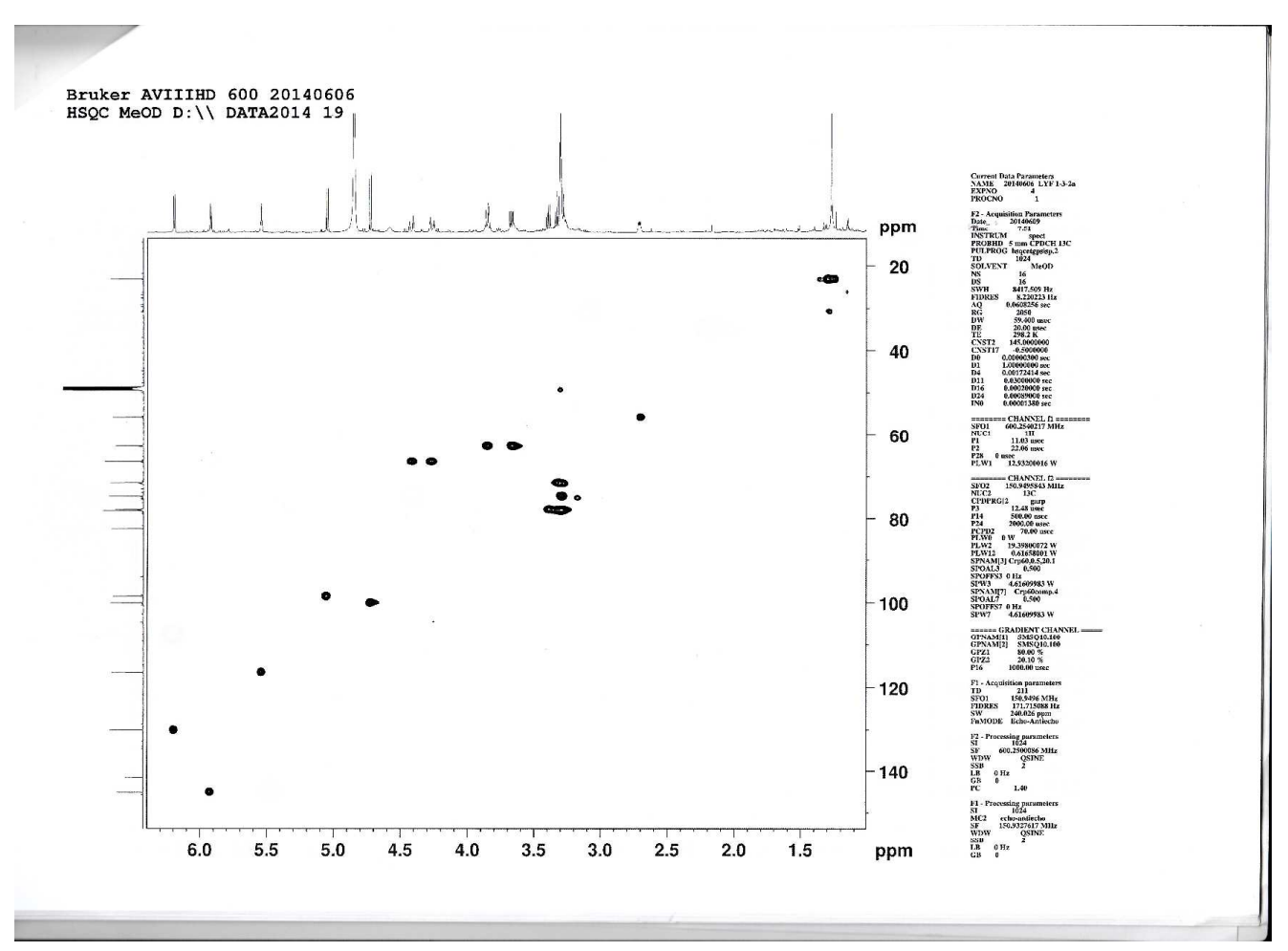

S5. HSQC Spectrum of compound $\mathbf{1}$

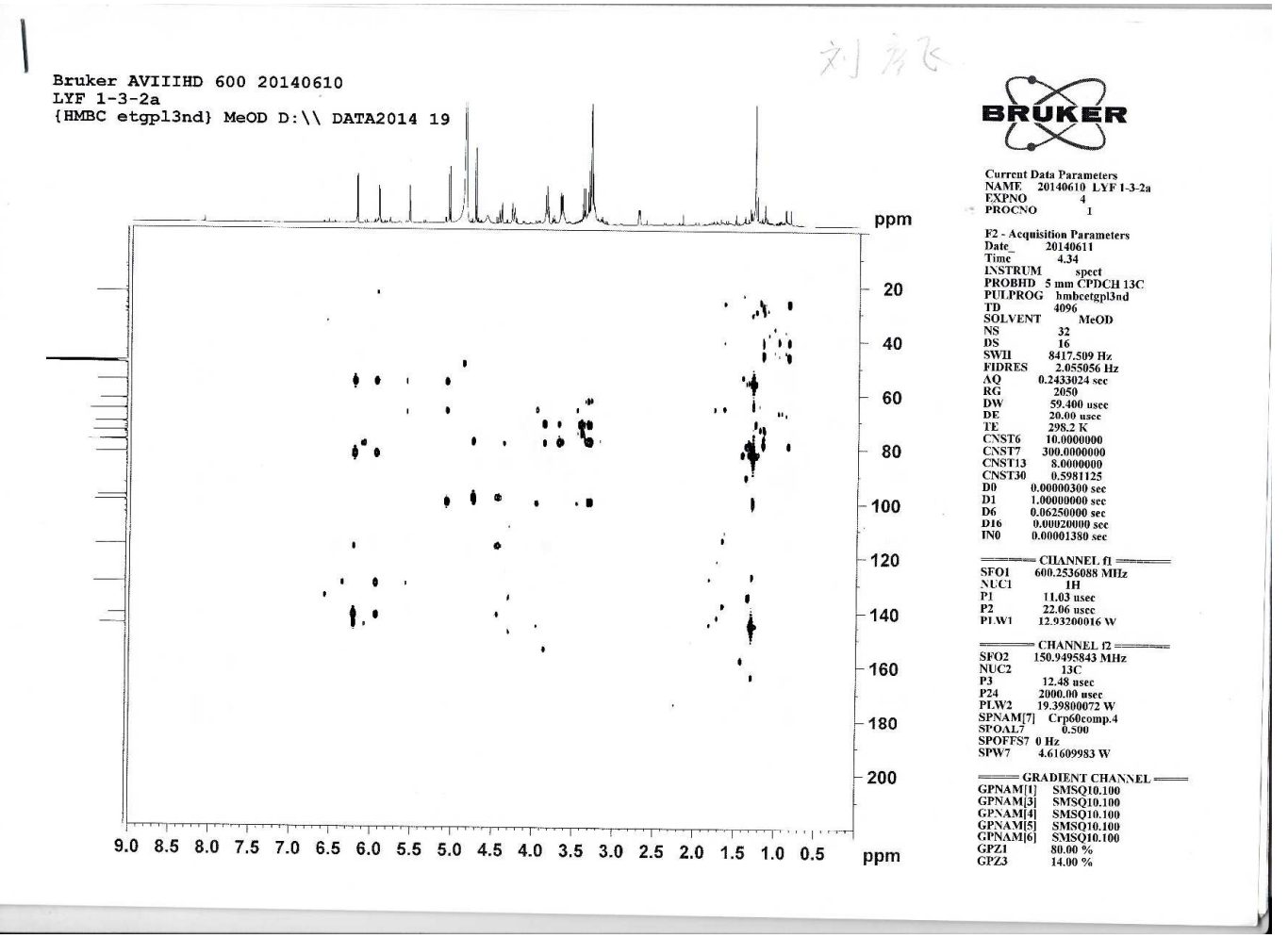

S6. HMBC Spectrum of compound 1 


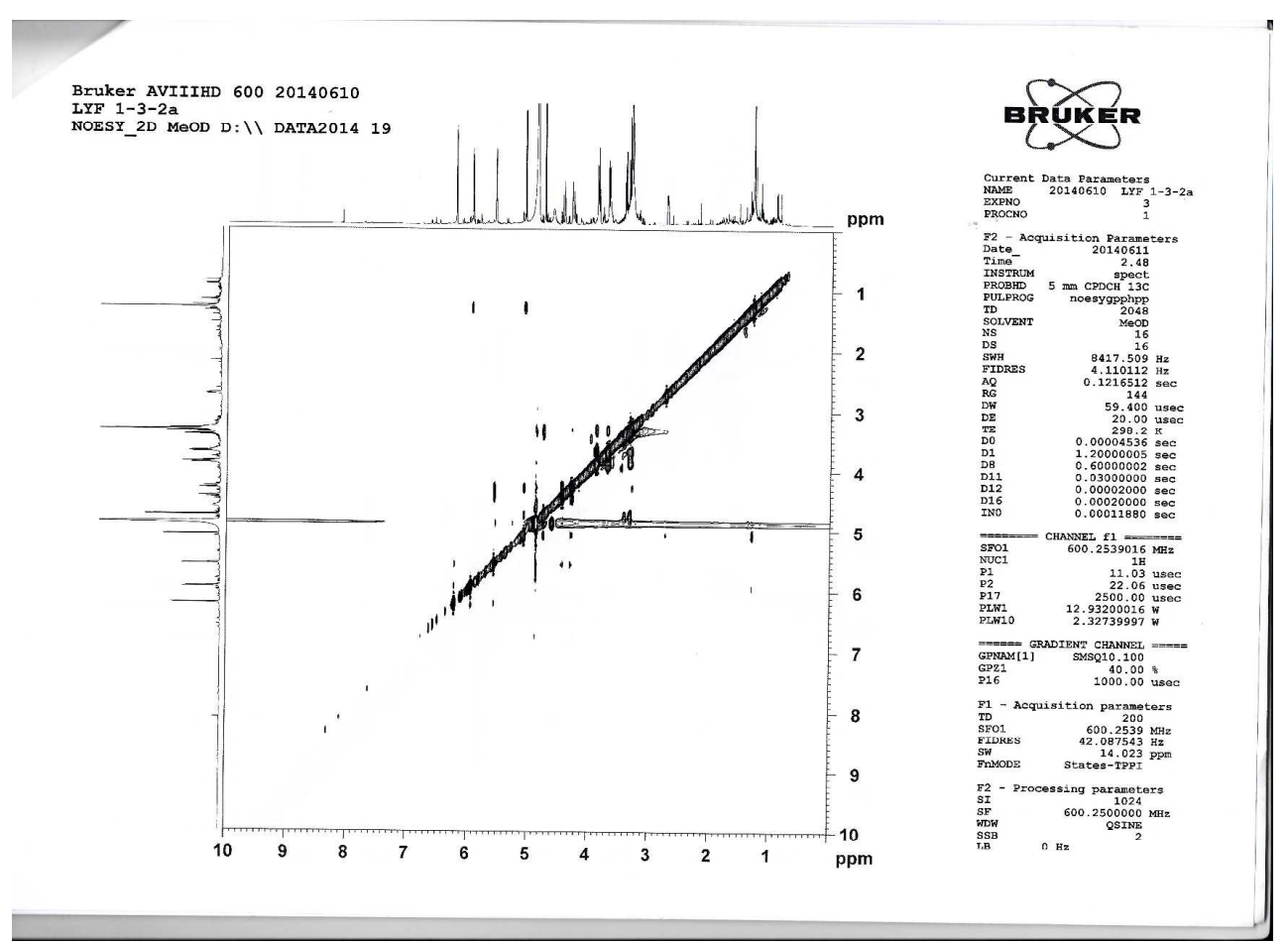

S7. NOESY Spectrum of compound $\mathbf{1}$

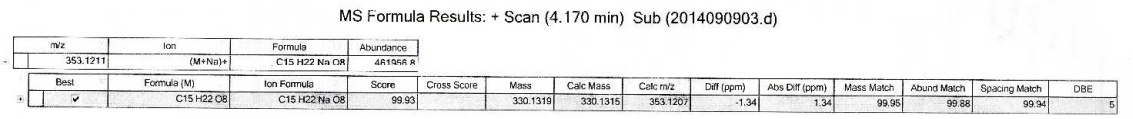

S8. HRESIMS Spectrum of compound 1

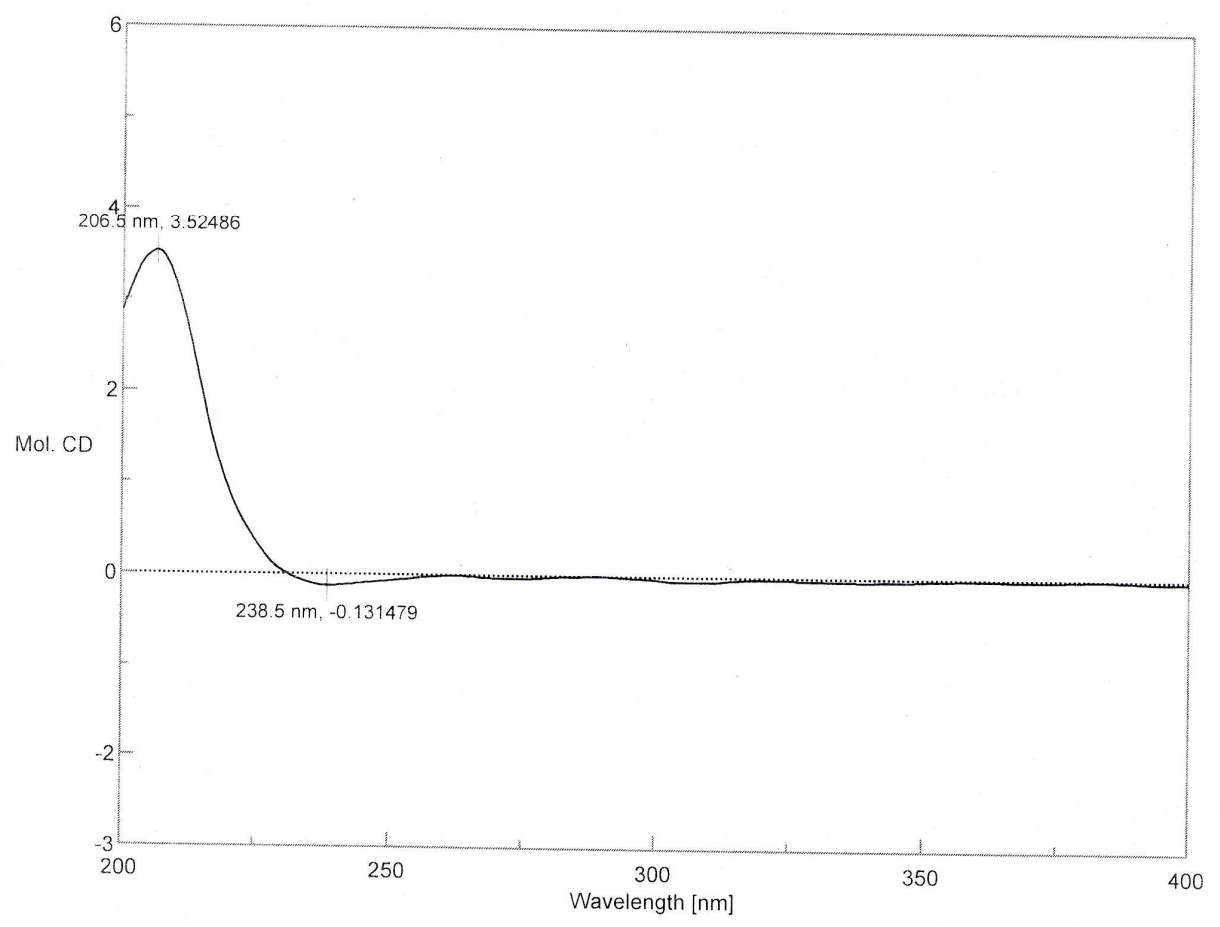


S9. CD Spectrum of compound $\mathbf{1}\left(\mathrm{CH}_{3} \mathrm{OH}\right)$

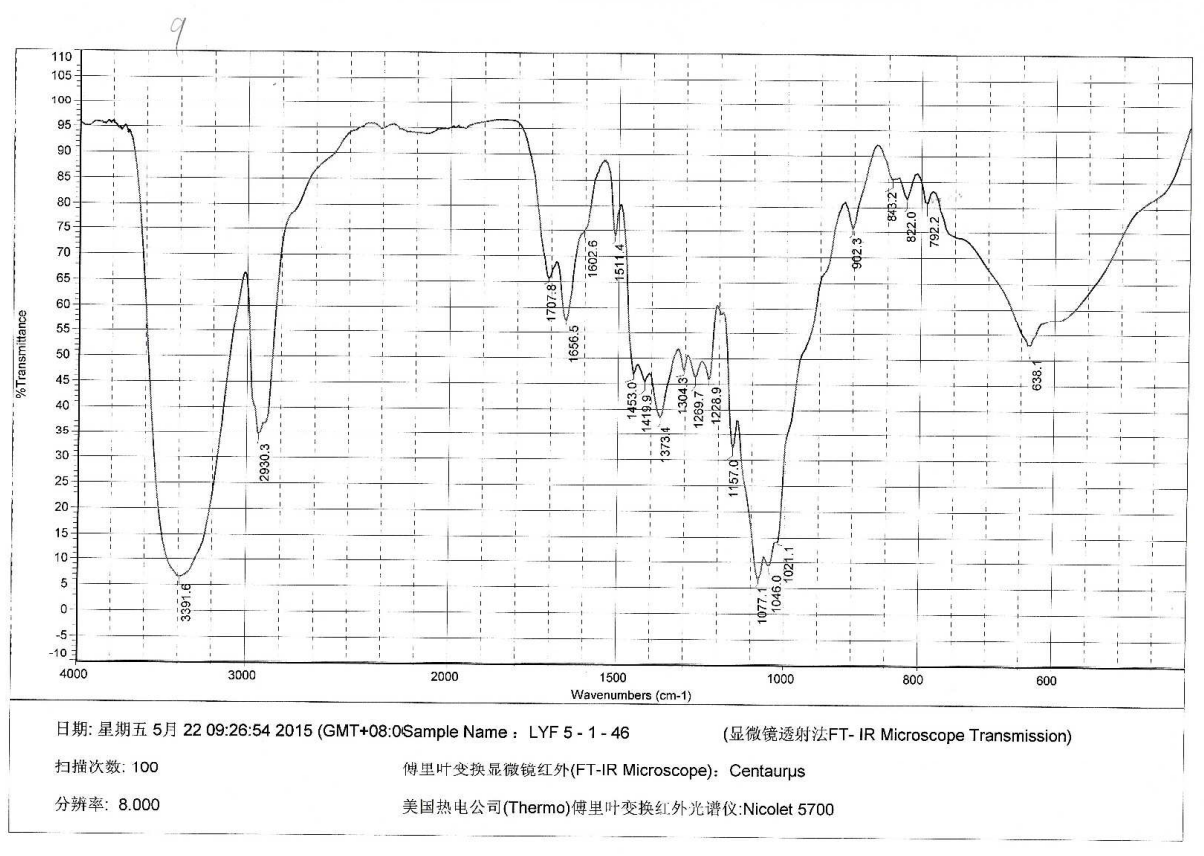

S10. IR Spectrum of compound 2

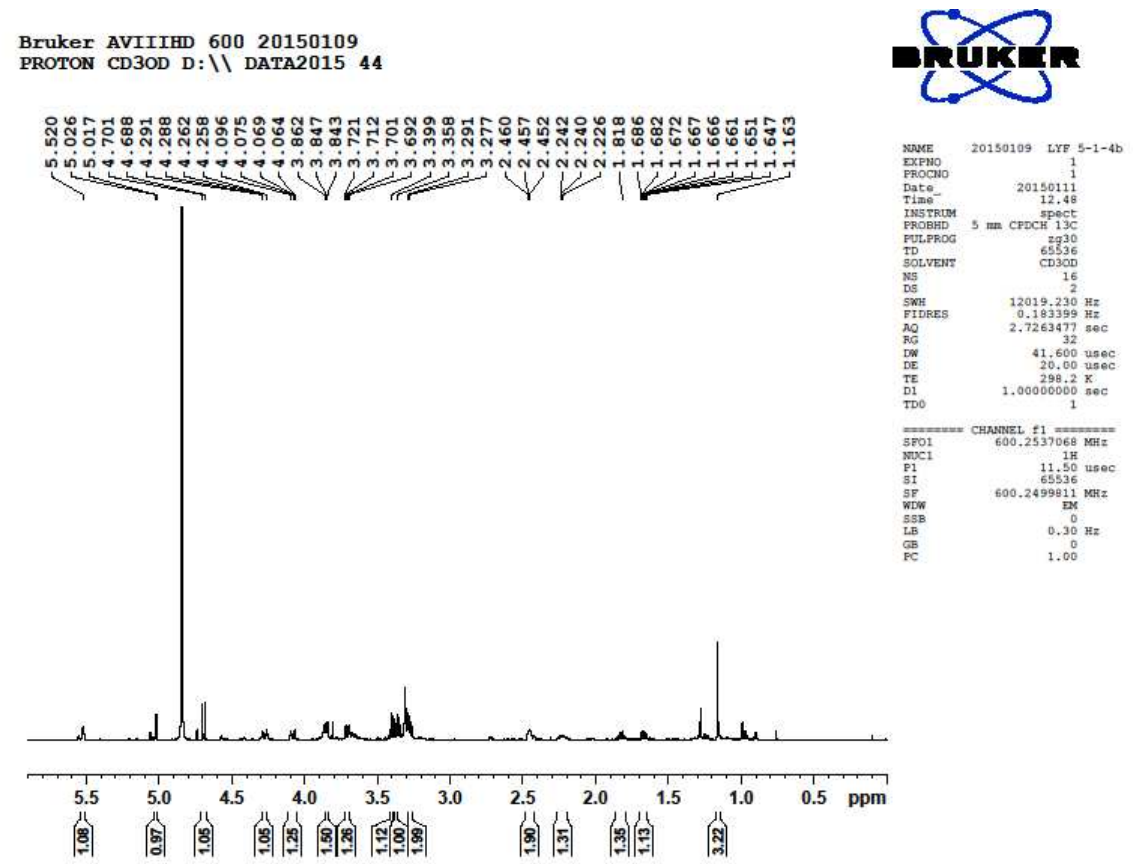

S11. ${ }^{1} \mathrm{H}$ NMR Spectrum of compound 2 (600 MHz, Methanol- $d_{4}$ ) 


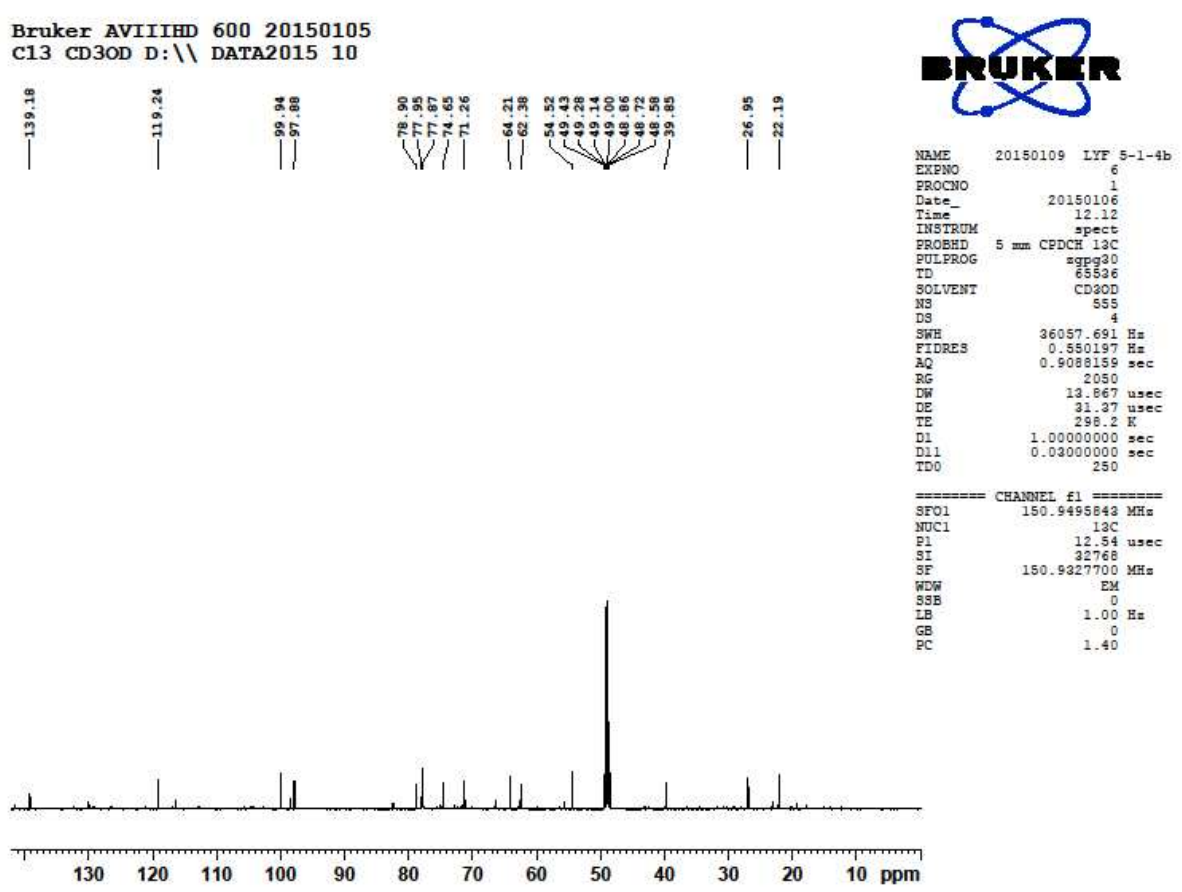

S12. ${ }^{13} \mathrm{C}$ NMR Spectrum of compound $2\left(150 \mathrm{MHz}\right.$, Methanol- $\left.d_{4}\right)$

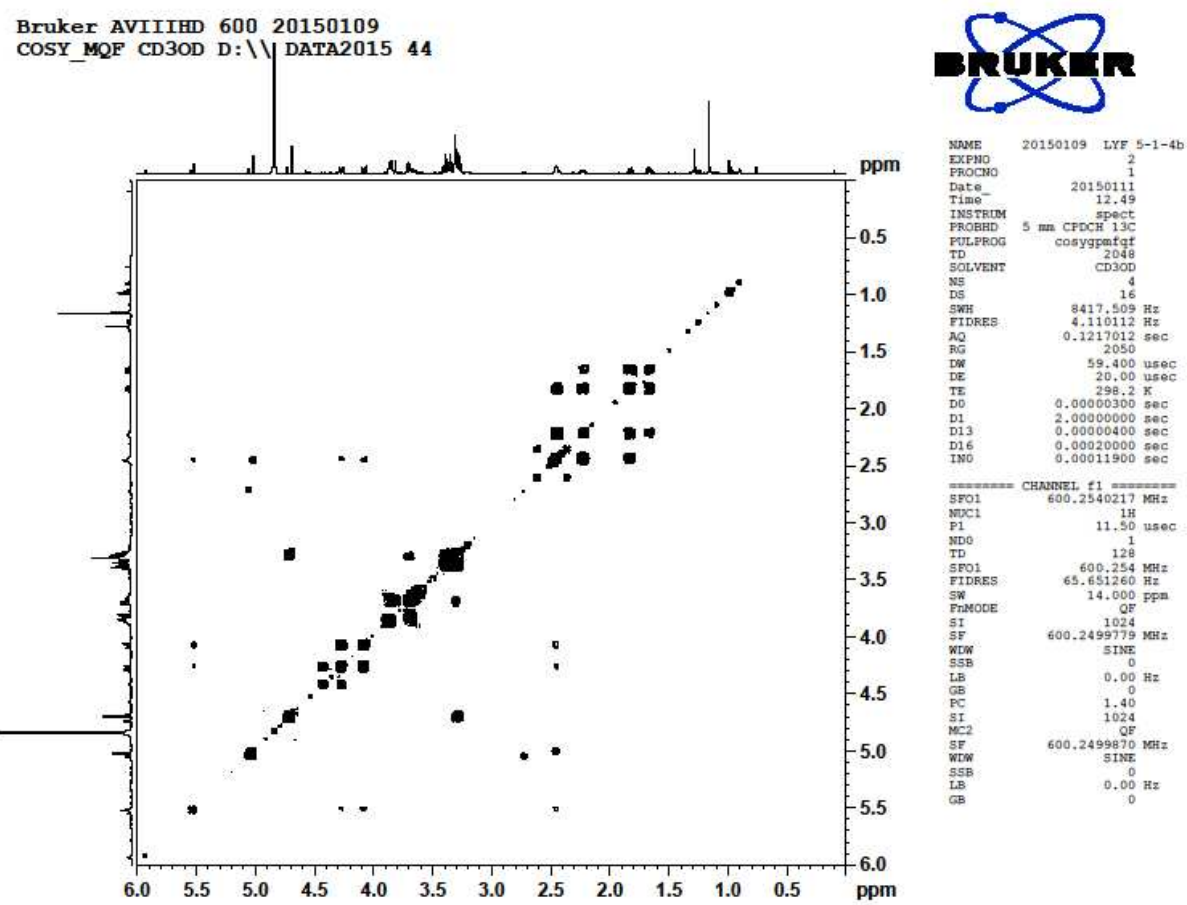

S13. ${ }^{1} \mathrm{H}-{ }^{1} \mathrm{H}$ COSY Spectrum of compound 2 


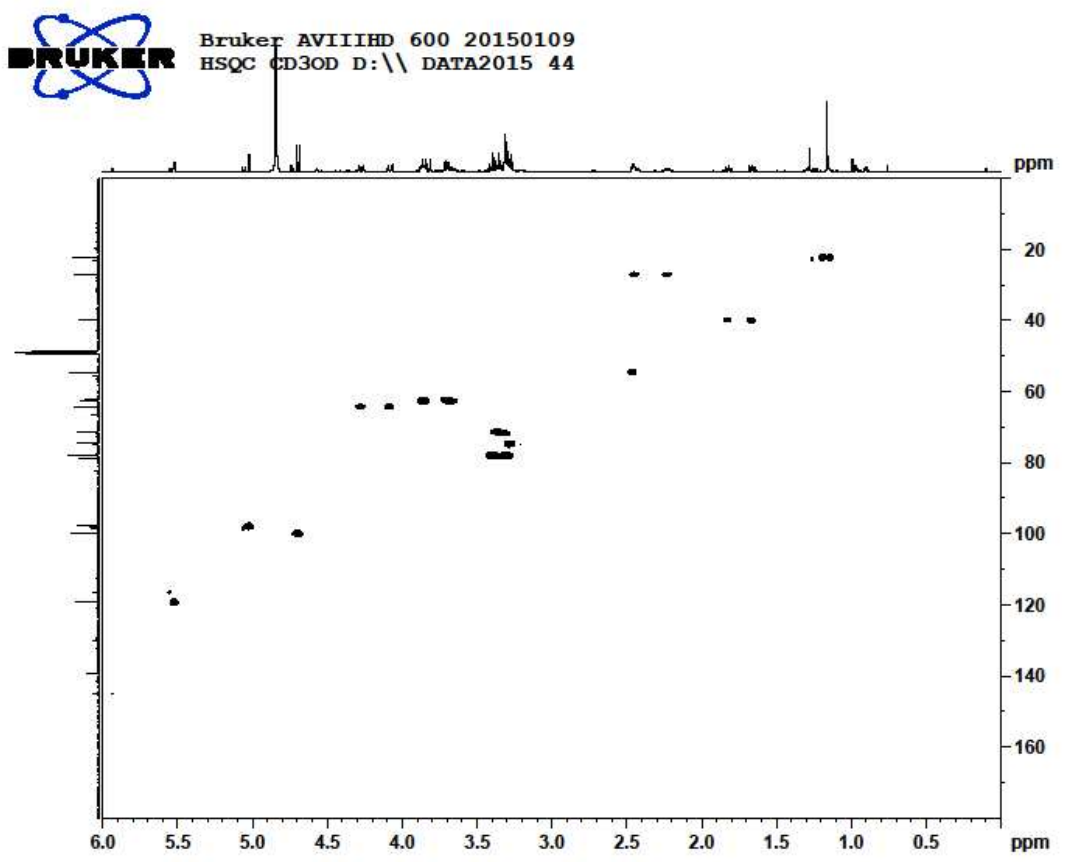

S14. HSQC Spectrum of compound 2

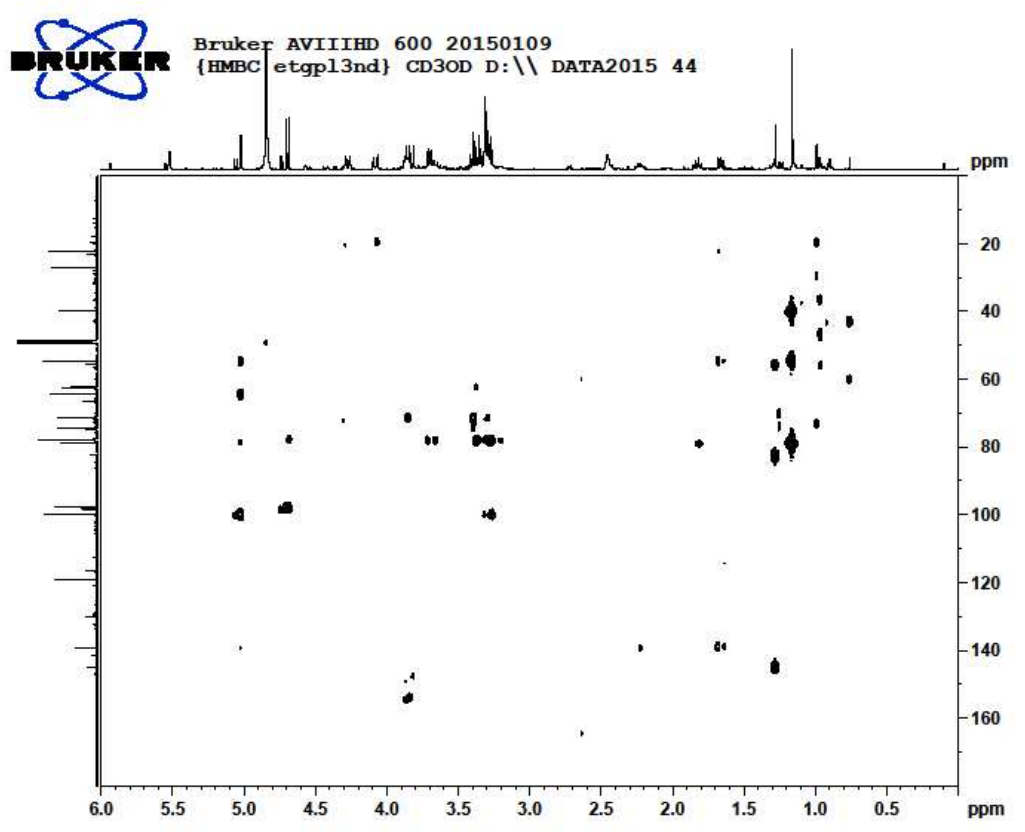

S15. HMBC Spectrum of compound 2 


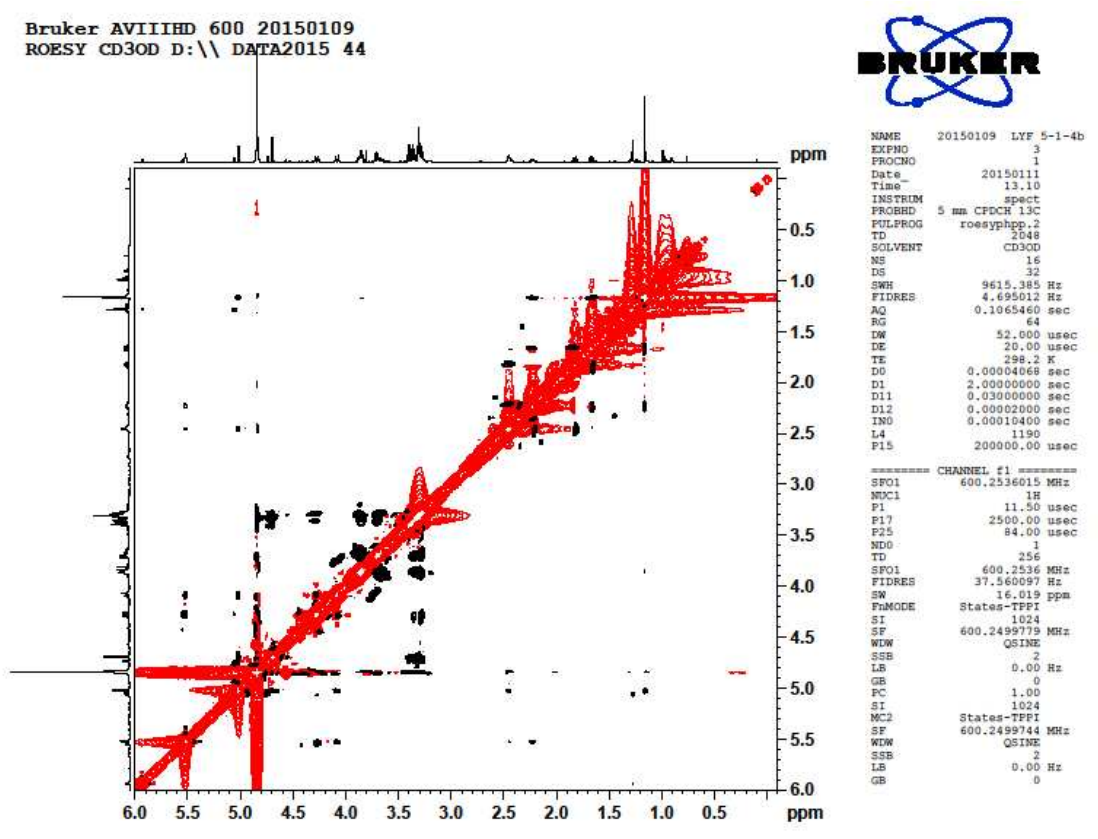

S16. ROESY Spectrum of compound 2

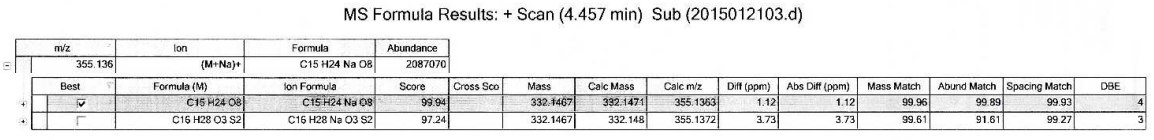

S17. HRESIMS Spectrum of compound 2

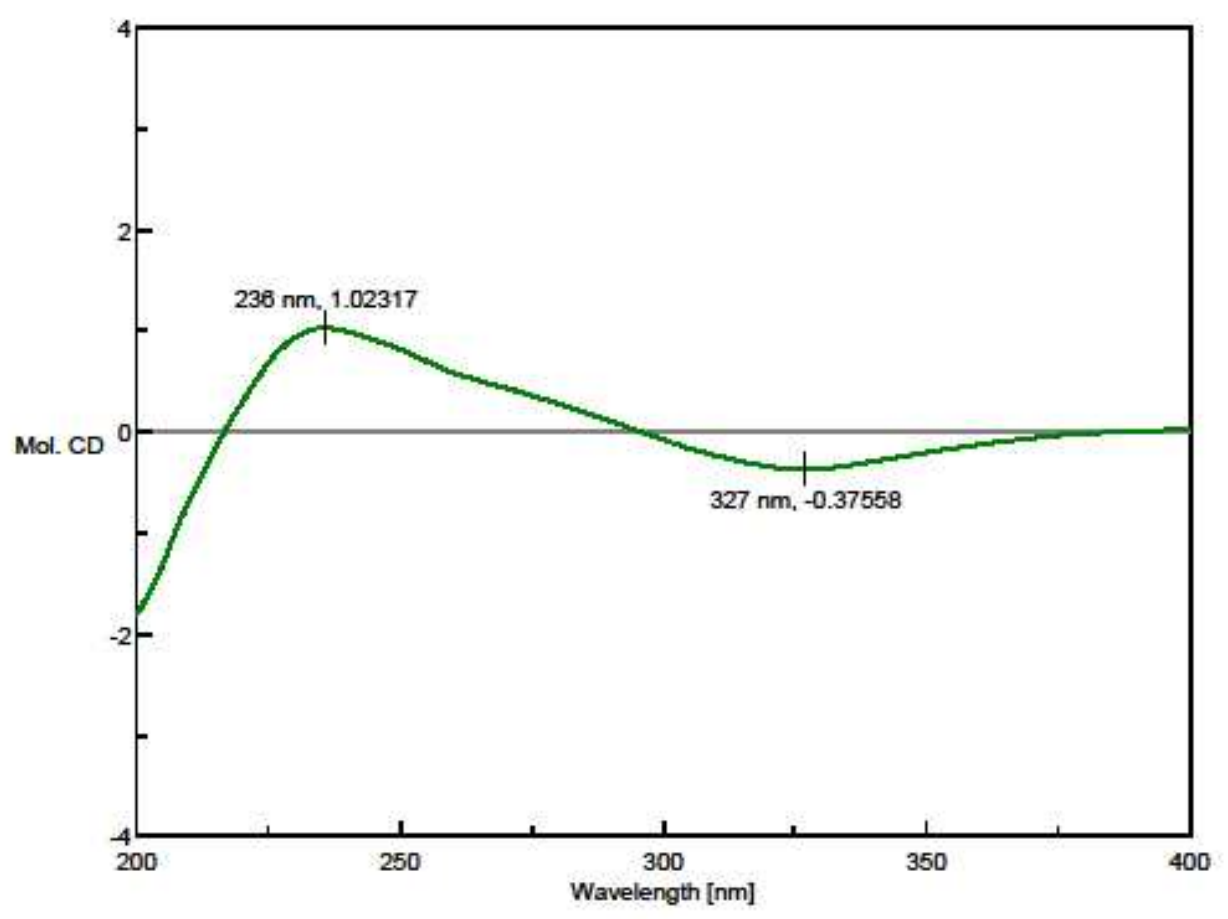

S18. CD Spectrum of compound $2\left(\mathrm{CH}_{3} \mathrm{OH}\right)$ 


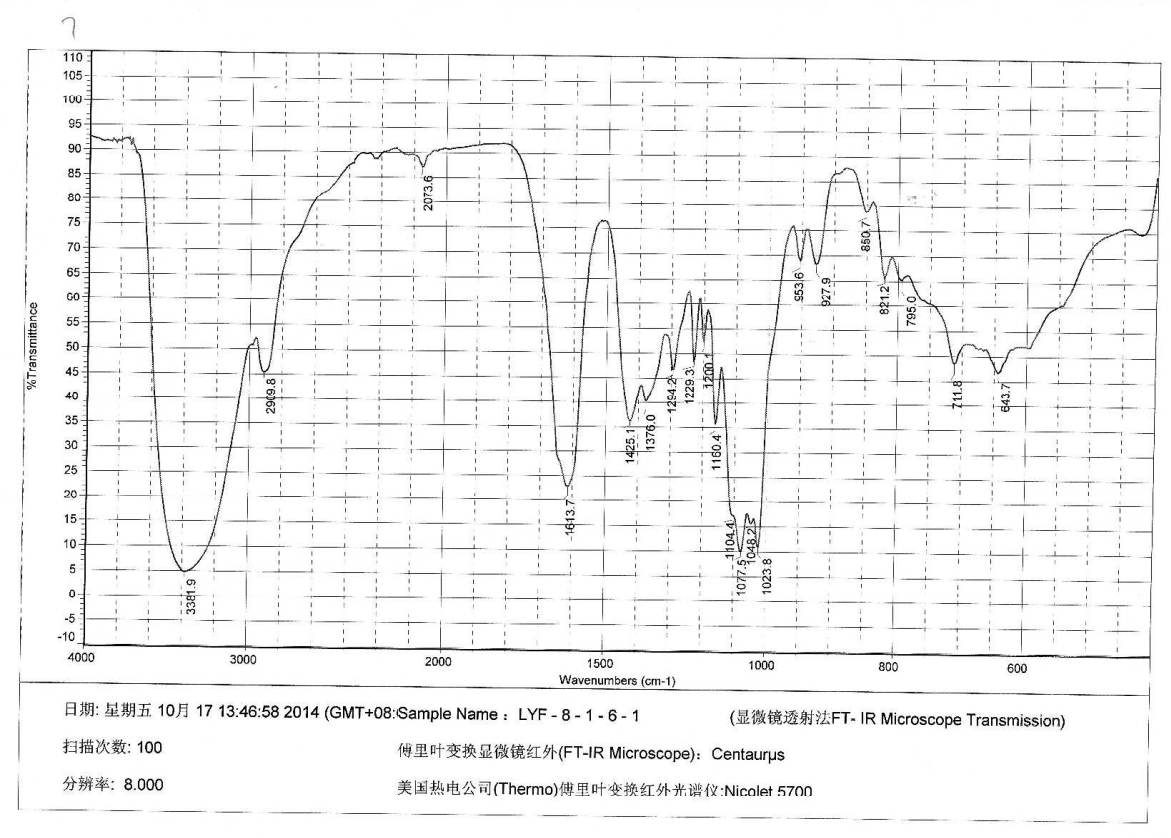

S19. IR Spectrum of compound 3

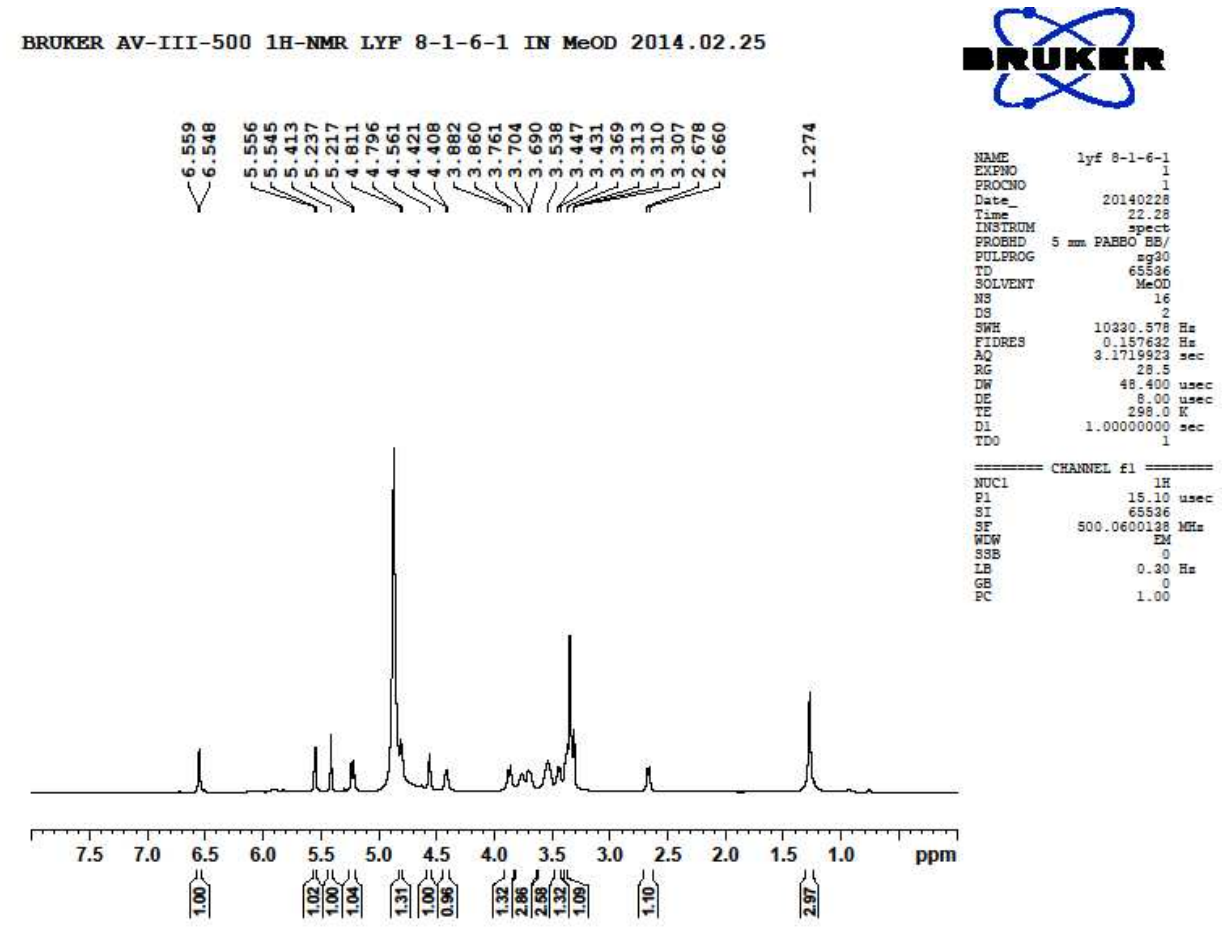

S20. ${ }^{1} \mathrm{H}$ NMR Spectrum of compound $3\left(500 \mathrm{MHz}\right.$, Methanol- $\left.d_{4}\right)$ 


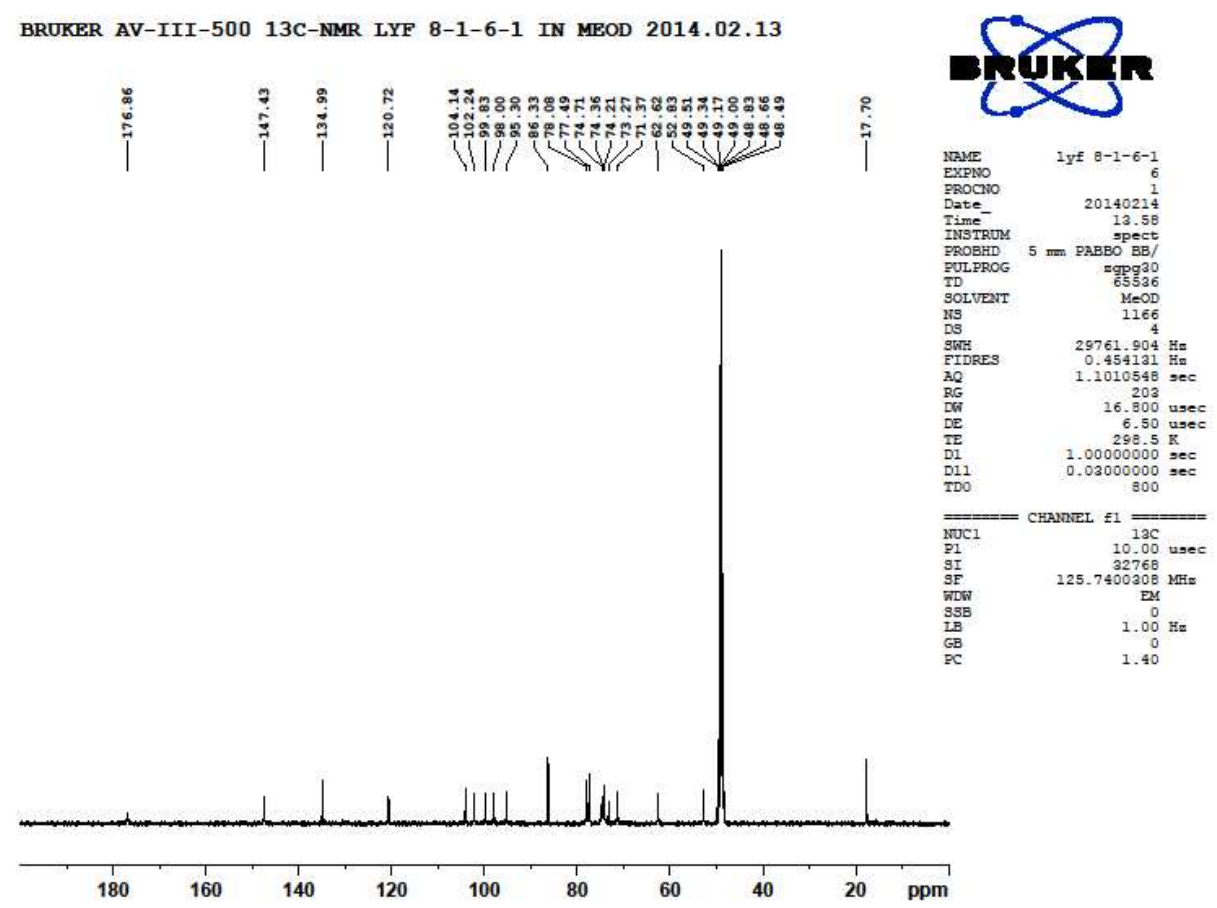

S21. ${ }^{13} \mathrm{C}$ NMR Spectrum of compound 3 (125 MHz, Methanol- $\left.d_{4}\right)$

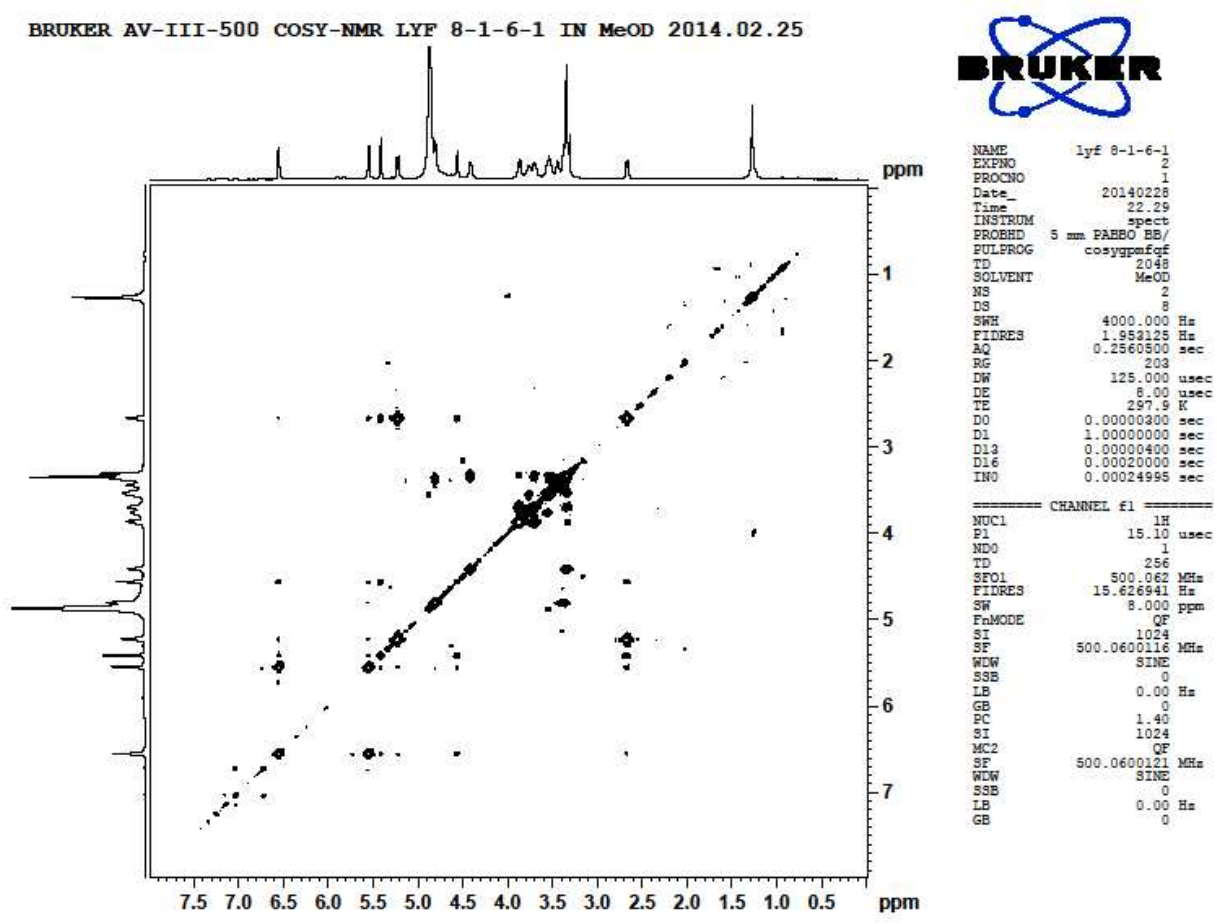

S22. ${ }^{1} \mathrm{H}-{ }^{1} \mathrm{H}$ COSY Spectrum of compound 3 


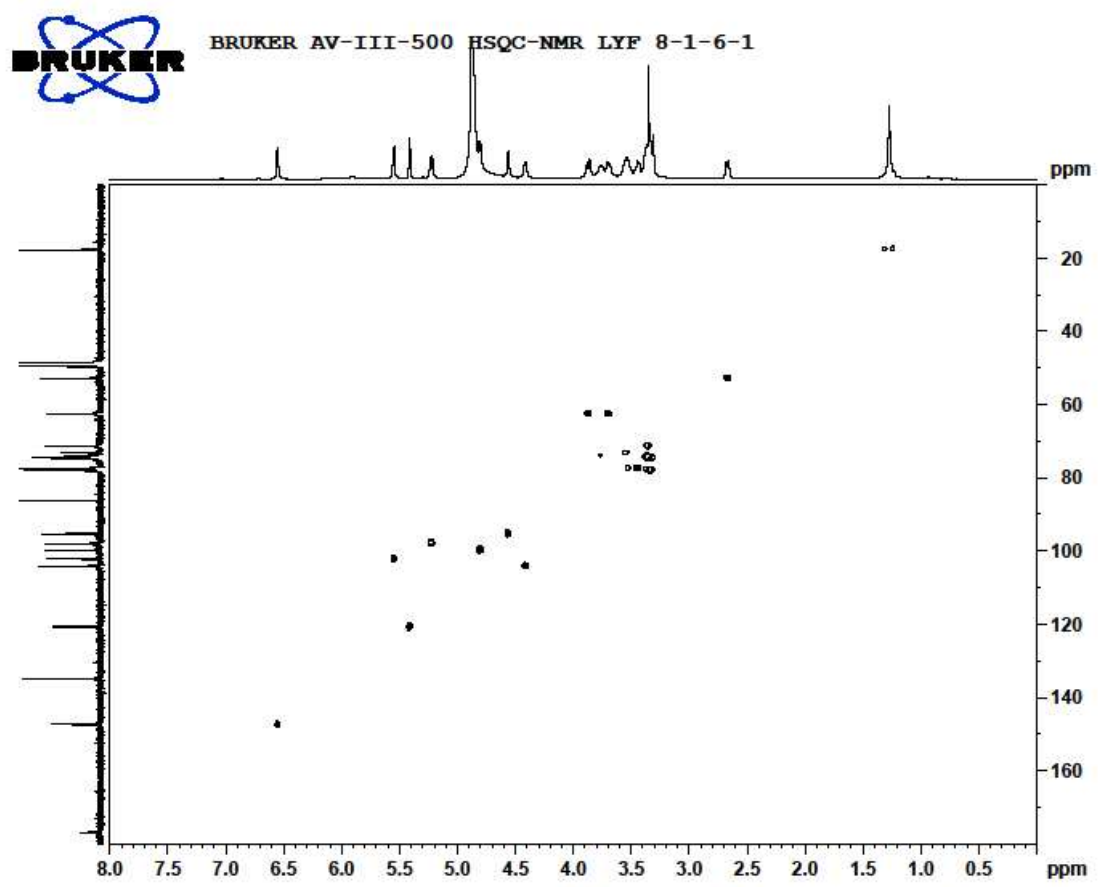

S23. HSQC Spectrum of compound $\mathbf{3}$

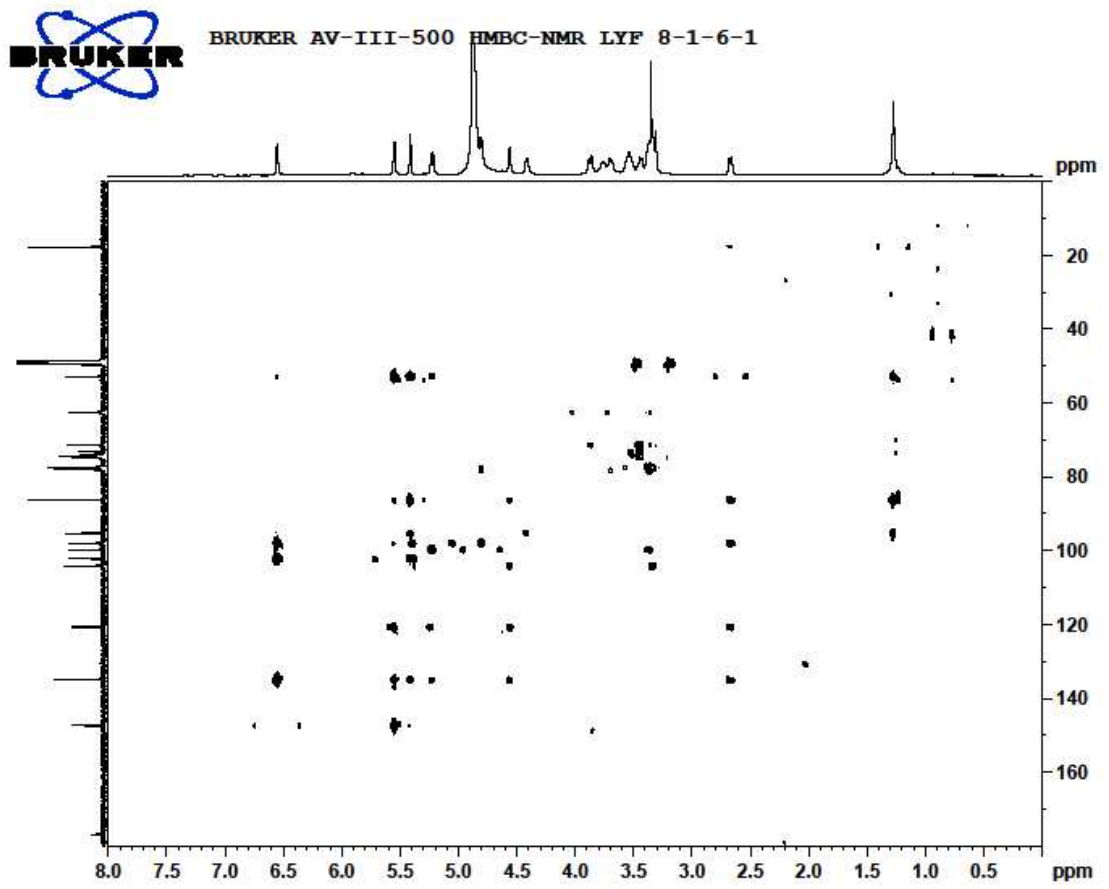

S24. HMBC Spectrum of compound 3 


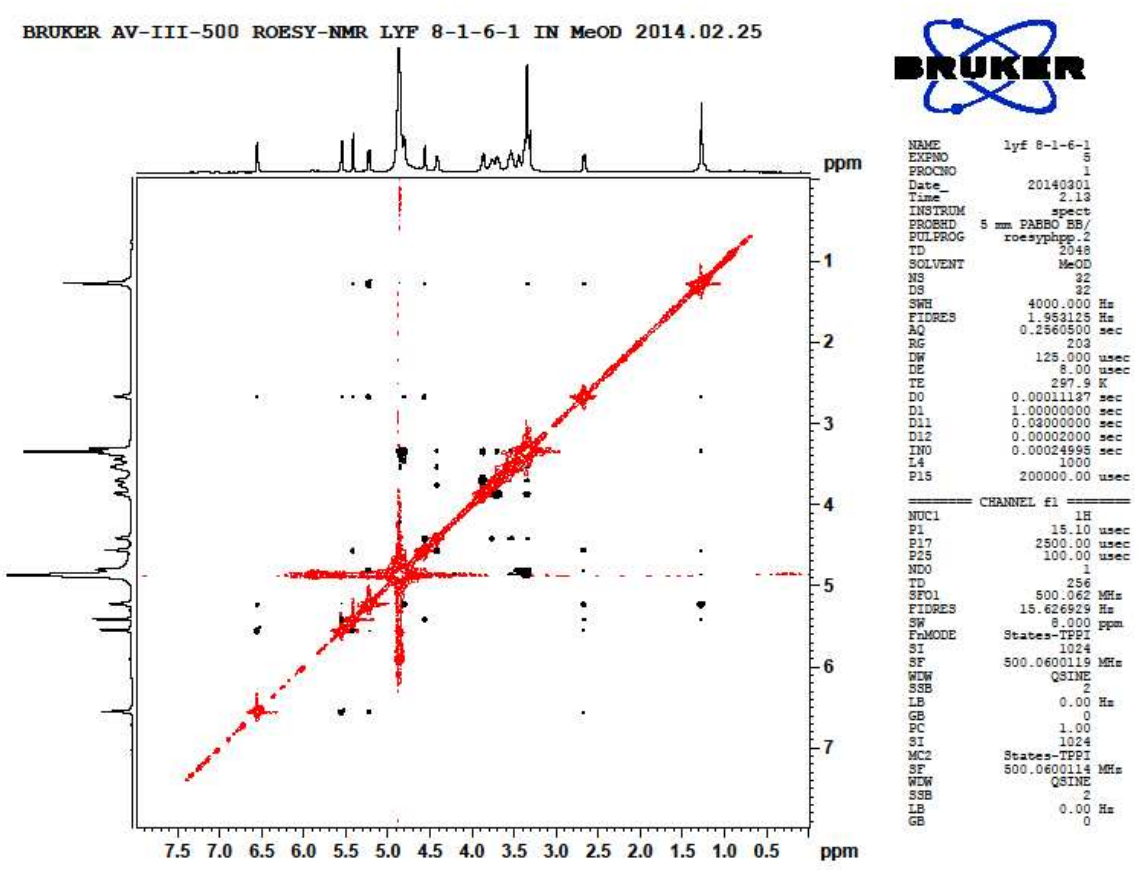

S25. ROESY Spectrum of compound 3

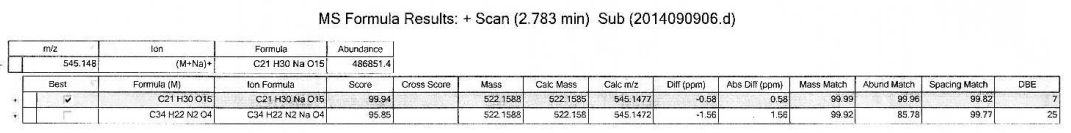

S26. HRESIMS Spectrum of compound $\mathbf{3}$

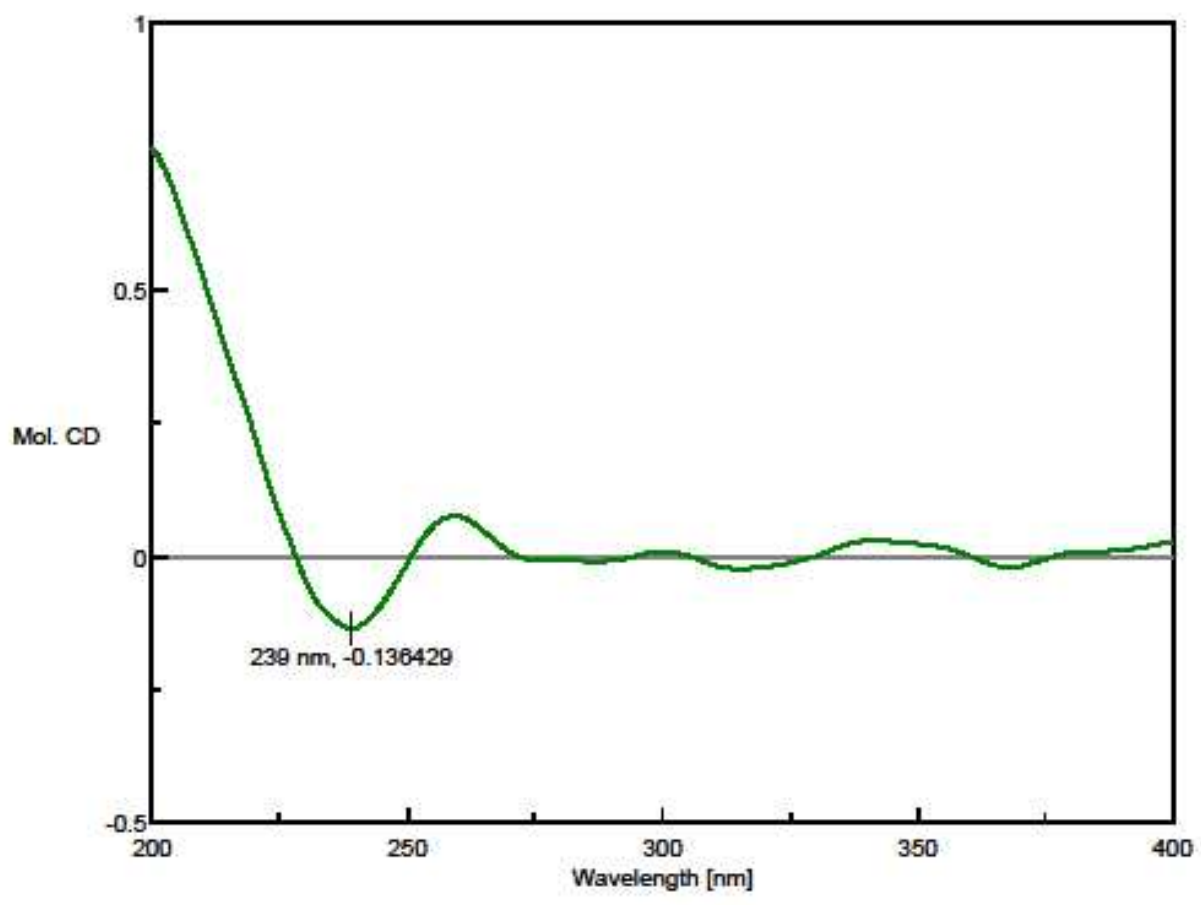

S27. CD Spectrum of compound $3\left(\mathrm{CH}_{3} \mathrm{OH}\right)$ 


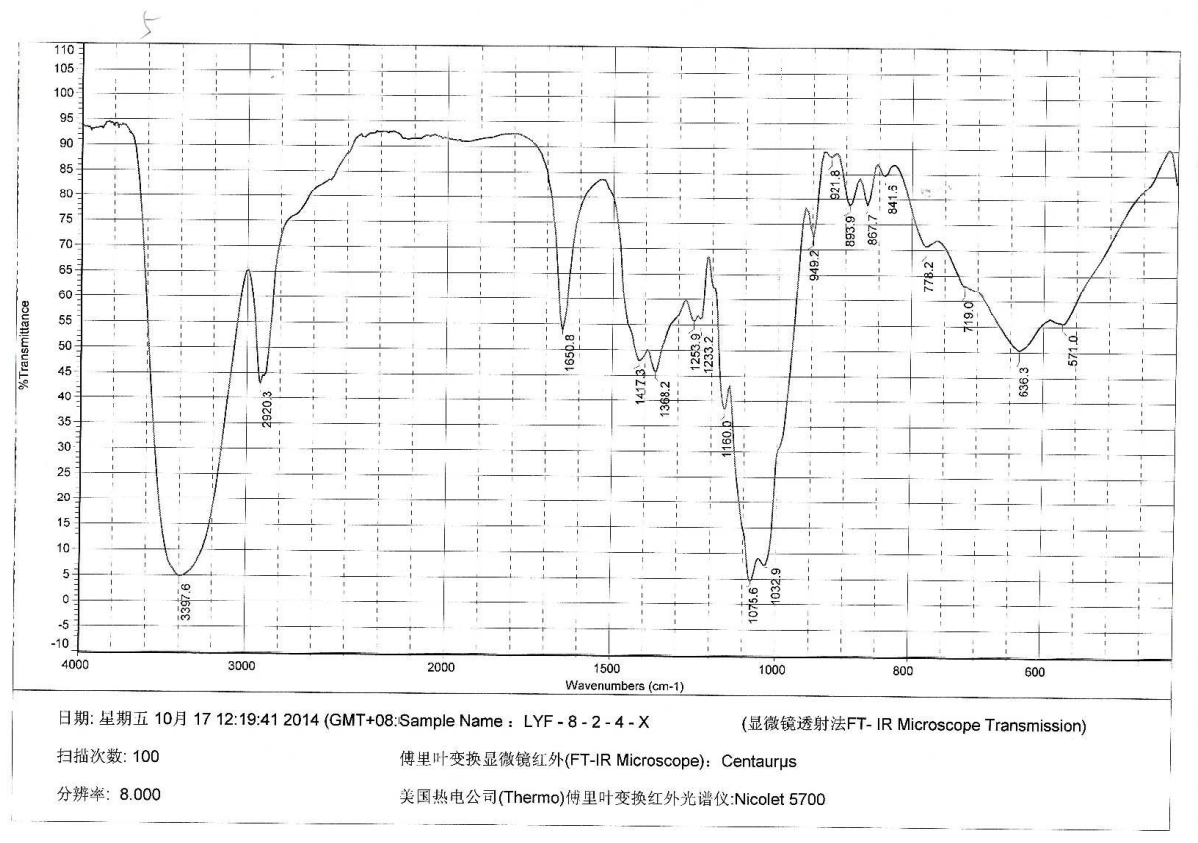

S28. IR Spectrum of compound 4

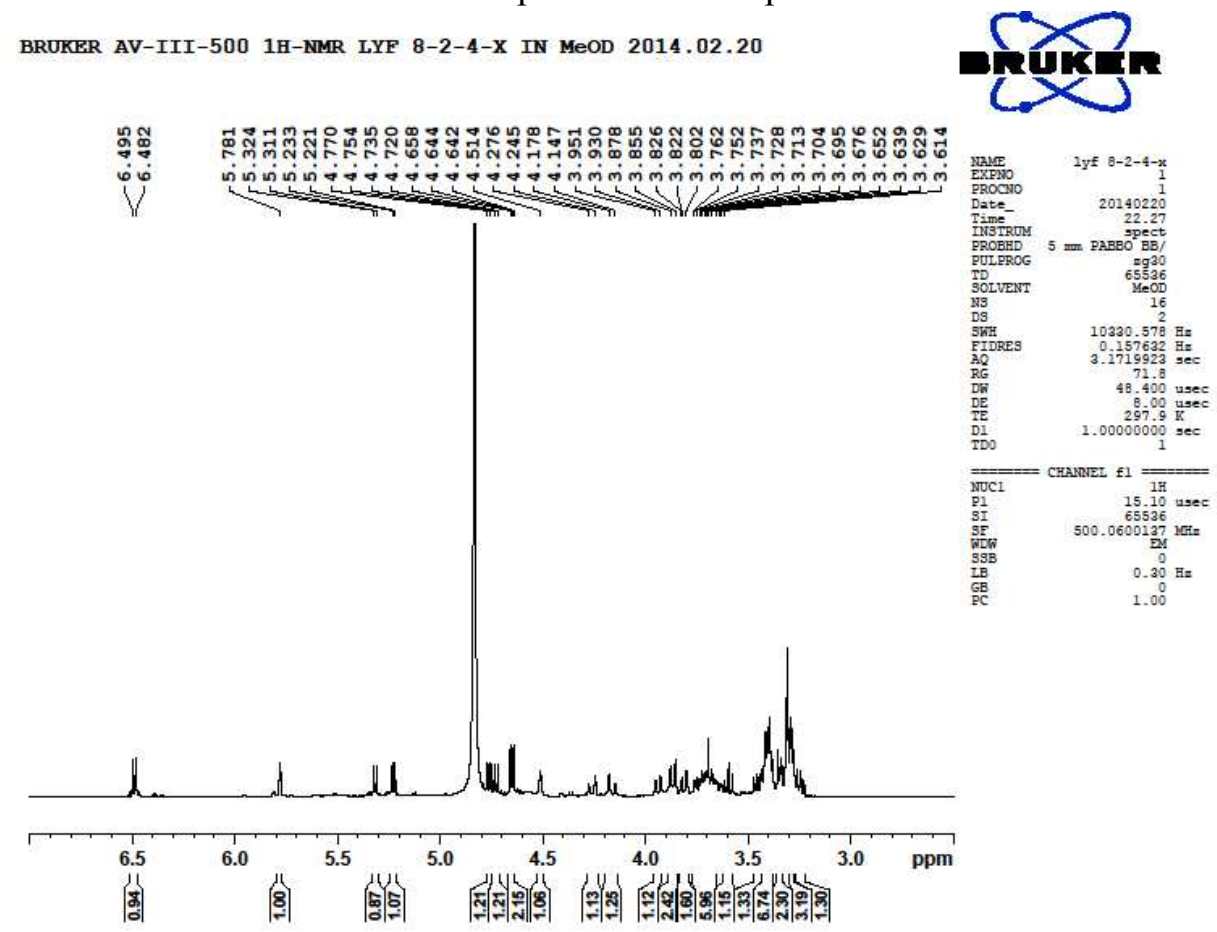

S29. ${ }^{1} \mathrm{H}$ NMR Spectrum of compound $4\left(500 \mathrm{MHz}\right.$, Methanol- $\left.d_{4}\right)$ 


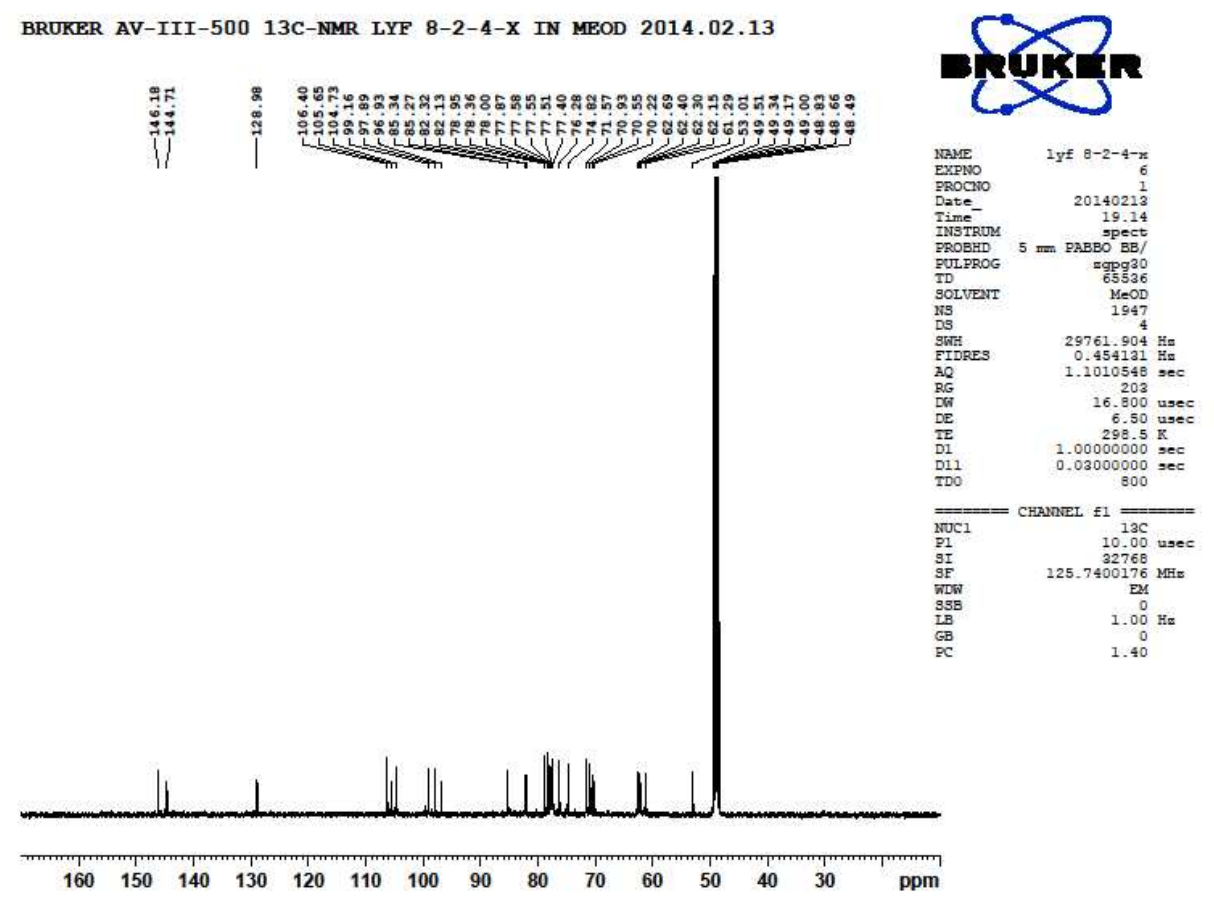

S30. ${ }^{13} \mathrm{C}$ NMR Spectrum of compound $4\left(125 \mathrm{MHz}\right.$, Methanol- $\left.d_{4}\right)$

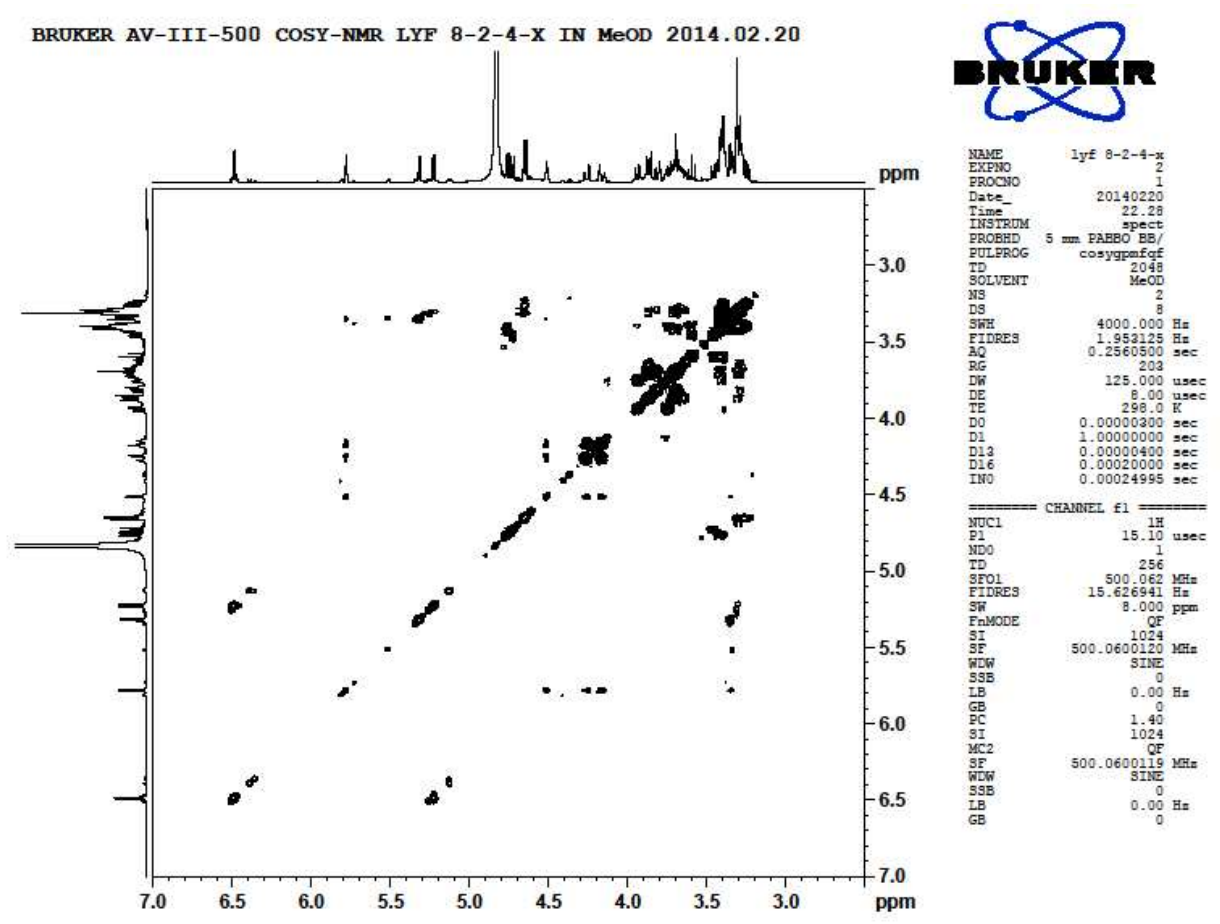

S31. ${ }^{1} \mathrm{H}-{ }^{1} \mathrm{H}$ COSY Spectrum of compound 4 


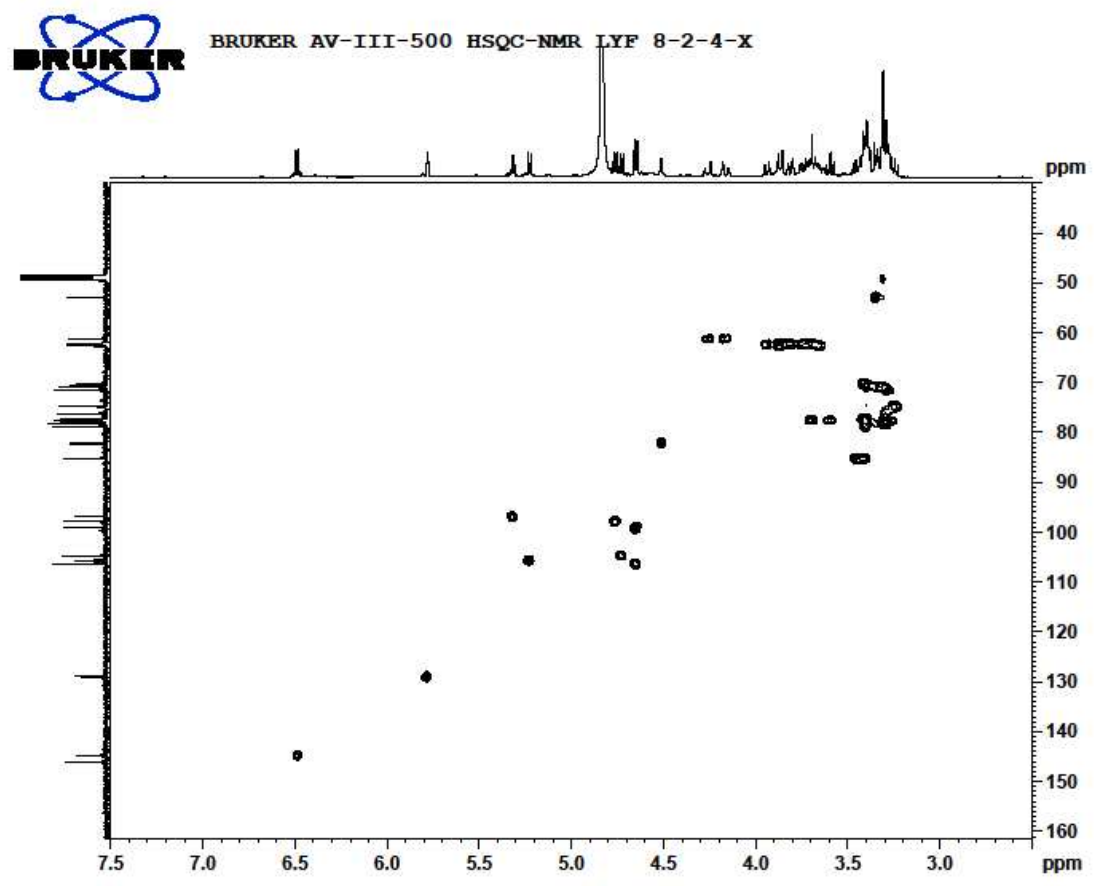

S32. HSQC Spectrum of compound 4

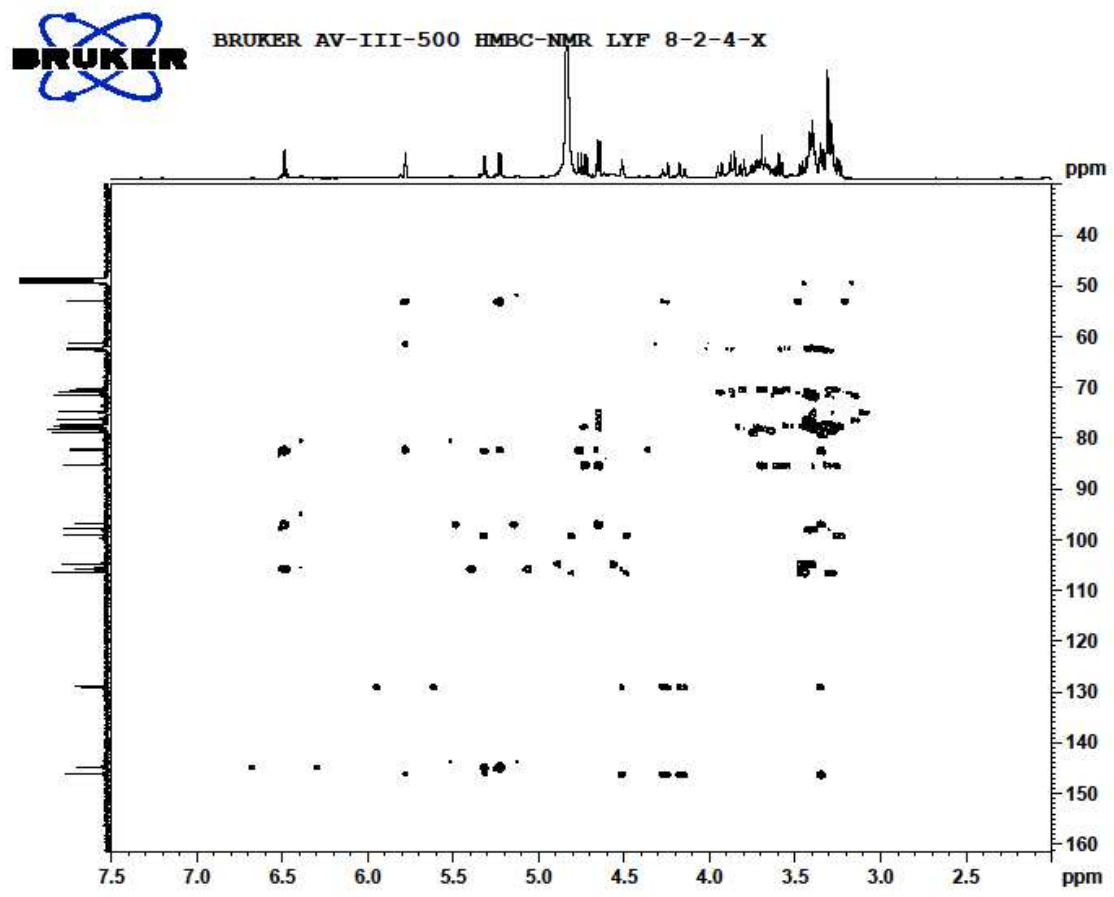

S33. HMBC Spectrum of compound 4 


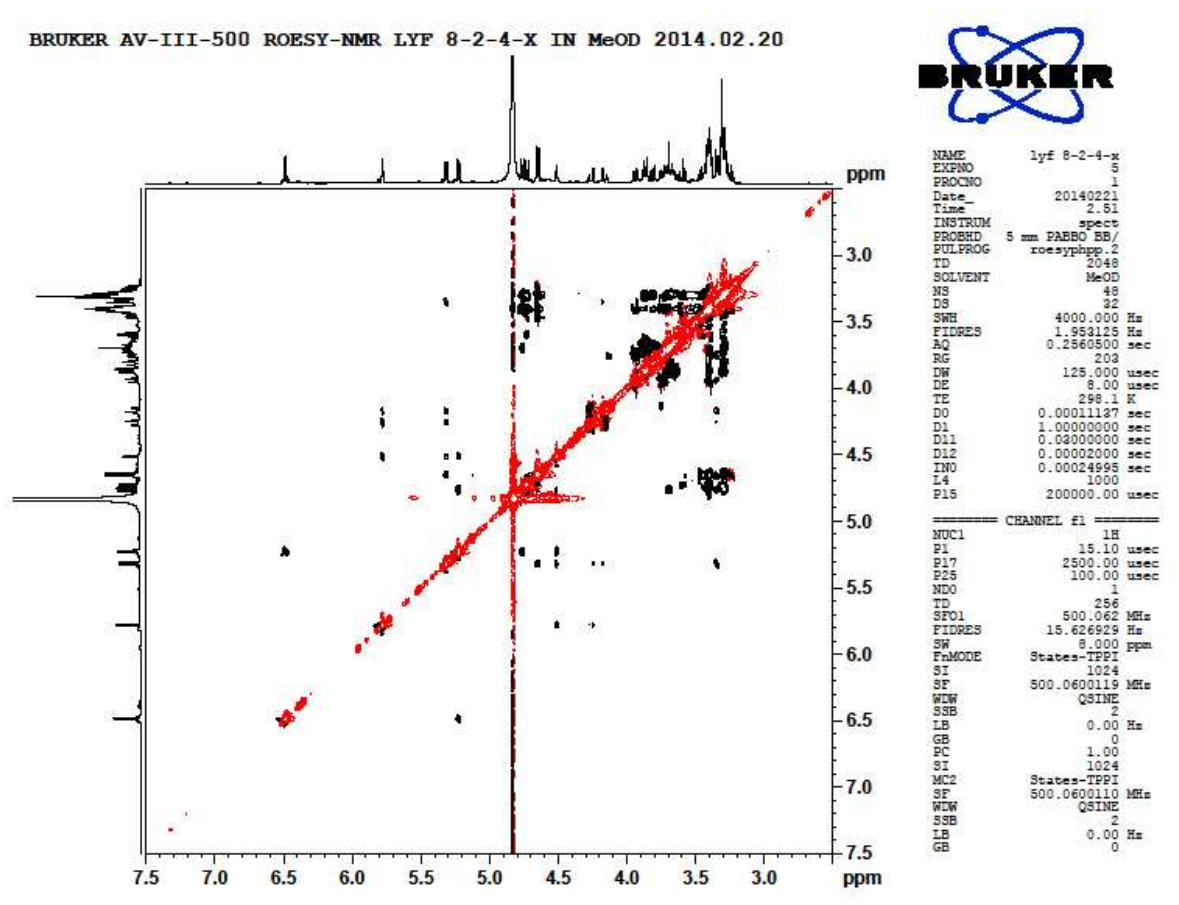

S34. ROESY Spectrum of compound 4

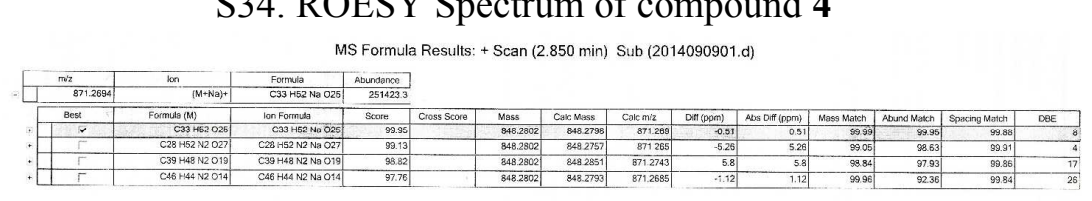

S35. HRESIMS Spectrum of compound 4

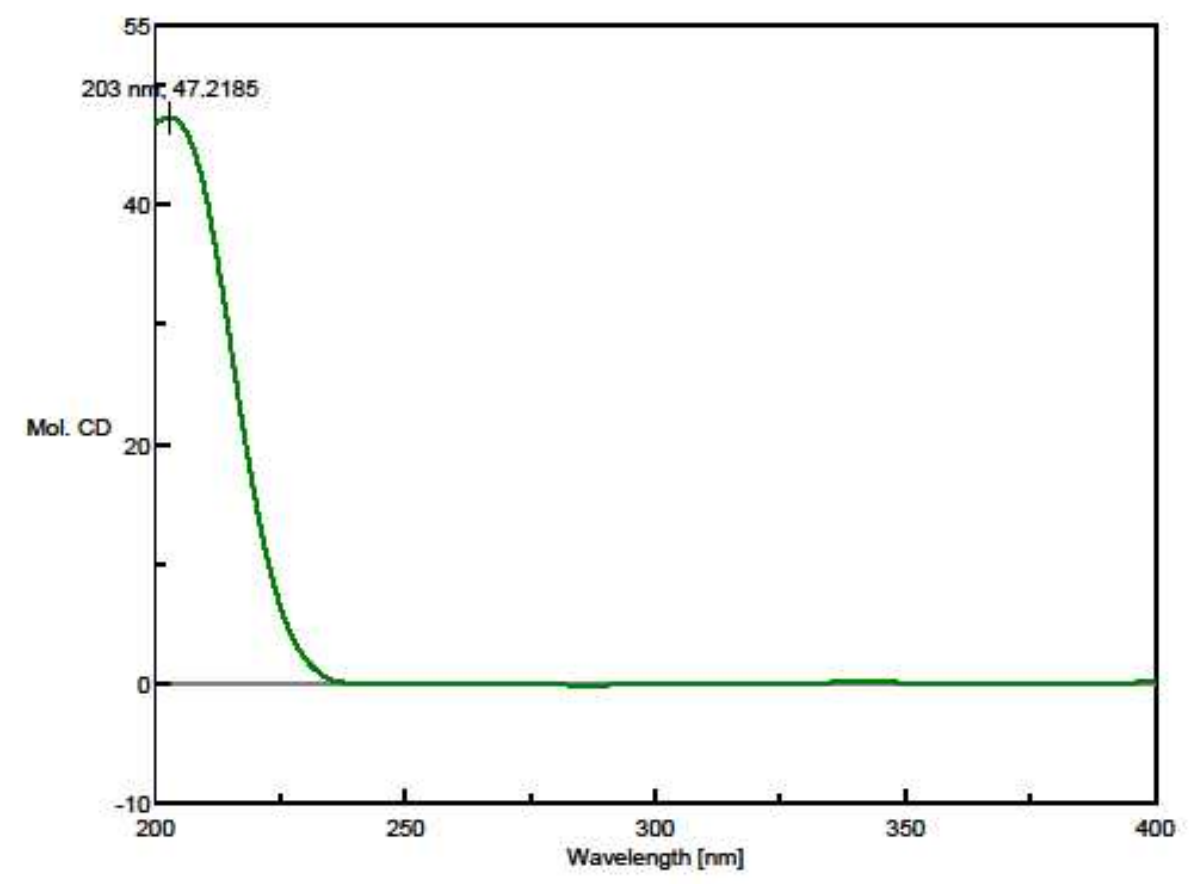

S36. CD Spectrum of compound $4\left(\mathrm{CH}_{3} \mathrm{OH}\right)$ 


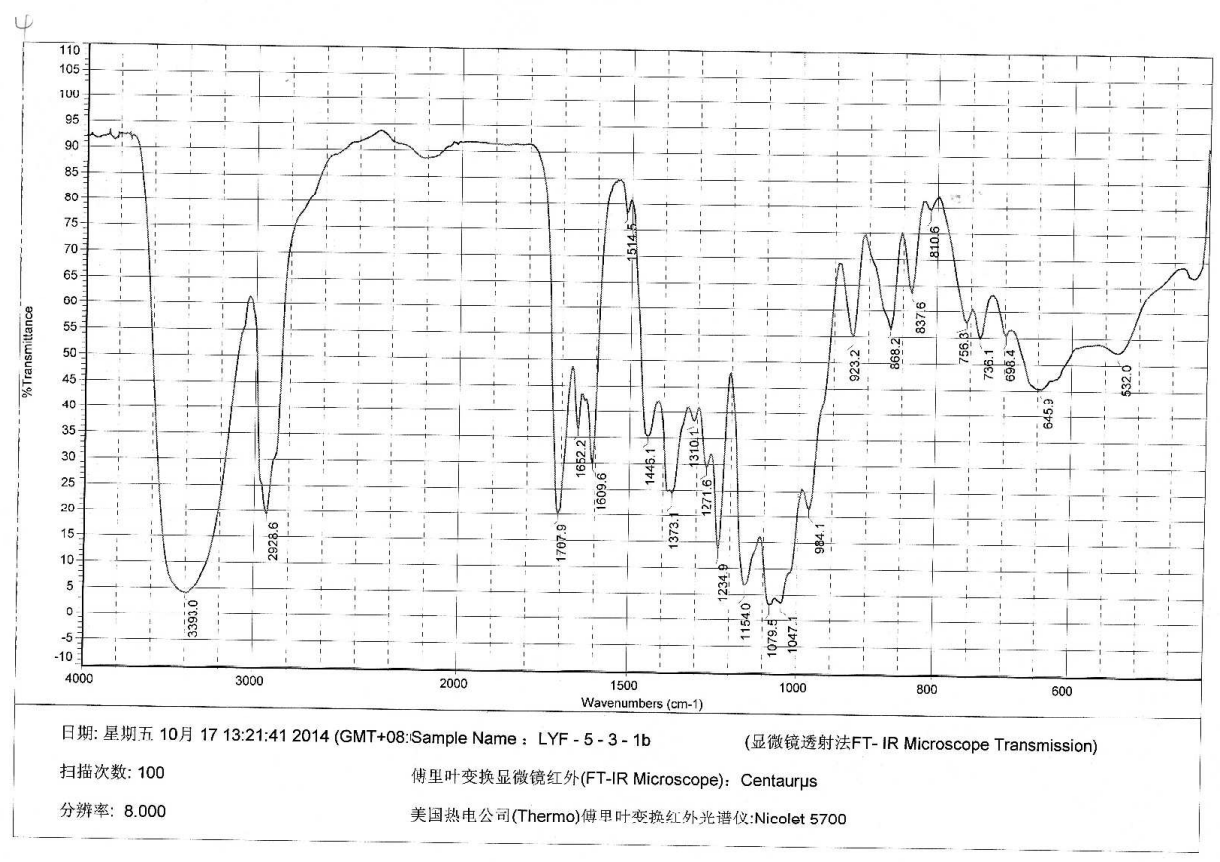

S37. IR Spectrum of compound 5

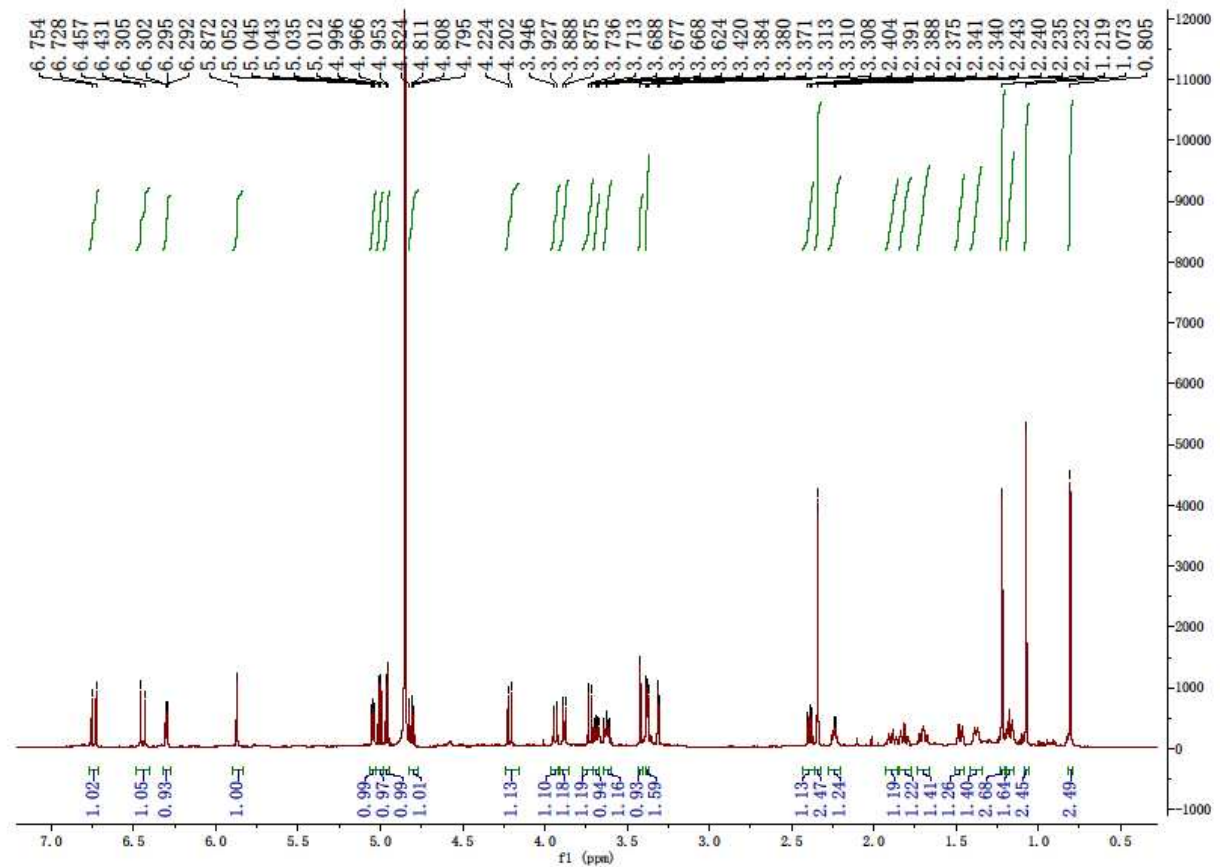

S38. ${ }^{1} \mathrm{H}$ NMR Spectrum of compound $5\left(600 \mathrm{MHz}\right.$, Methanol- $\left.d_{4}\right)$ 


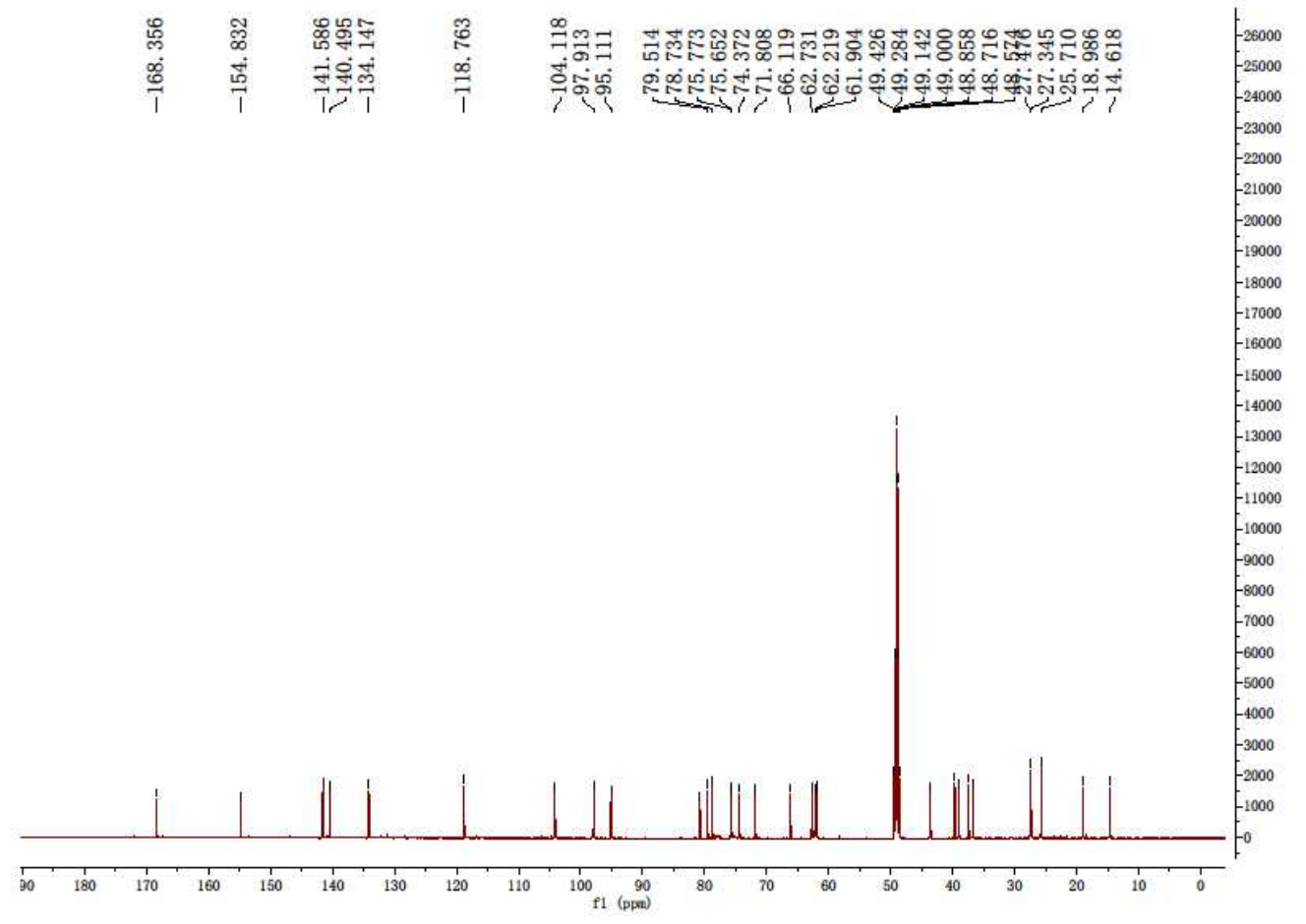

S39. ${ }^{13} \mathrm{C}$ NMR Spectrum of compound $5\left(150 \mathrm{MHz}\right.$, Methanol- $\left.d_{4}\right)$

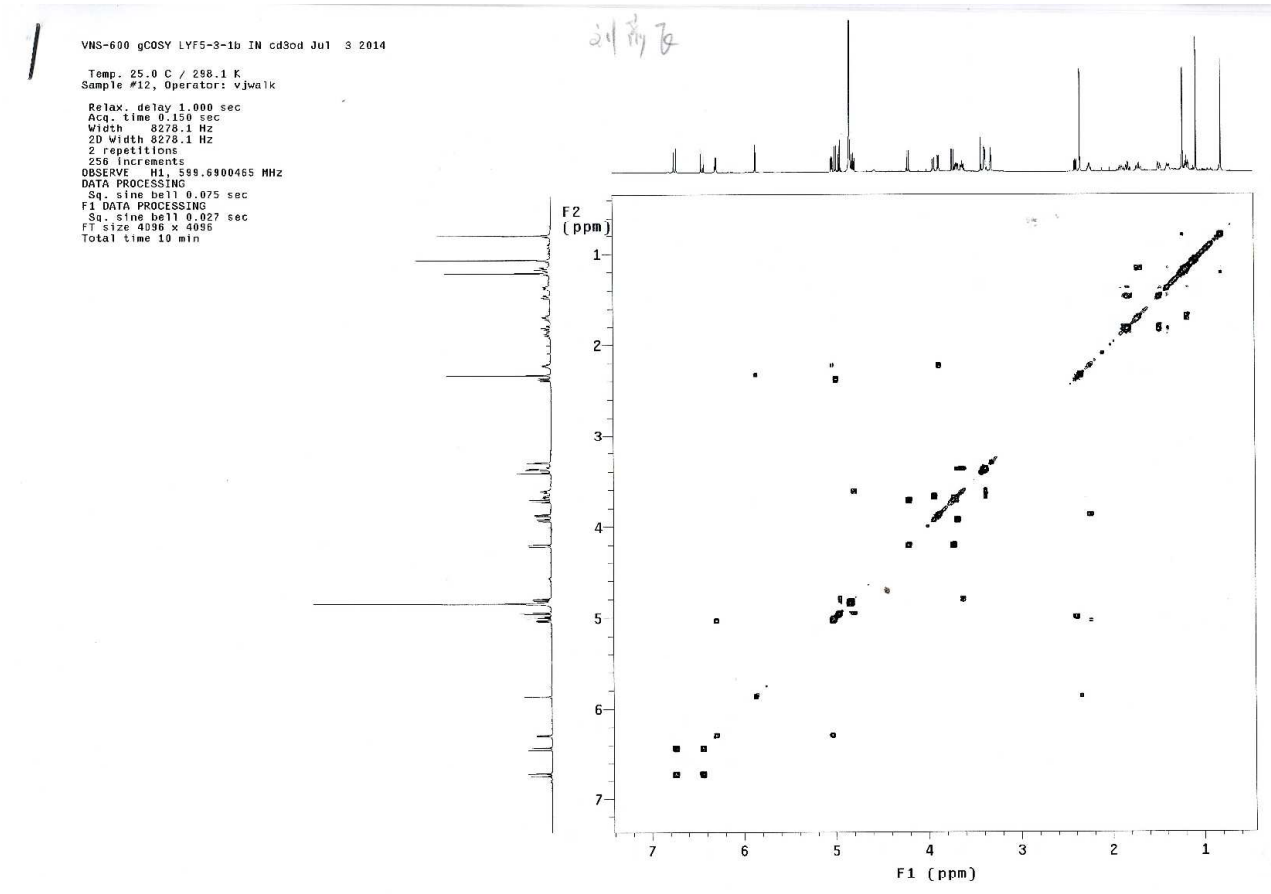

S40. ${ }^{1} \mathrm{H}-{ }^{1} \mathrm{H}$ COSY Spectrum of compound $\mathbf{5}$ 


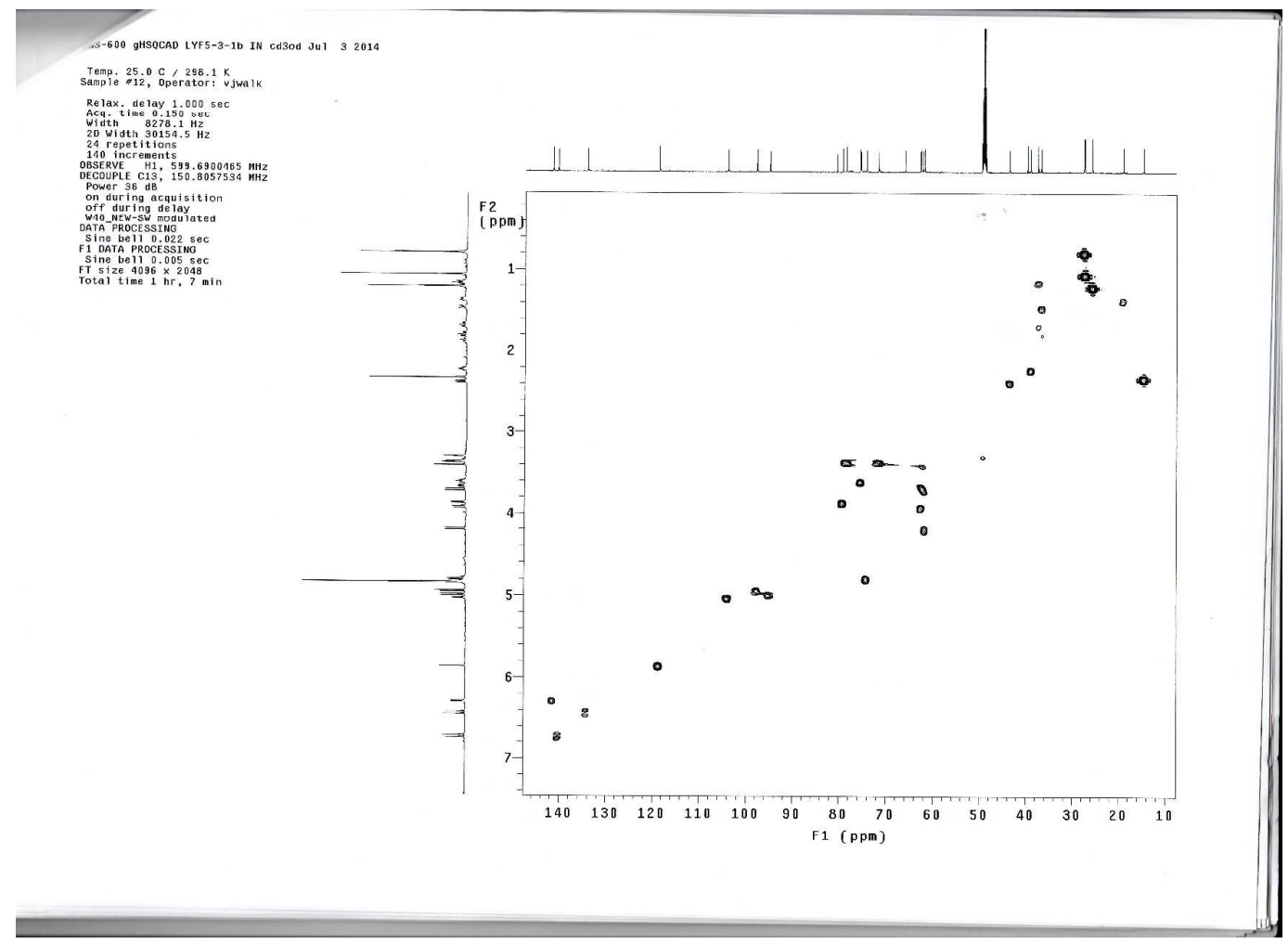

S41. HSQC Spectrum of compound $\mathbf{5}$

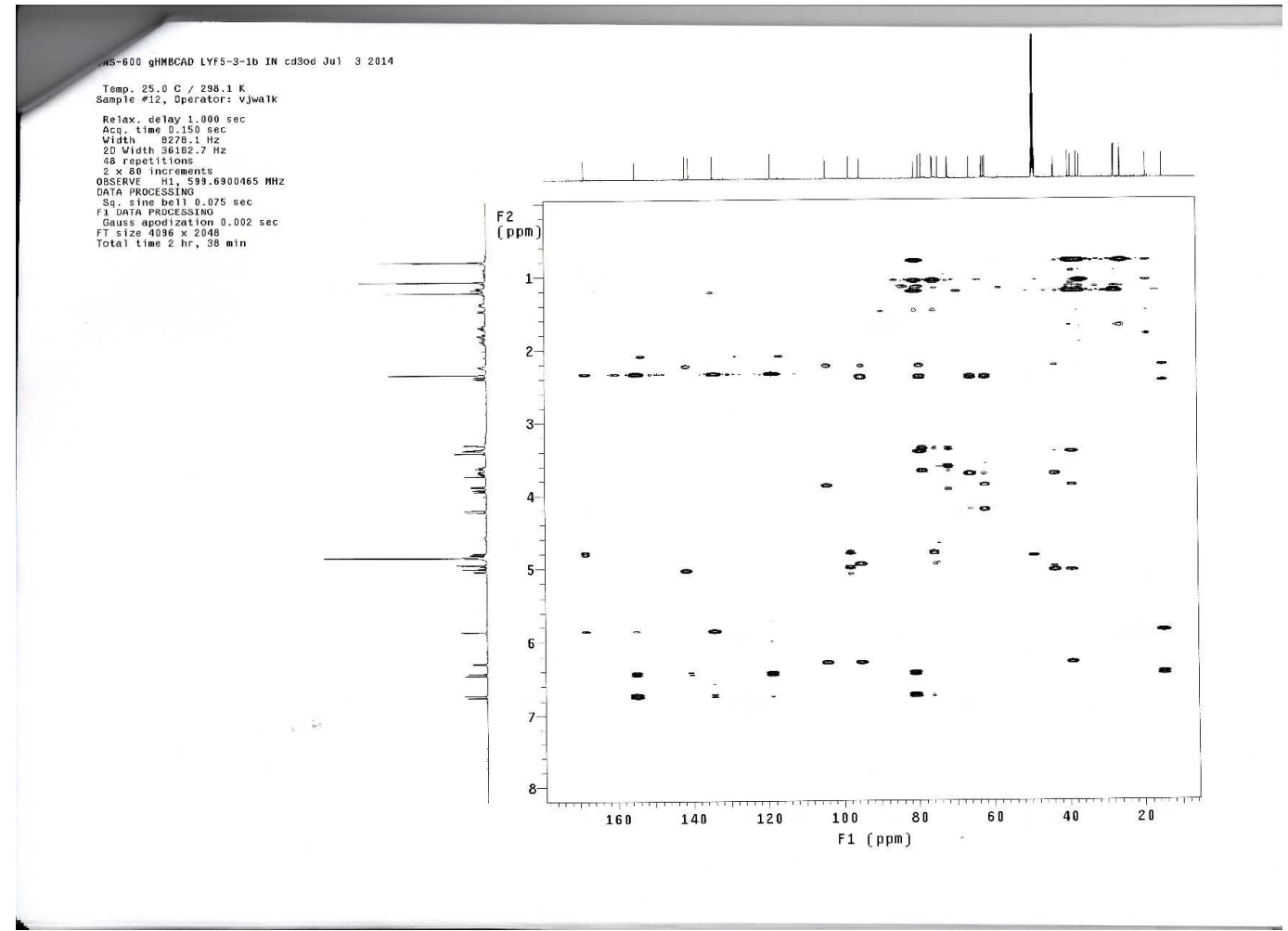

S42. HMBC Spectrum of compound 5 


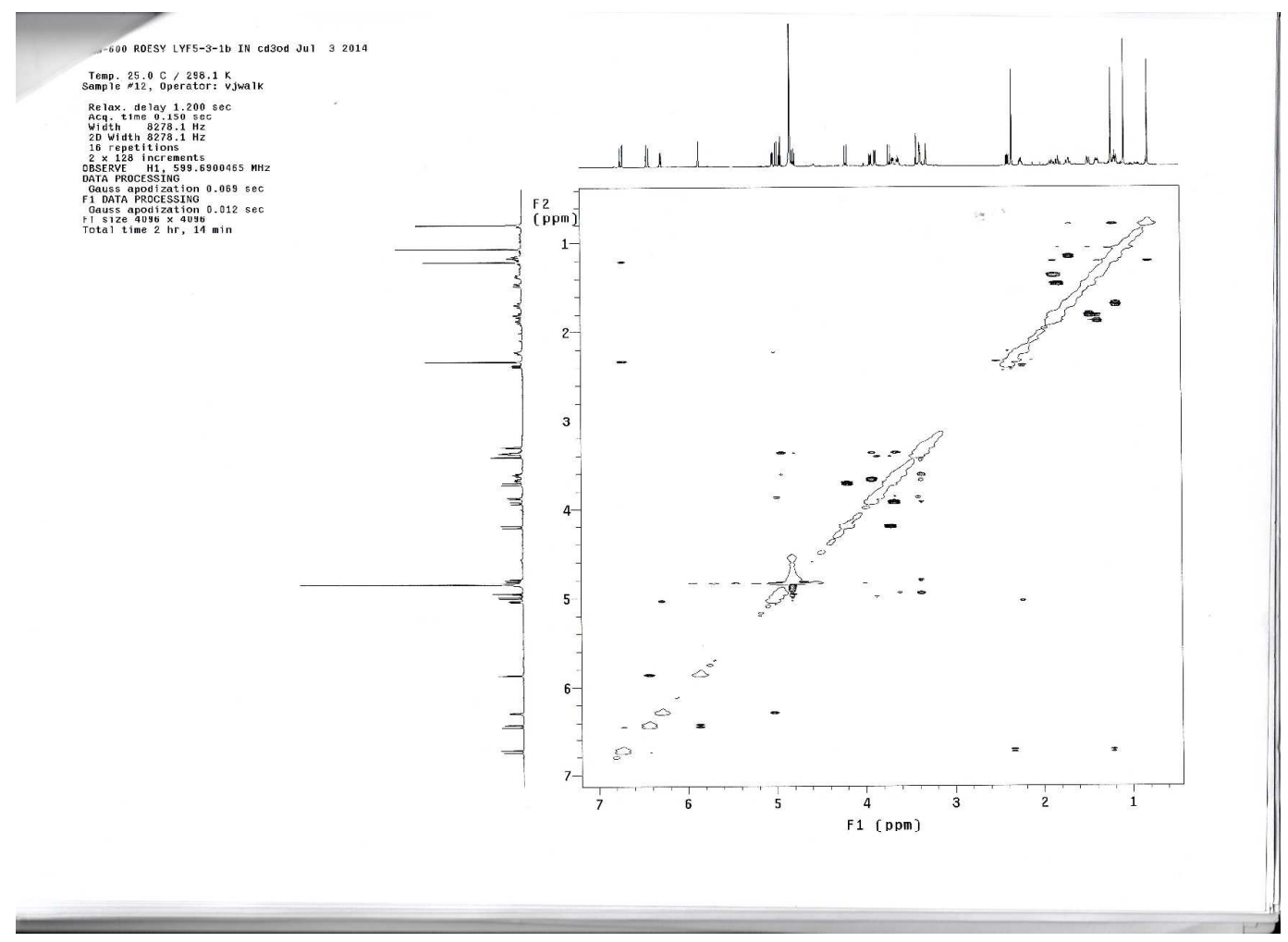

S43. ROESY Spectrum of compound 5

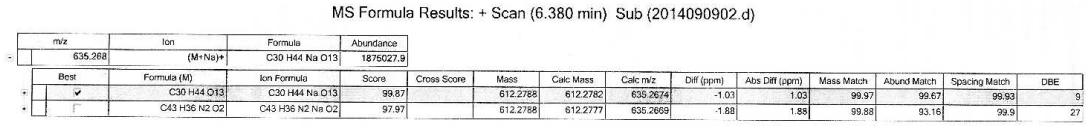

S44. HRESIMS Spectrum of compound 5

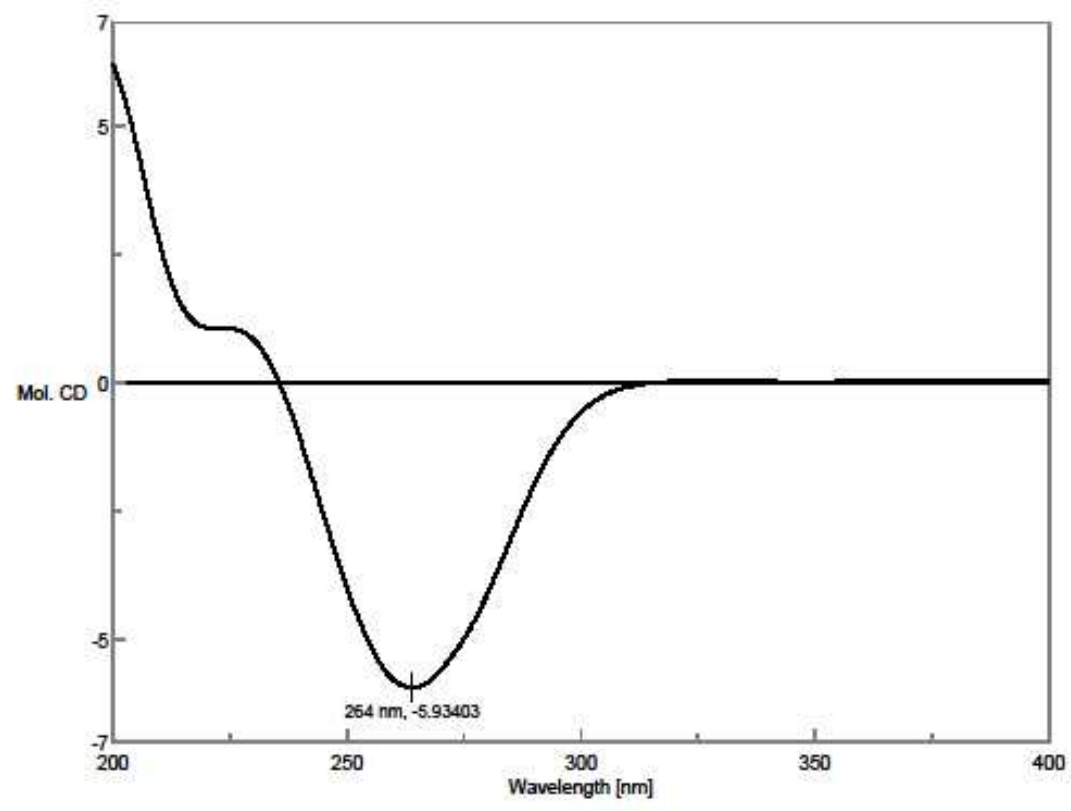

S45. CD Spectrum of compound $5\left(\mathrm{CH}_{3} \mathrm{OH}\right)$ 


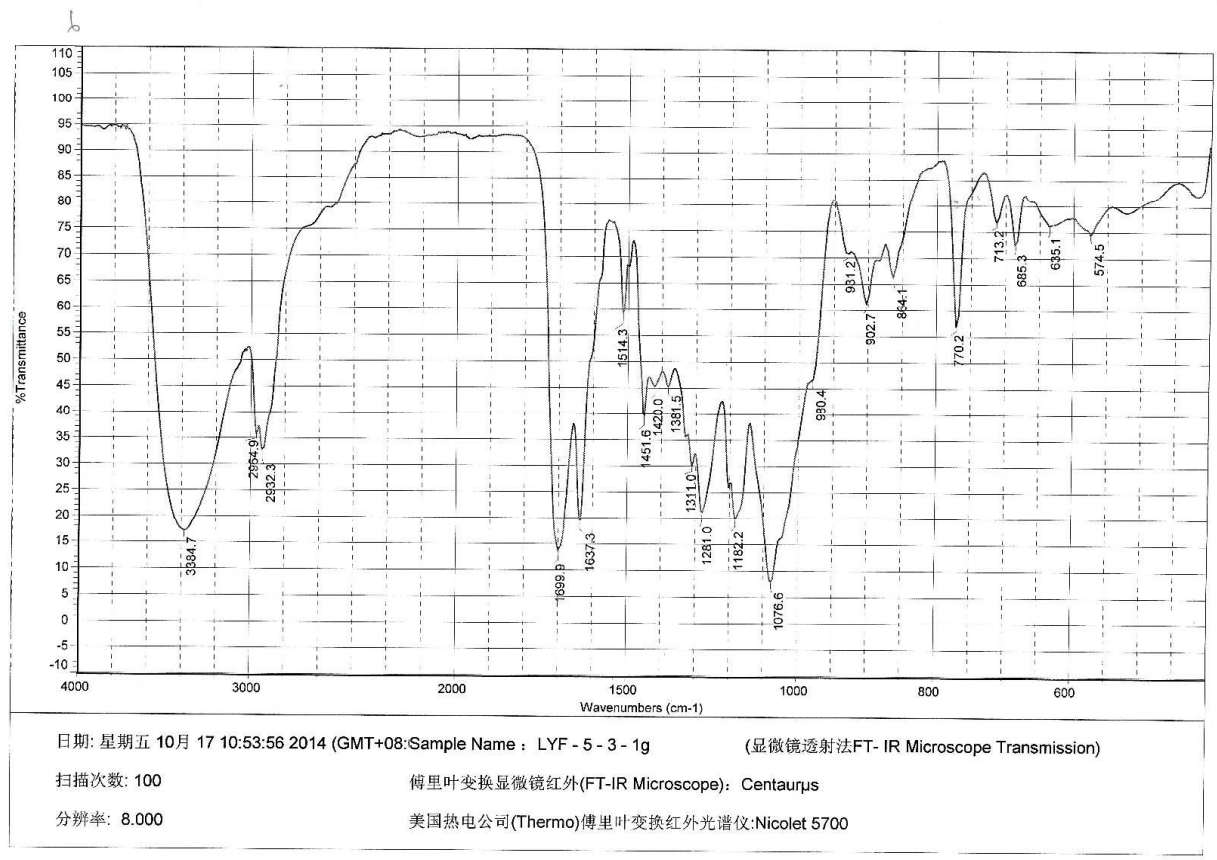

S46. IR Spectrum of compound 6
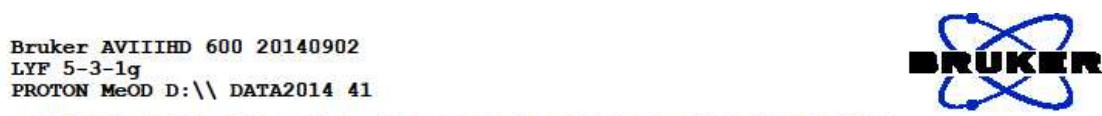

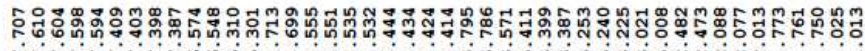

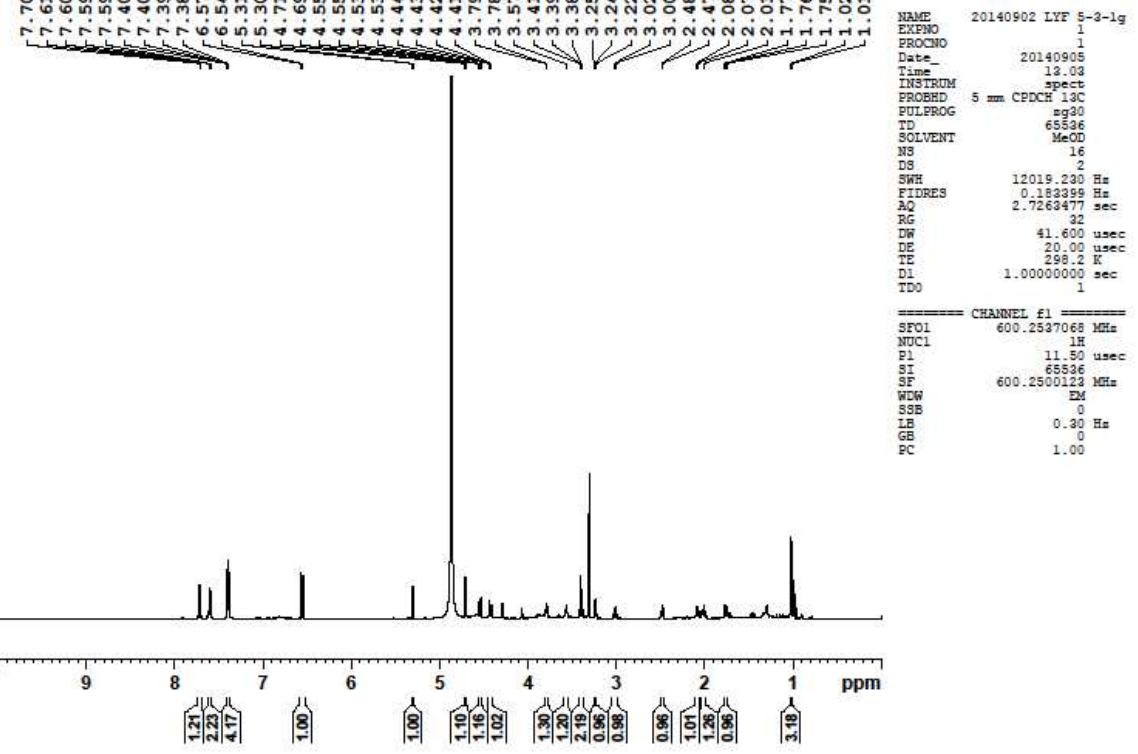

S47. ${ }^{1} \mathrm{H}$ NMR Spectrum of compound $6\left(600 \mathrm{MHz}\right.$, Methanol- $\left.d_{4}\right)$ 


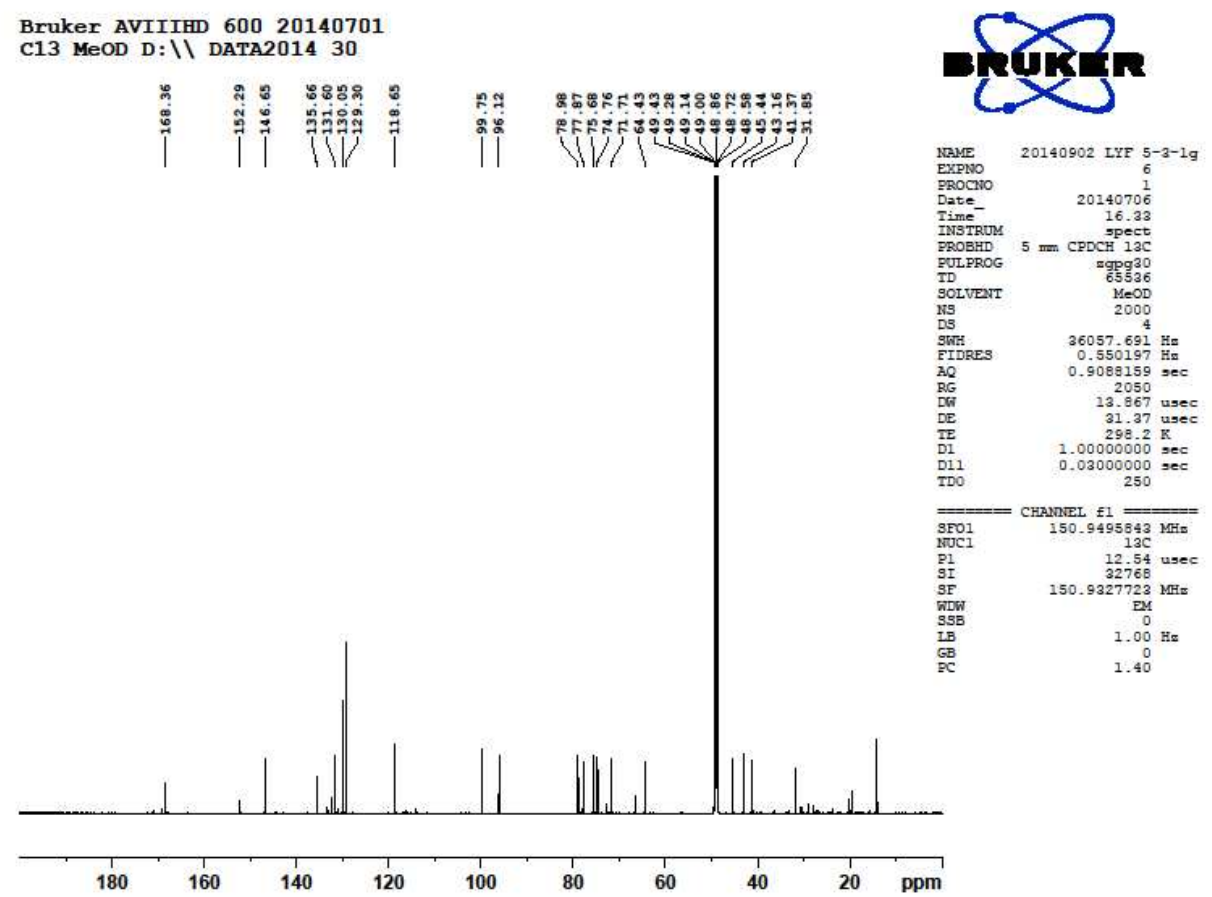

S48. ${ }^{13} \mathrm{C}$ NMR Spectrum of compound 6 (150 MHz, Methanol- $\left.d_{4}\right)$

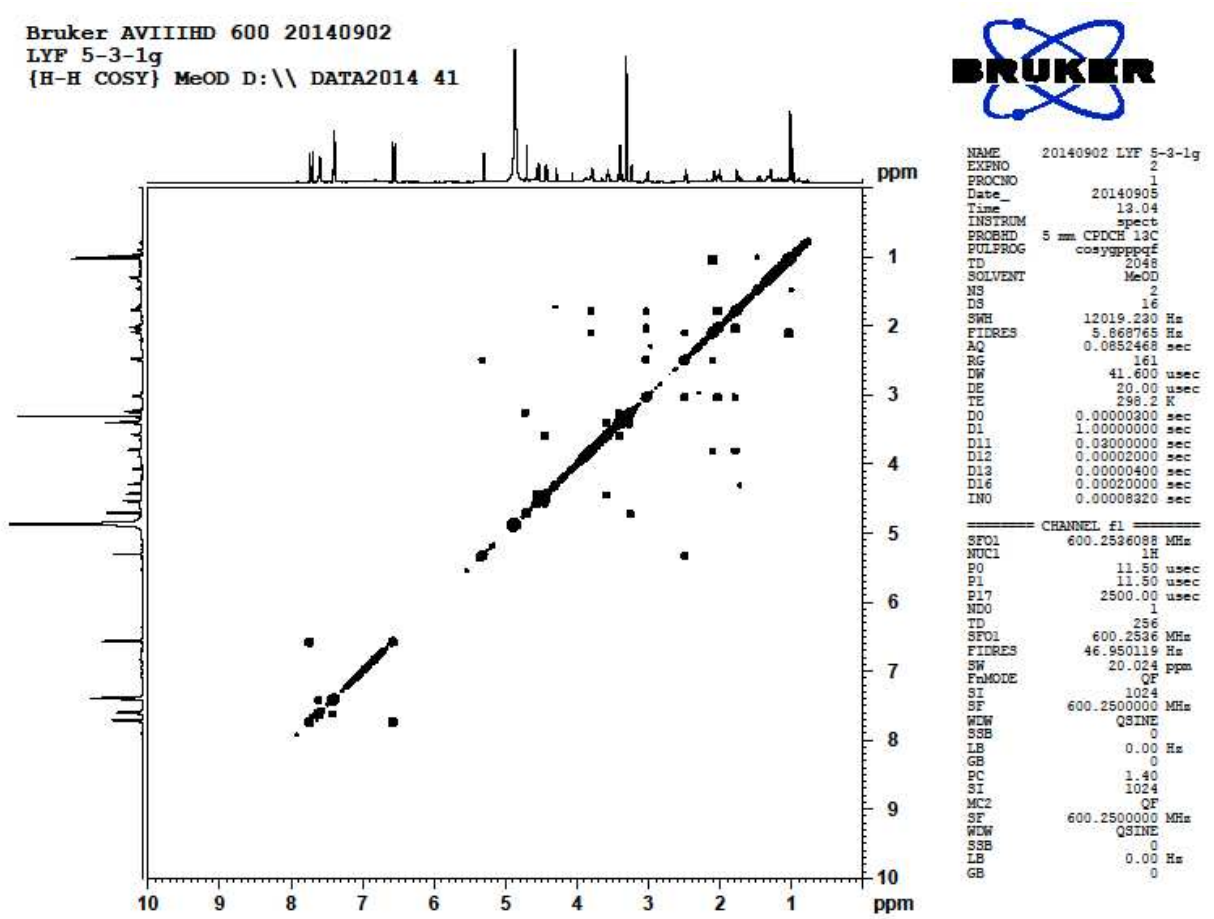

S49. ${ }^{1} \mathrm{H}-{ }^{1} \mathrm{H}$ COSY Spectrum of compound 6 


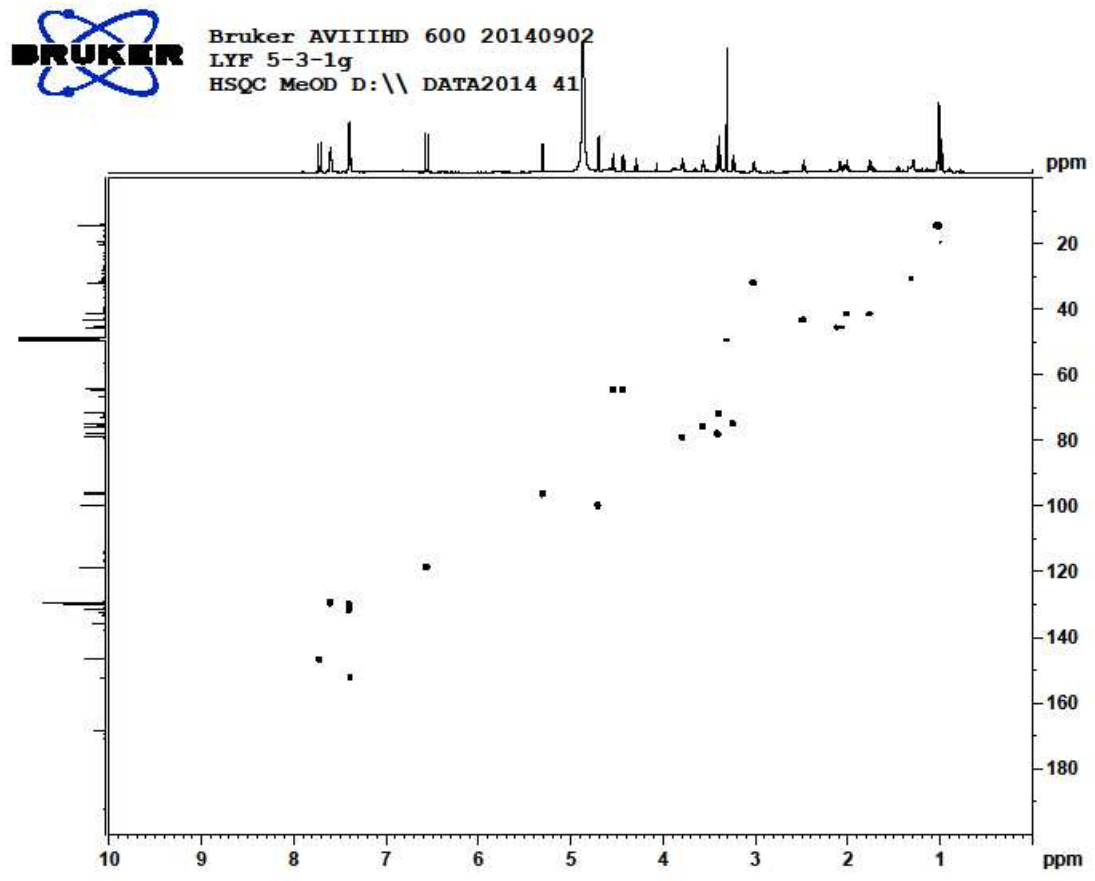

S450. HSQC Spectrum of compound 6

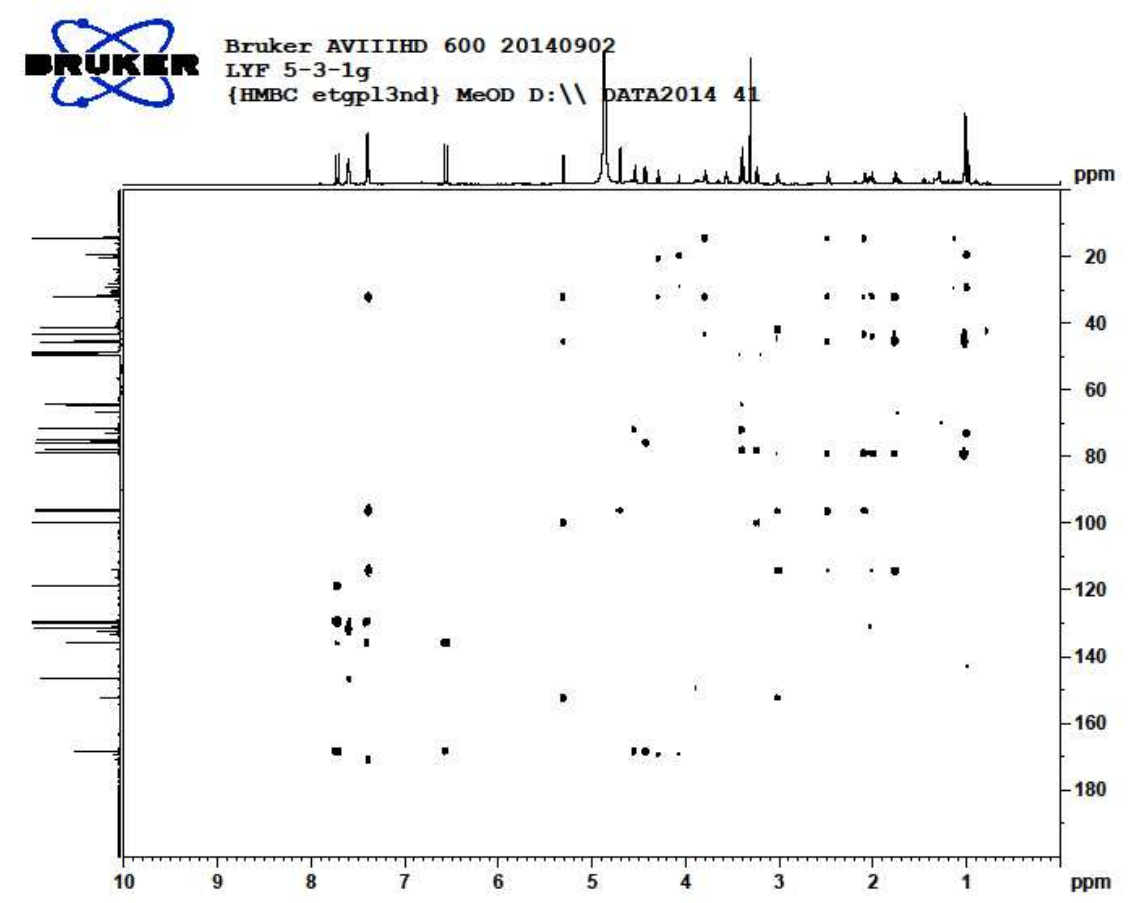

S51. HMBC Spectrum of compound 6 


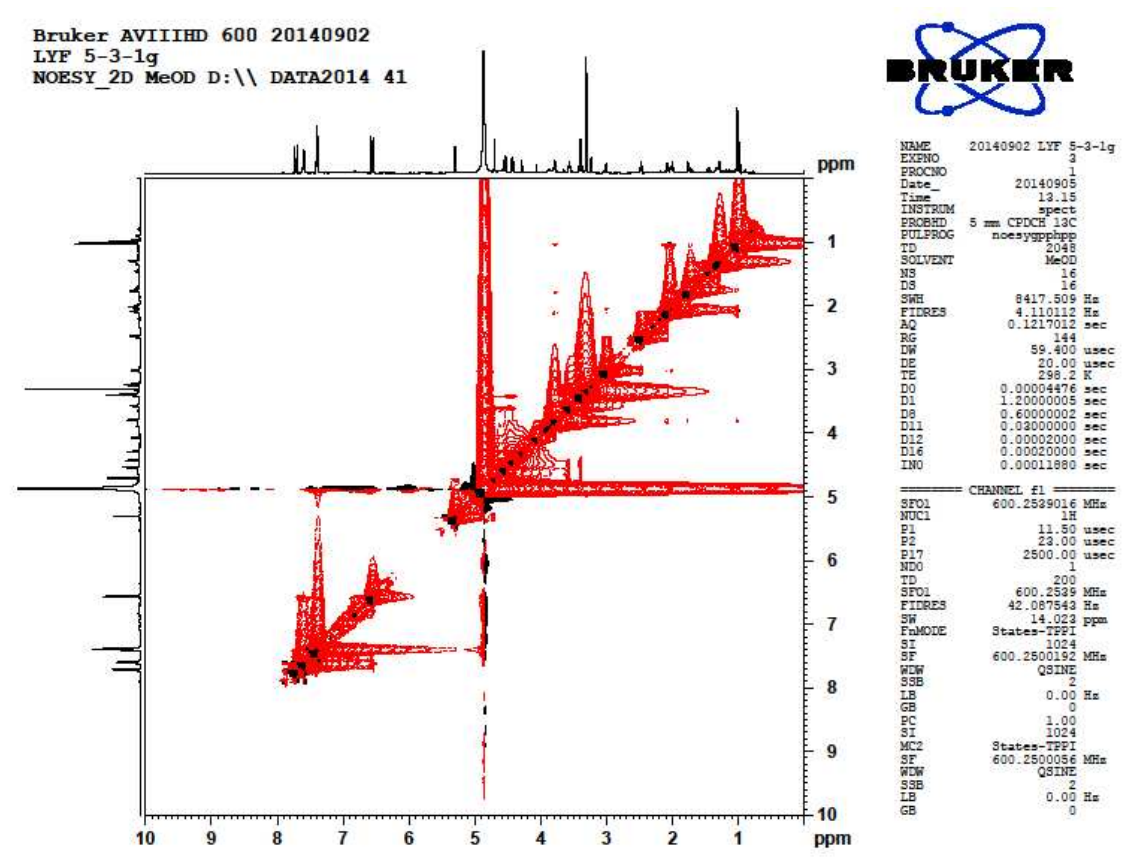

S52. NOESY Spectrum of compound 6

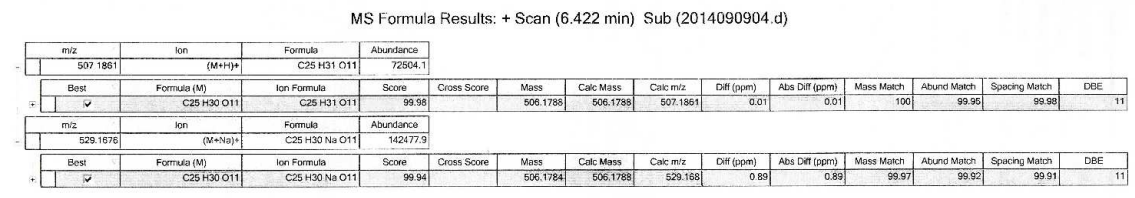

S53. HRESIMS Spectrum of compound 6

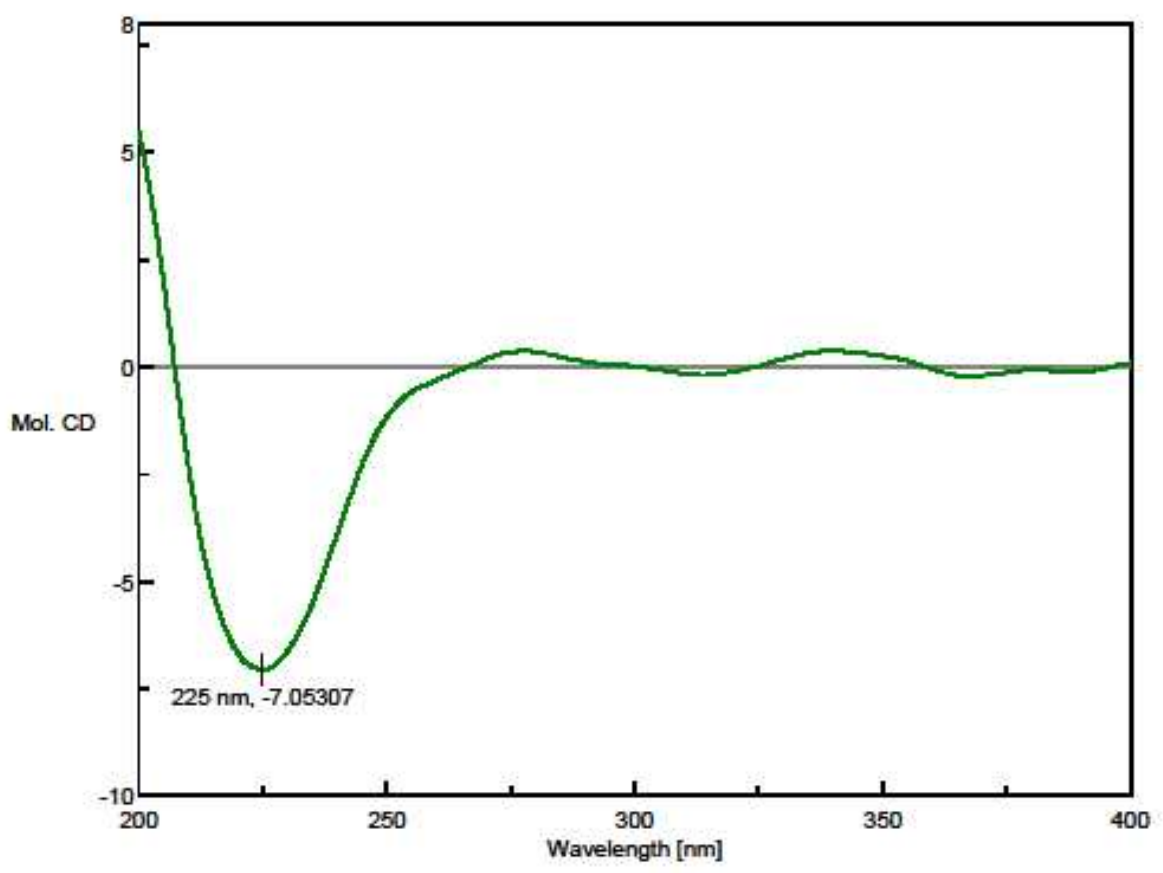

S54. CD Spectrum of compound $6\left(\mathrm{CH}_{3} \mathrm{OH}\right)$ 


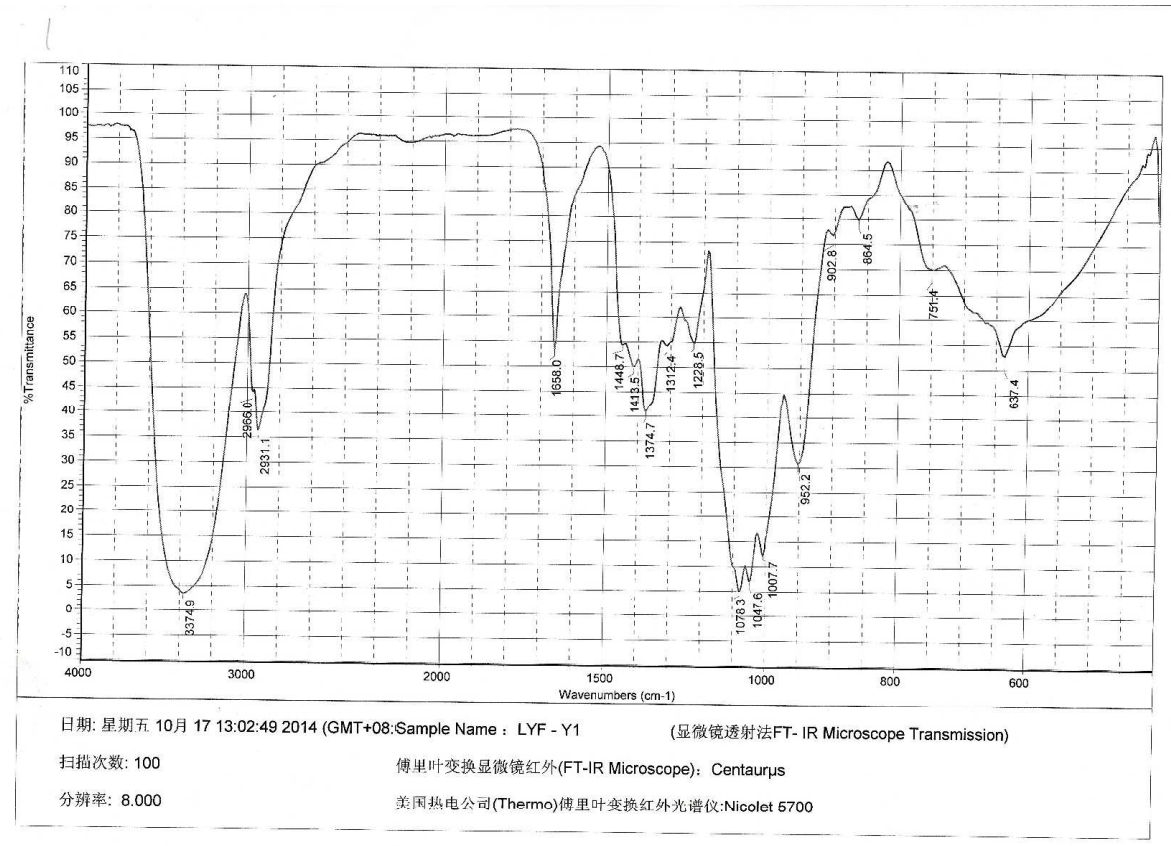

S55. IR Spectrum of compound 7

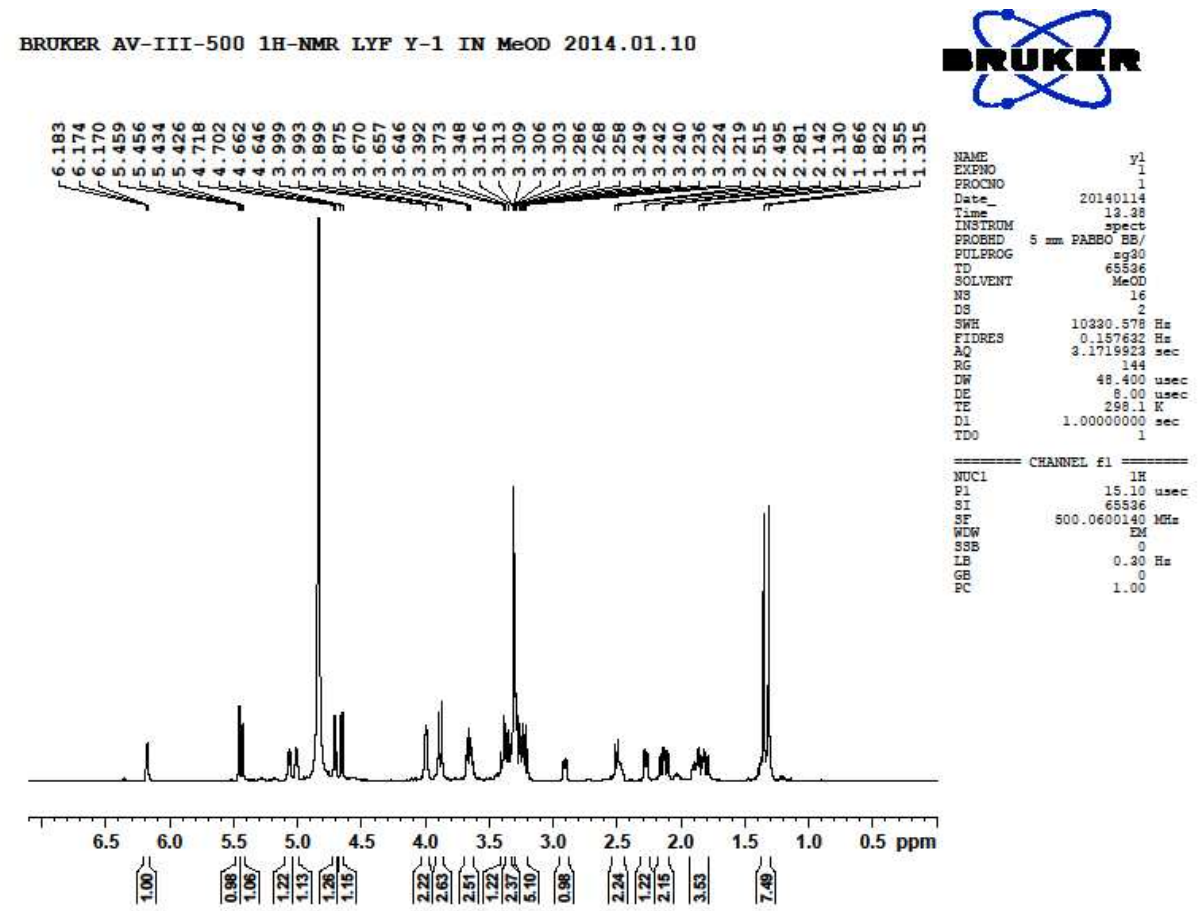

S56. ${ }^{1} \mathrm{H}$ NMR Spectrum of compound 7 (500MHz, Methanol- $\left.d_{4}\right)$ 
BRUKRE AV-III-500 13C-NMR LYF Y-1 IN MEOD 2014.01.10

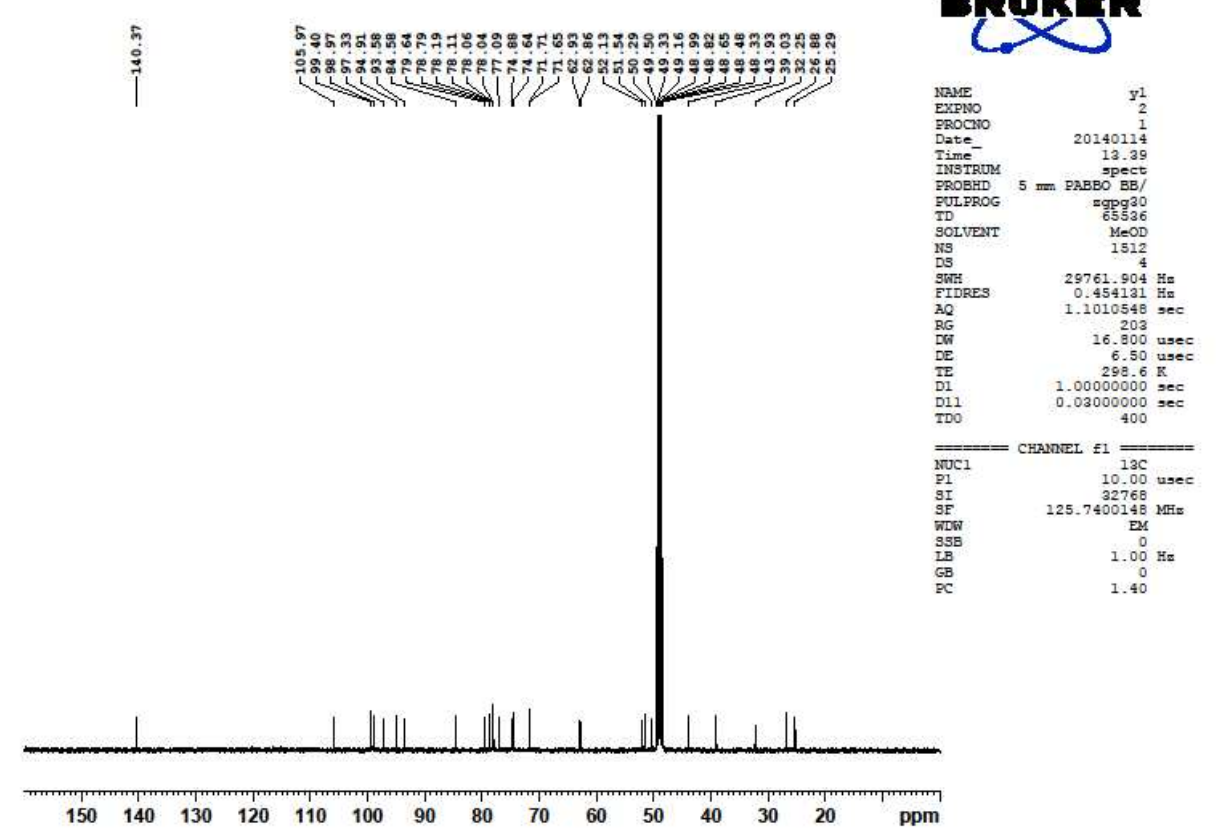

S57. ${ }^{13} \mathrm{C}$ NMR Spectrum of compound 7 (125 MHz, Methanol- $\left.d_{4}\right)$

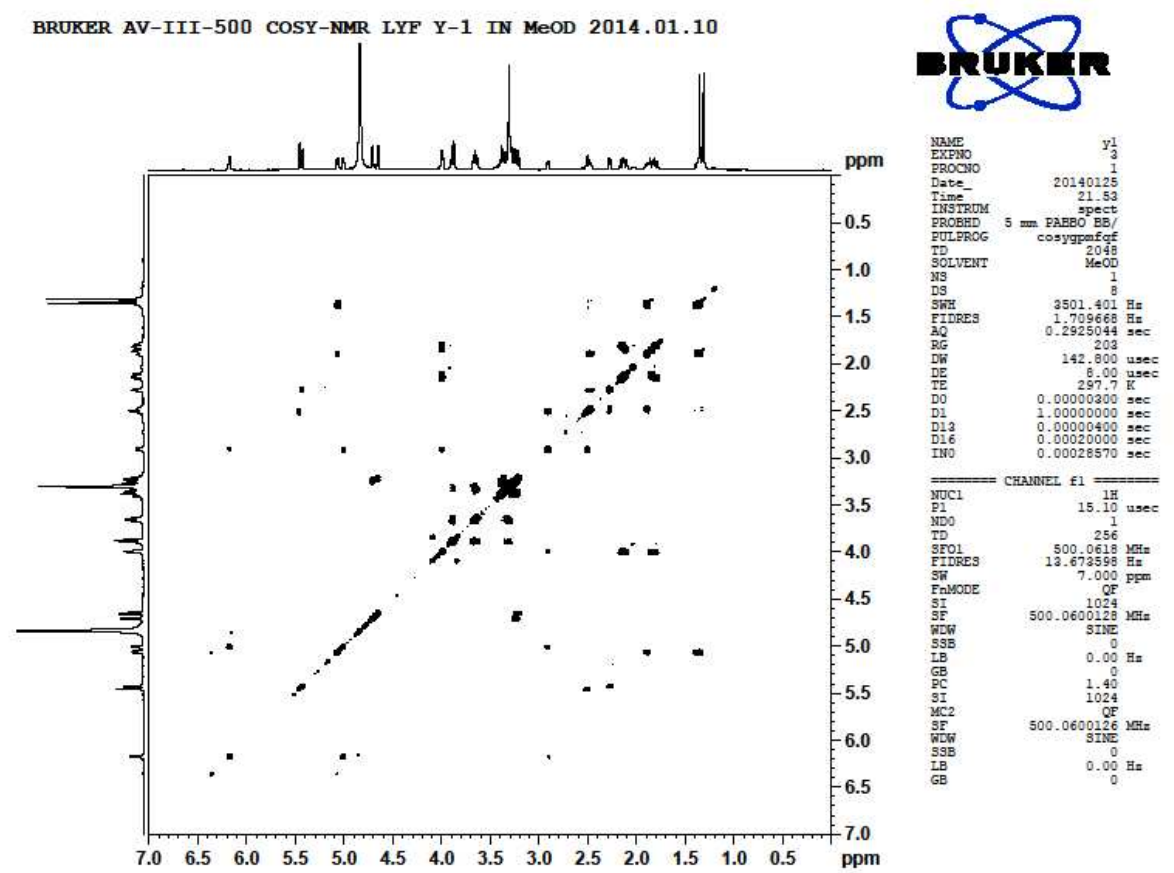

S58. ${ }^{1} \mathrm{H}-{ }^{1} \mathrm{H}$ COSY Spectrum of compound 7 


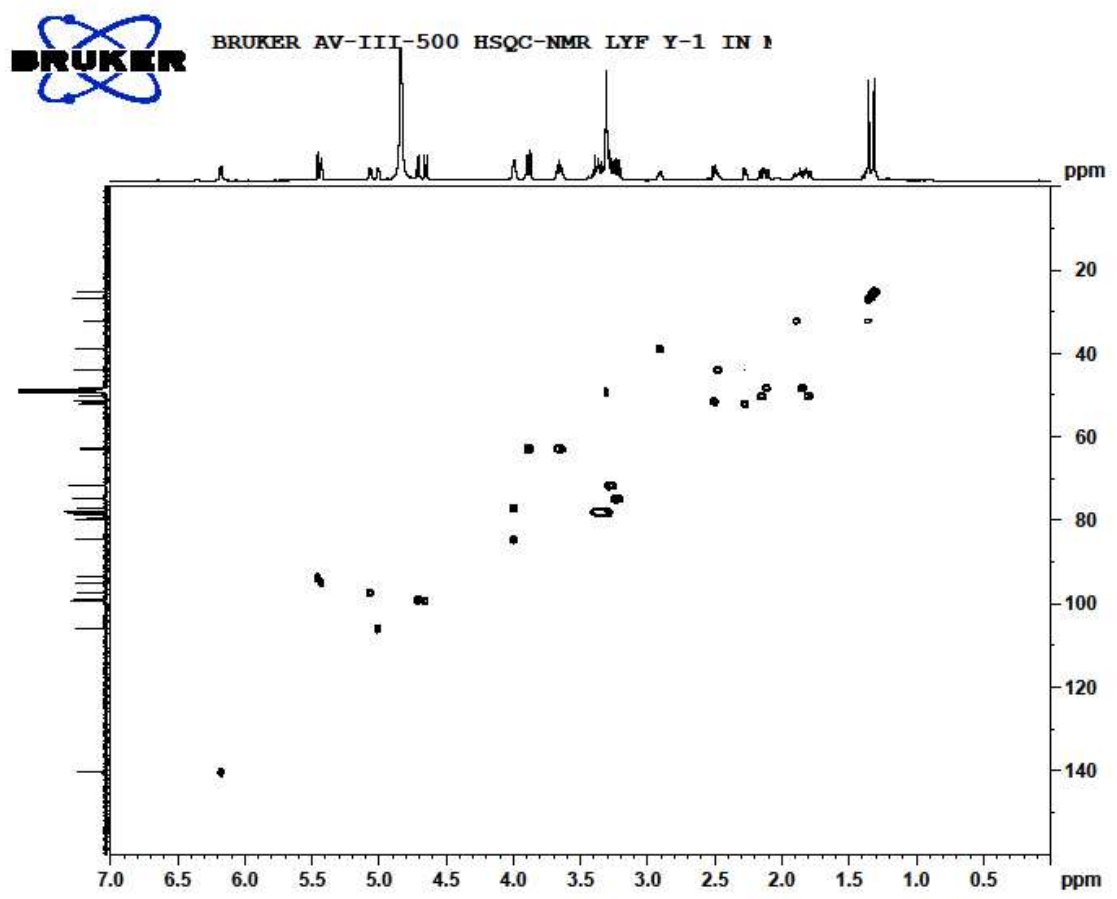

S59. HSQC Spectrum of compound 7

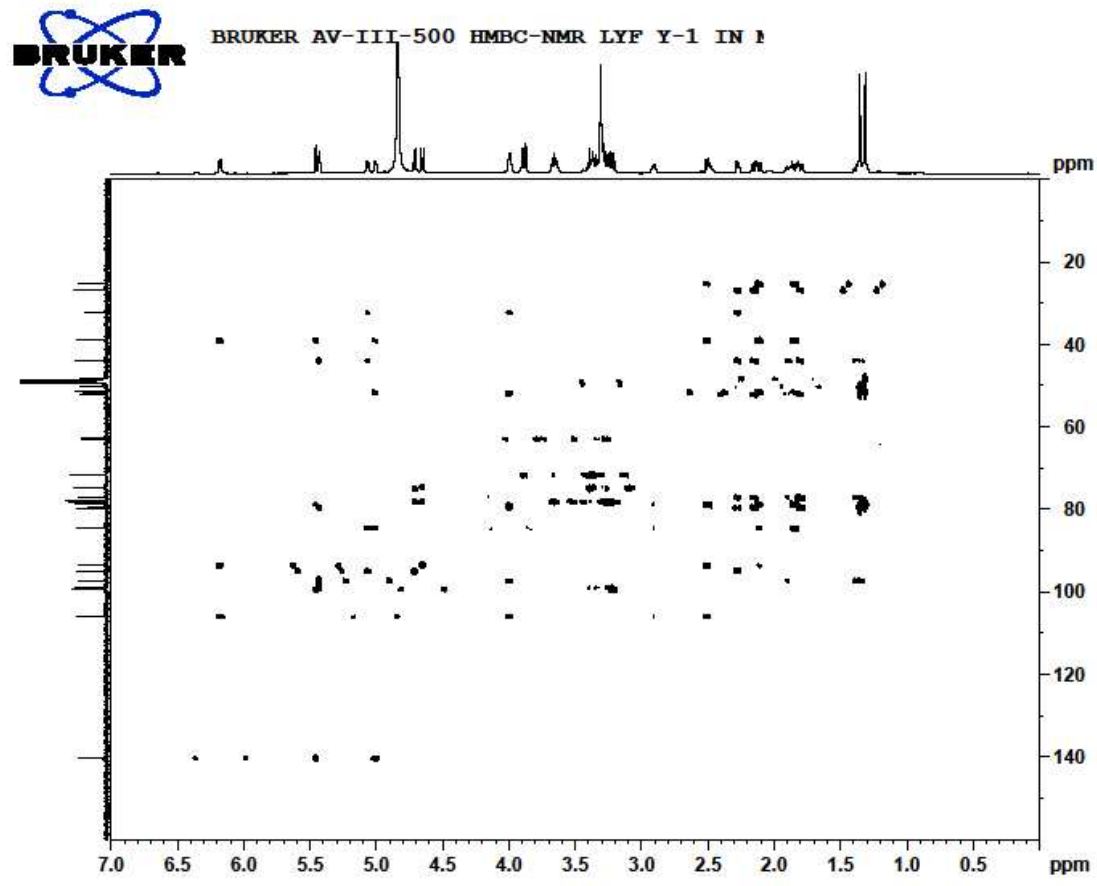

S60. HMBC Spectrum of compound 7 


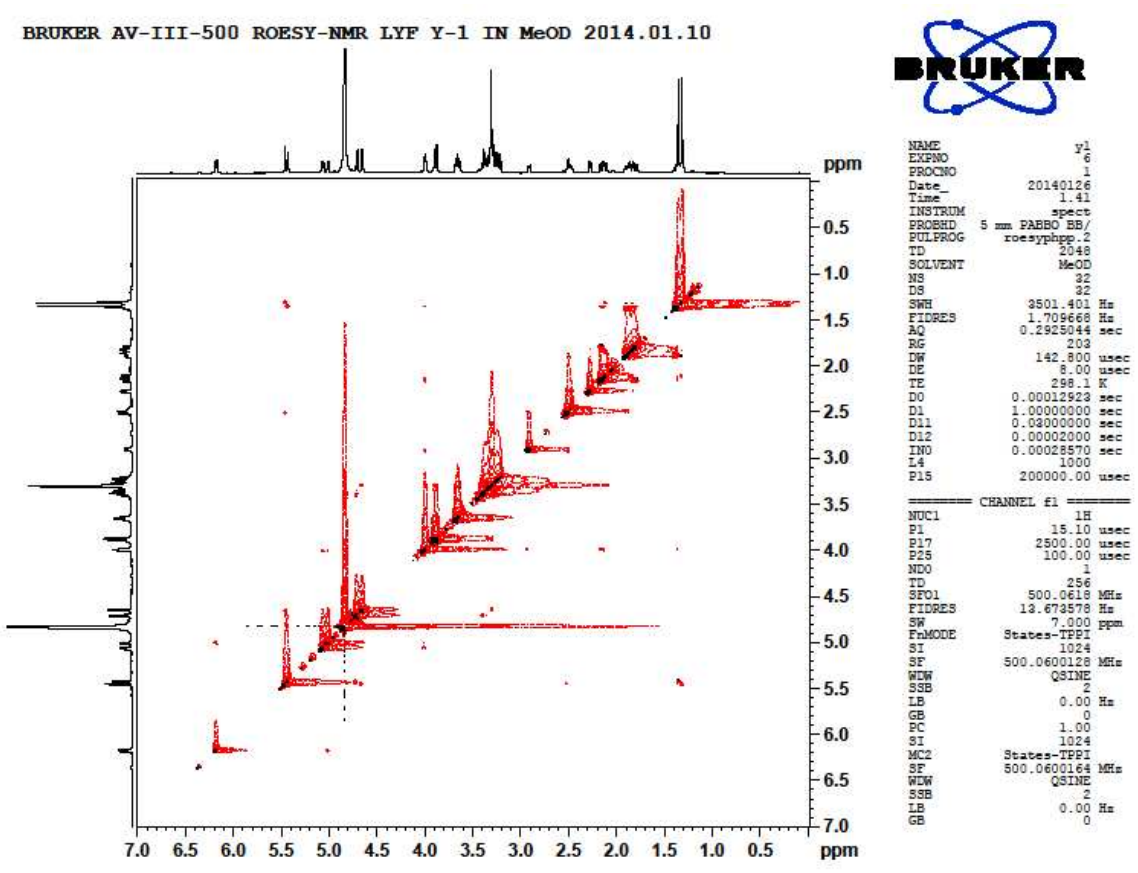

S61. ROESY Spectrum of compound 7

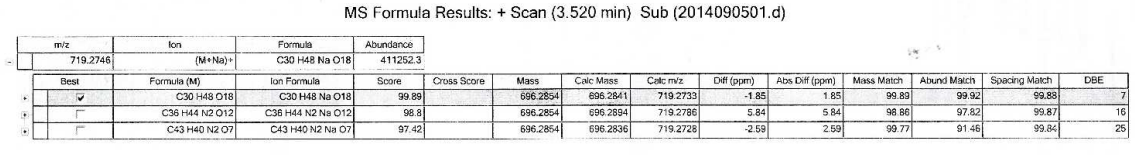

S62. HRESIMS Spectrum of compound 7

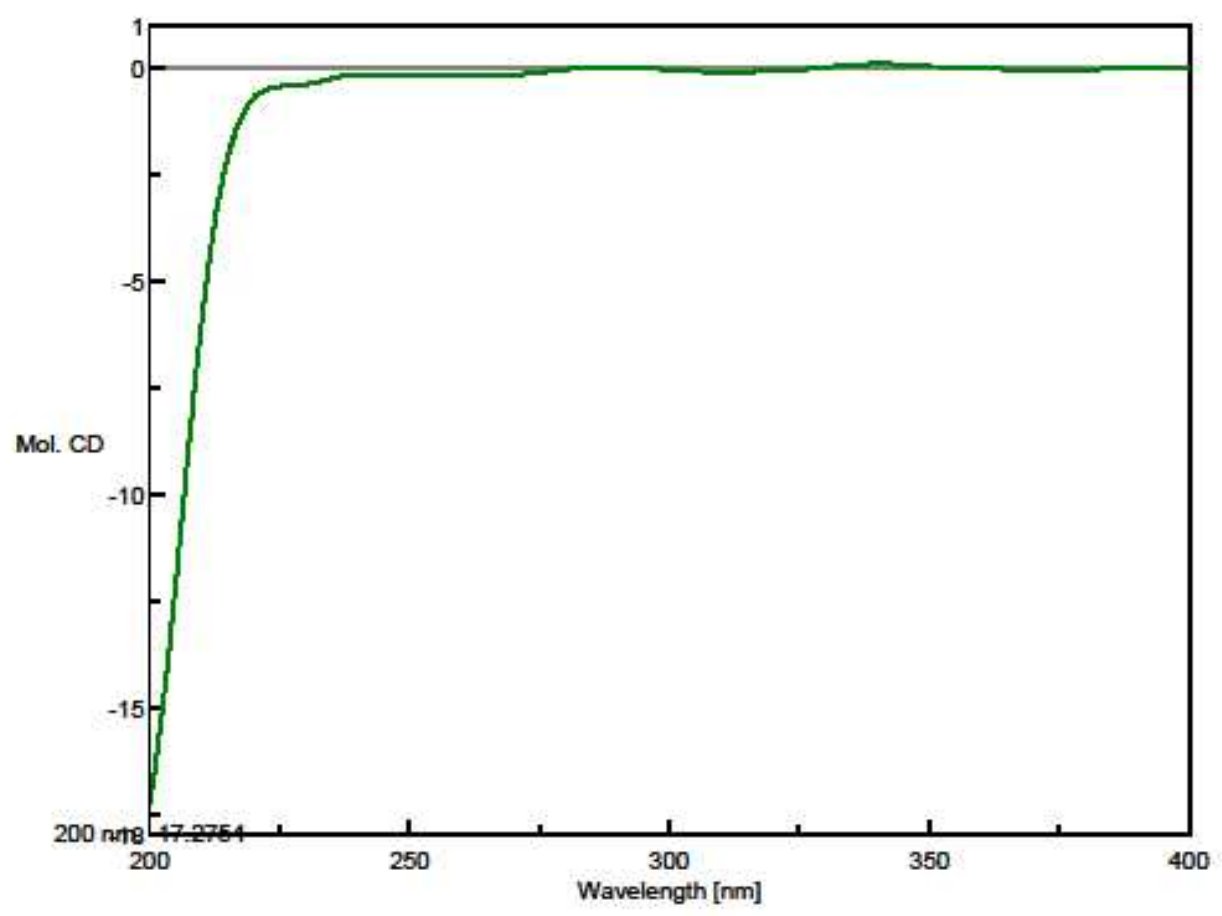

S63. CD Spectrum of compound $7\left(\mathrm{CH}_{3} \mathrm{OH}\right)$ 


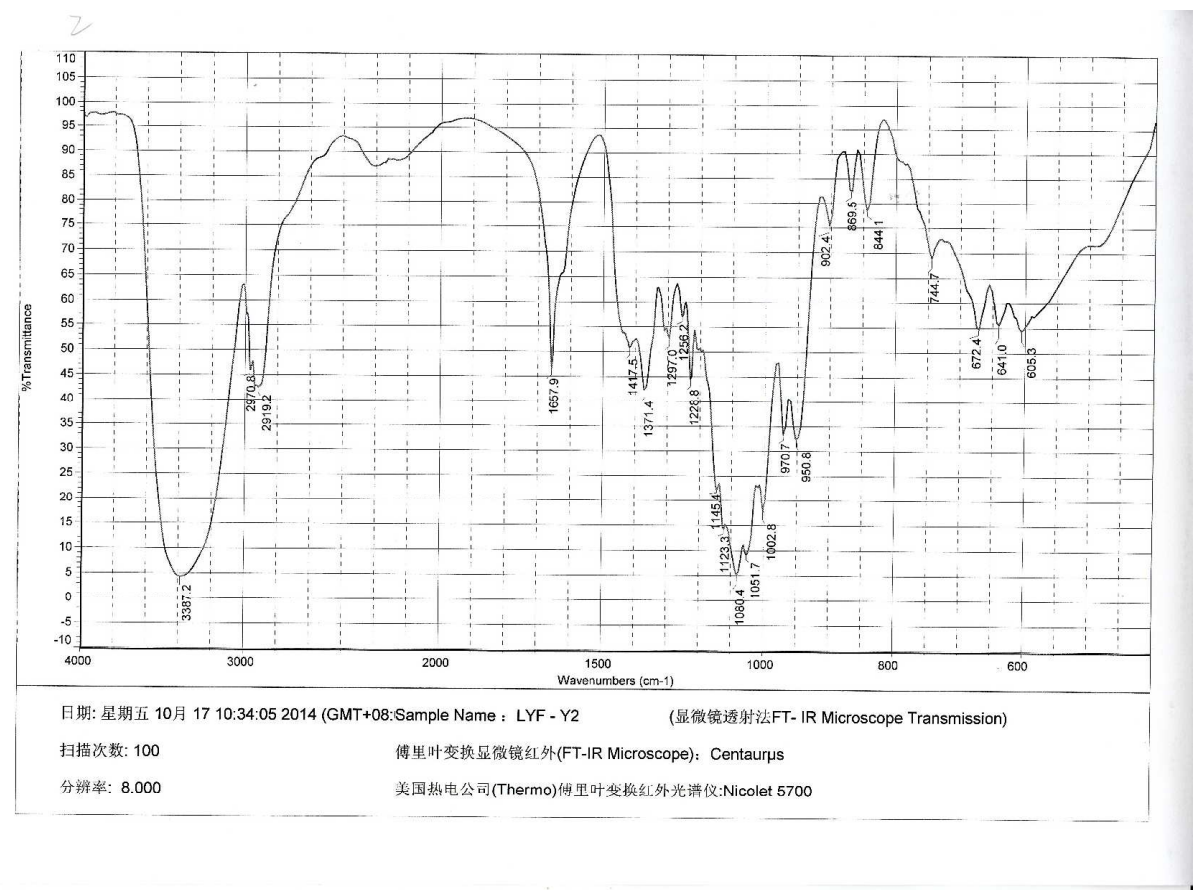

S64. IR Spectrum of compound $\mathbf{8}$

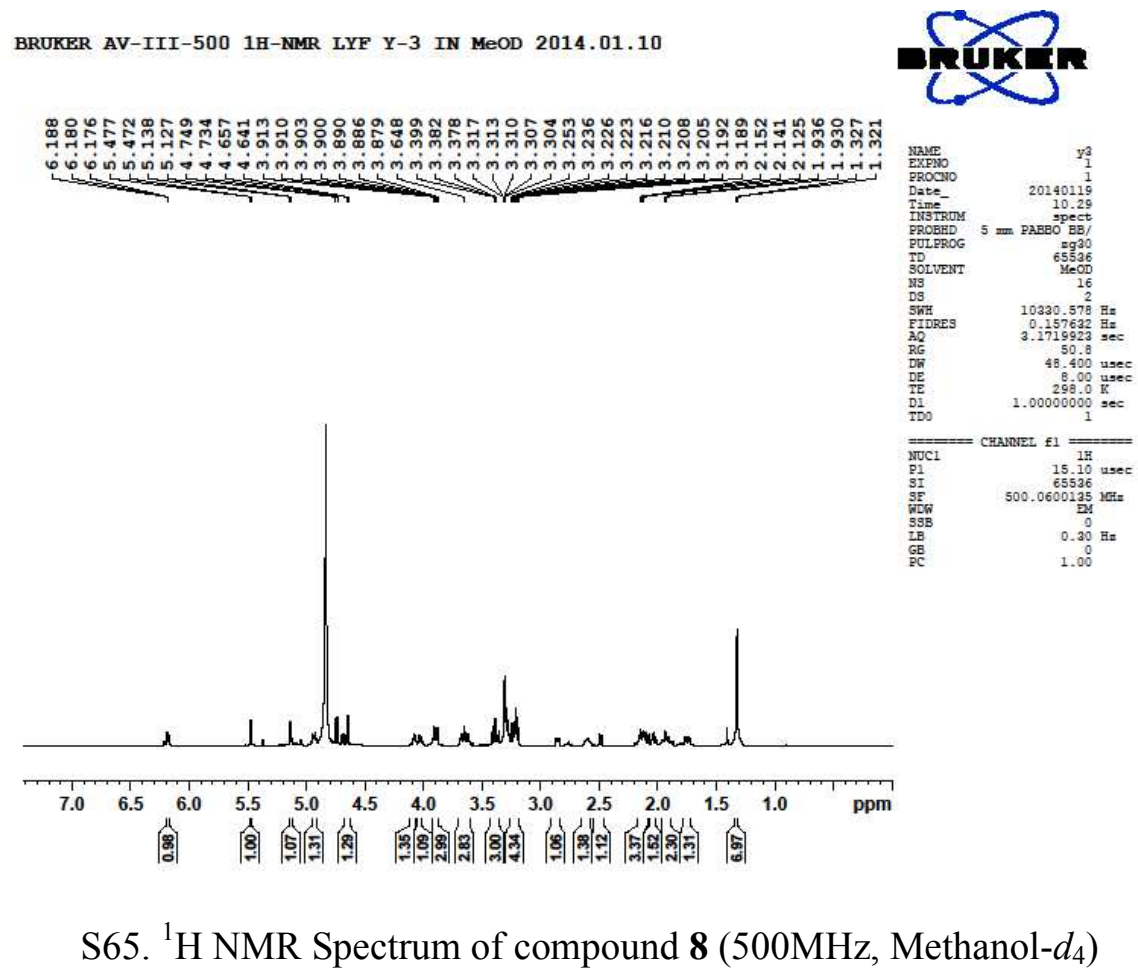




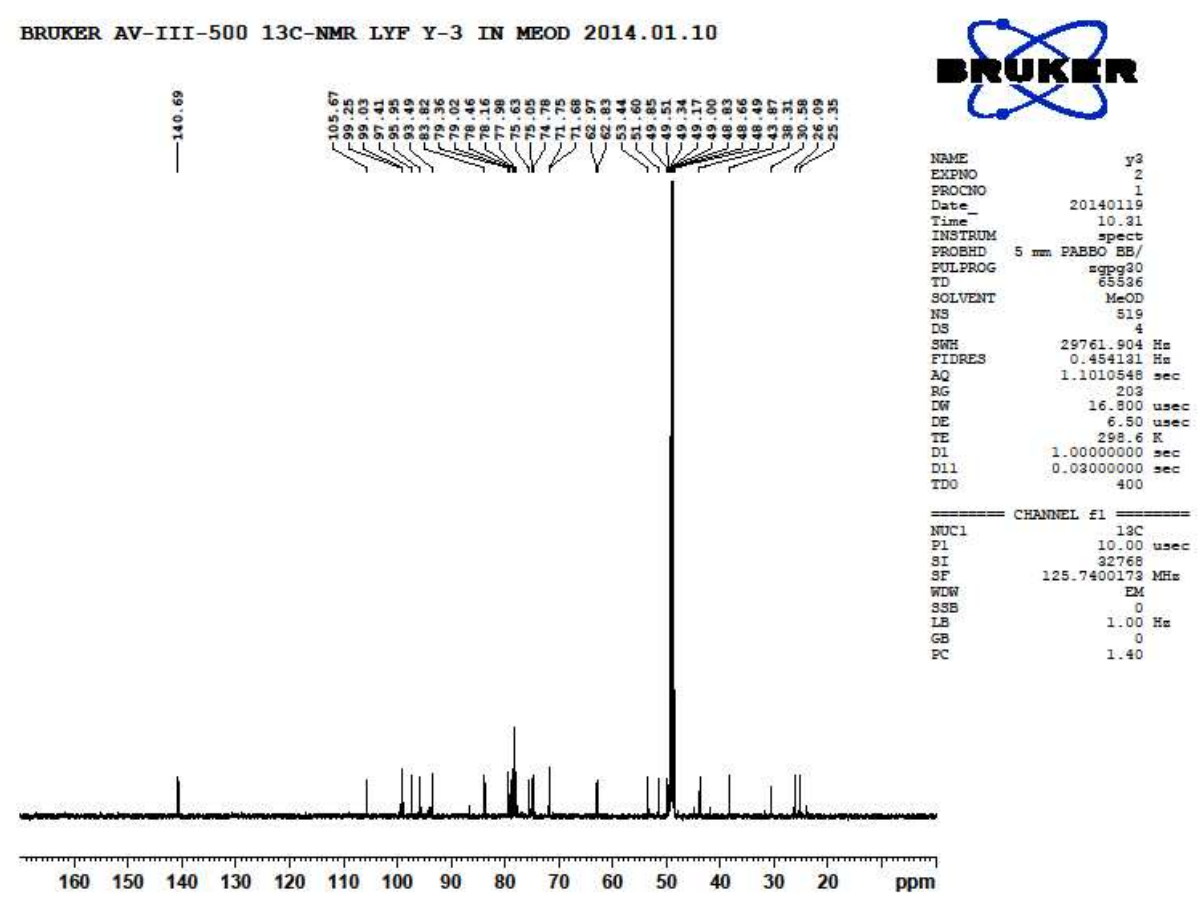

S66. ${ }^{13} \mathrm{C}$ NMR spectrum of compound 8 (125 MHz, Methanol- $\left.d_{4}\right)$

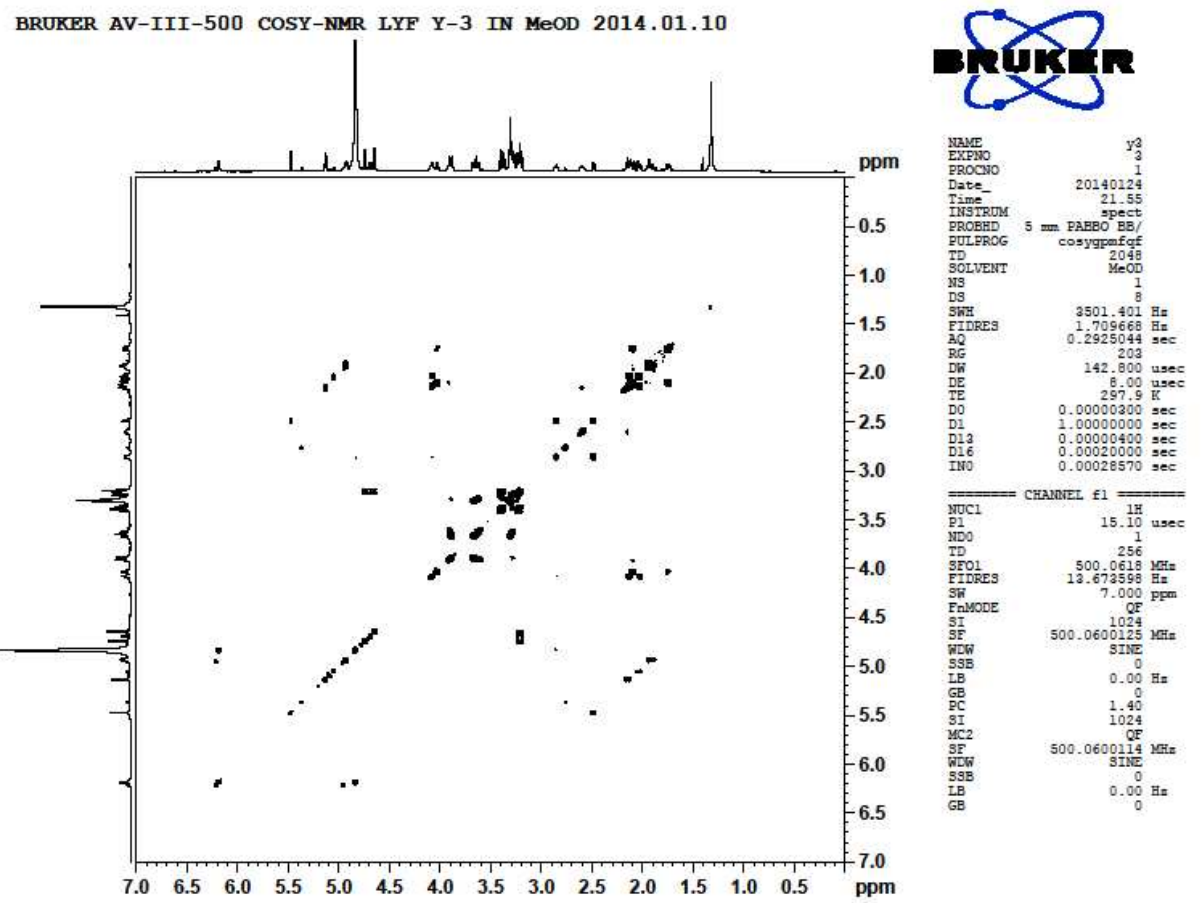

S67. ${ }^{1} \mathrm{H}-{ }^{1} \mathrm{H}$ COSY Spectrum of compound 8 


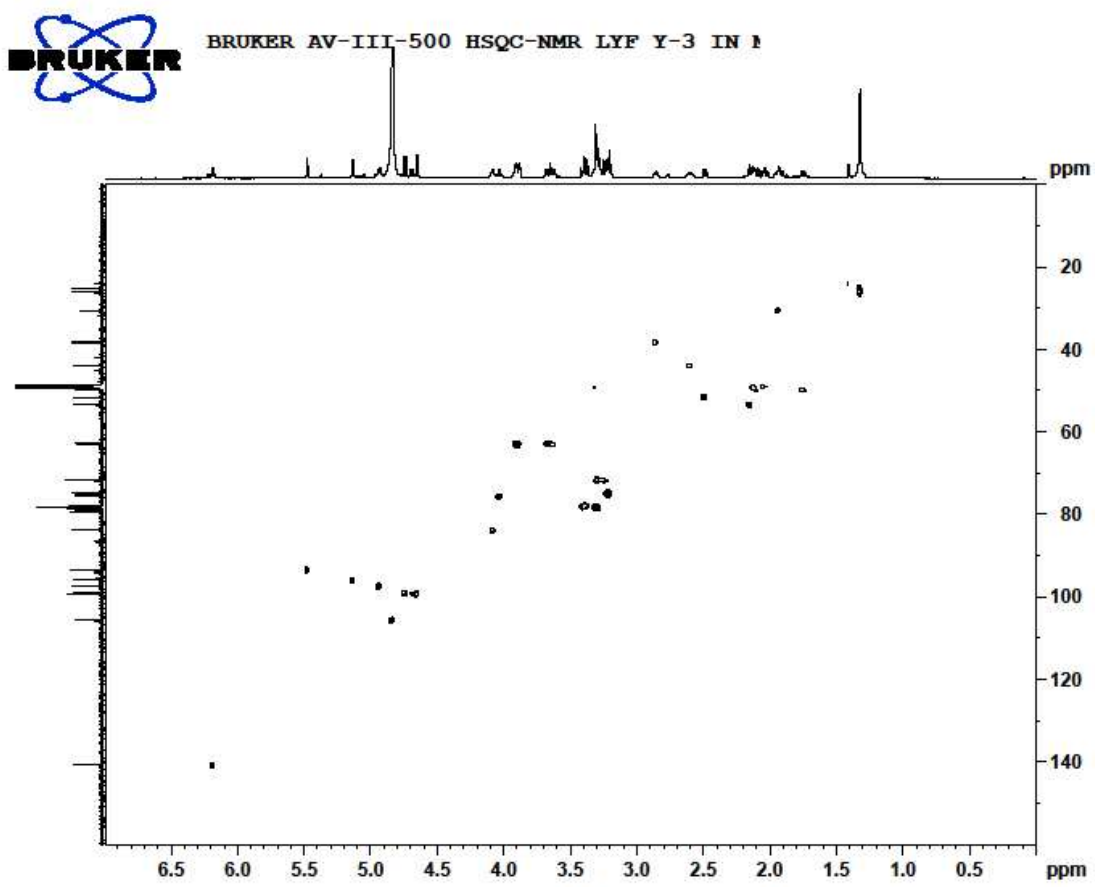

S68. HSQC Spectrum of compound $\mathbf{8}$

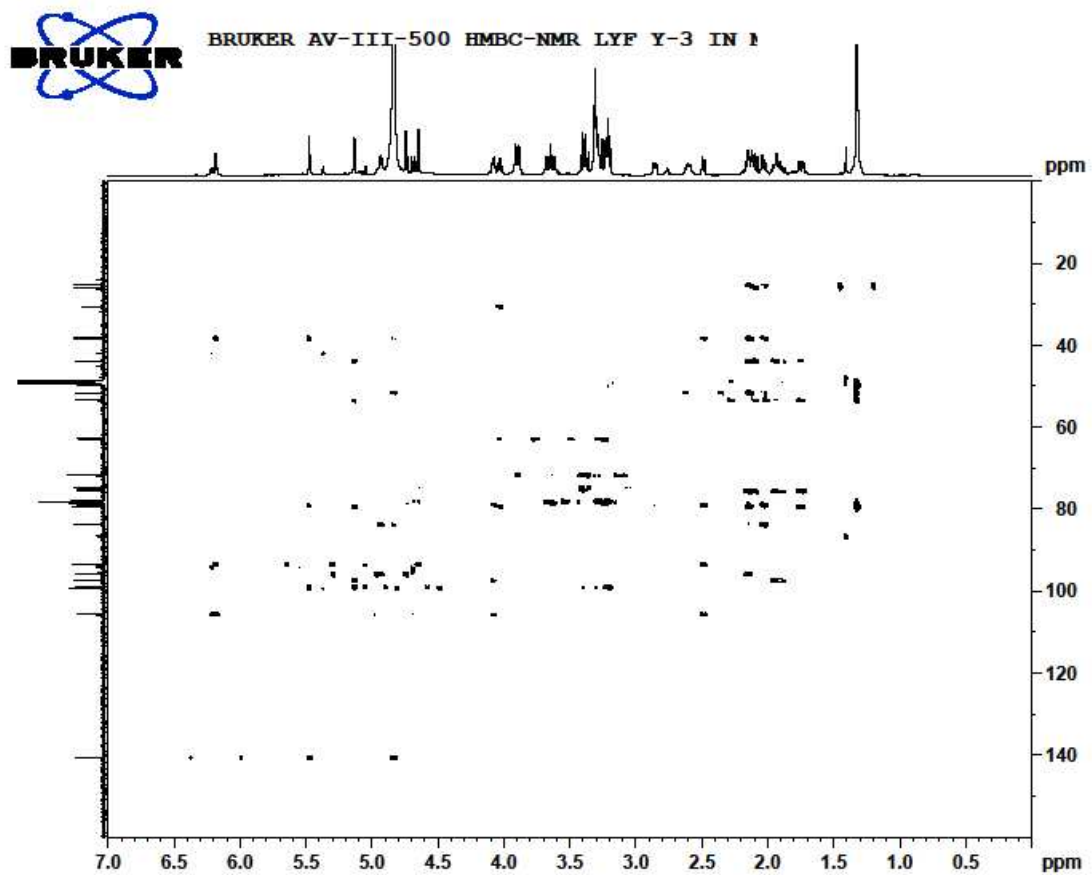

S69. HMBC Spectrum of compound $\mathbf{8}$ 


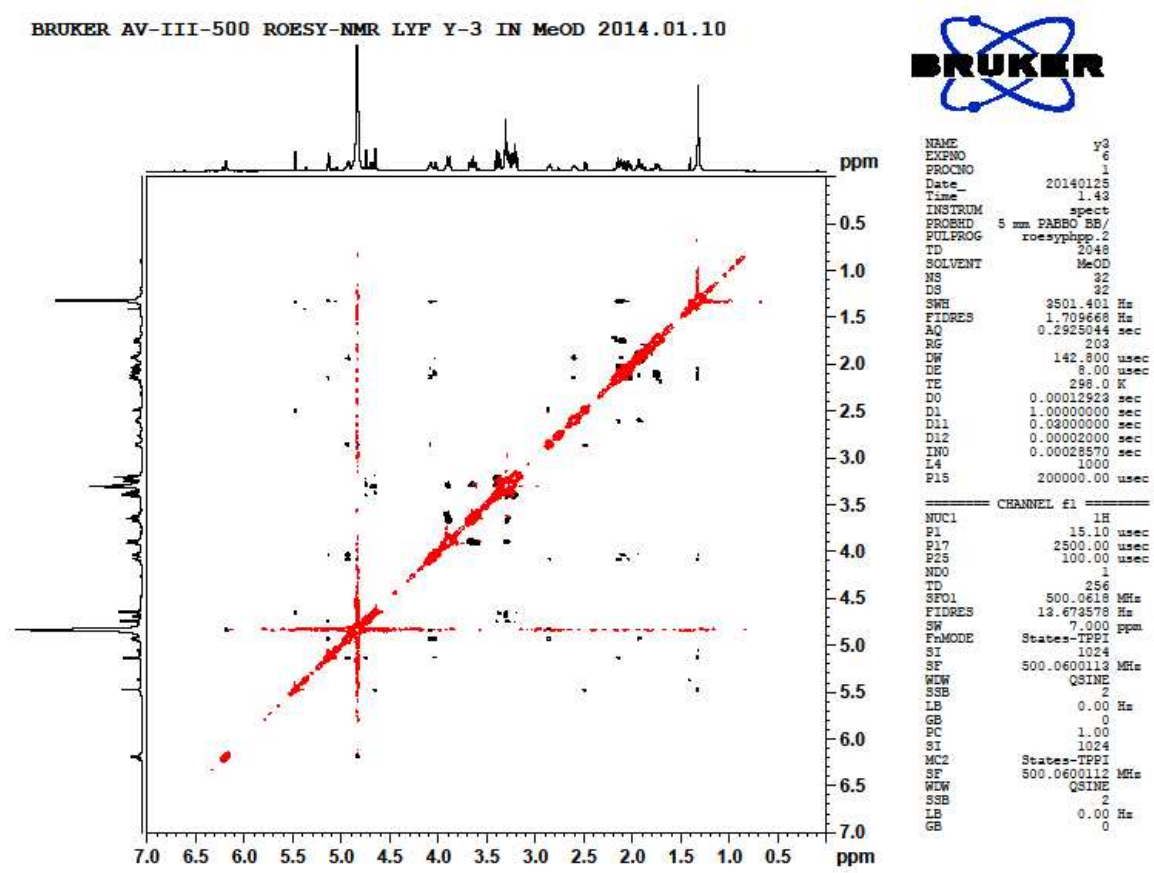

70. ROESY Spectrum of compound $\mathbf{8}$

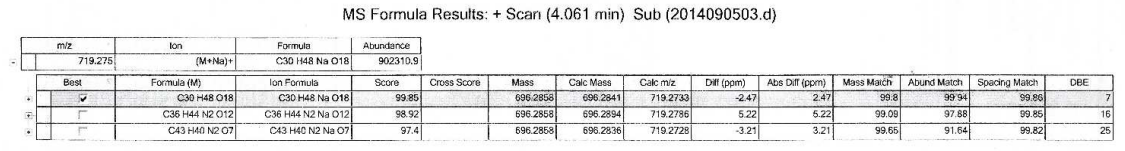

S71. HRESIMS Spectrum of compound $\mathbf{8}$

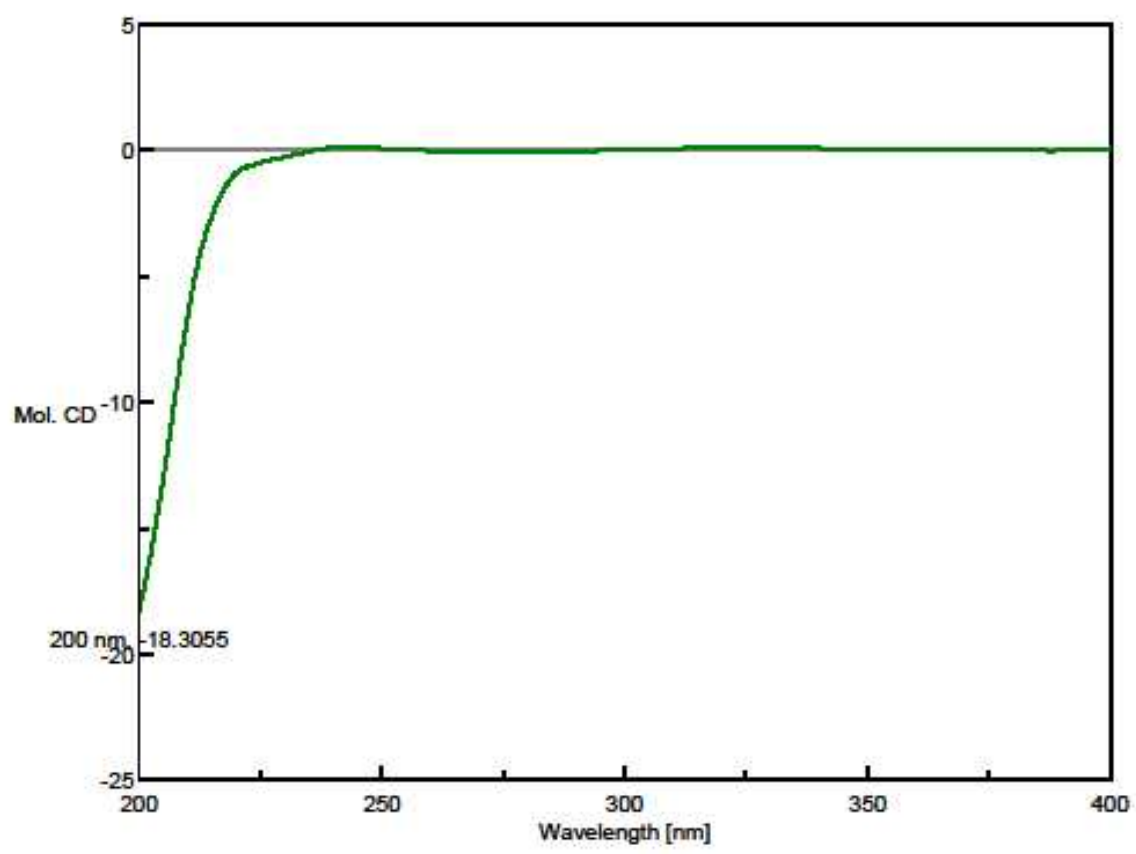

S72. CD Spectrum of compound $\mathbf{8}\left(\mathrm{CH}_{3} \mathrm{OH}\right)$ 


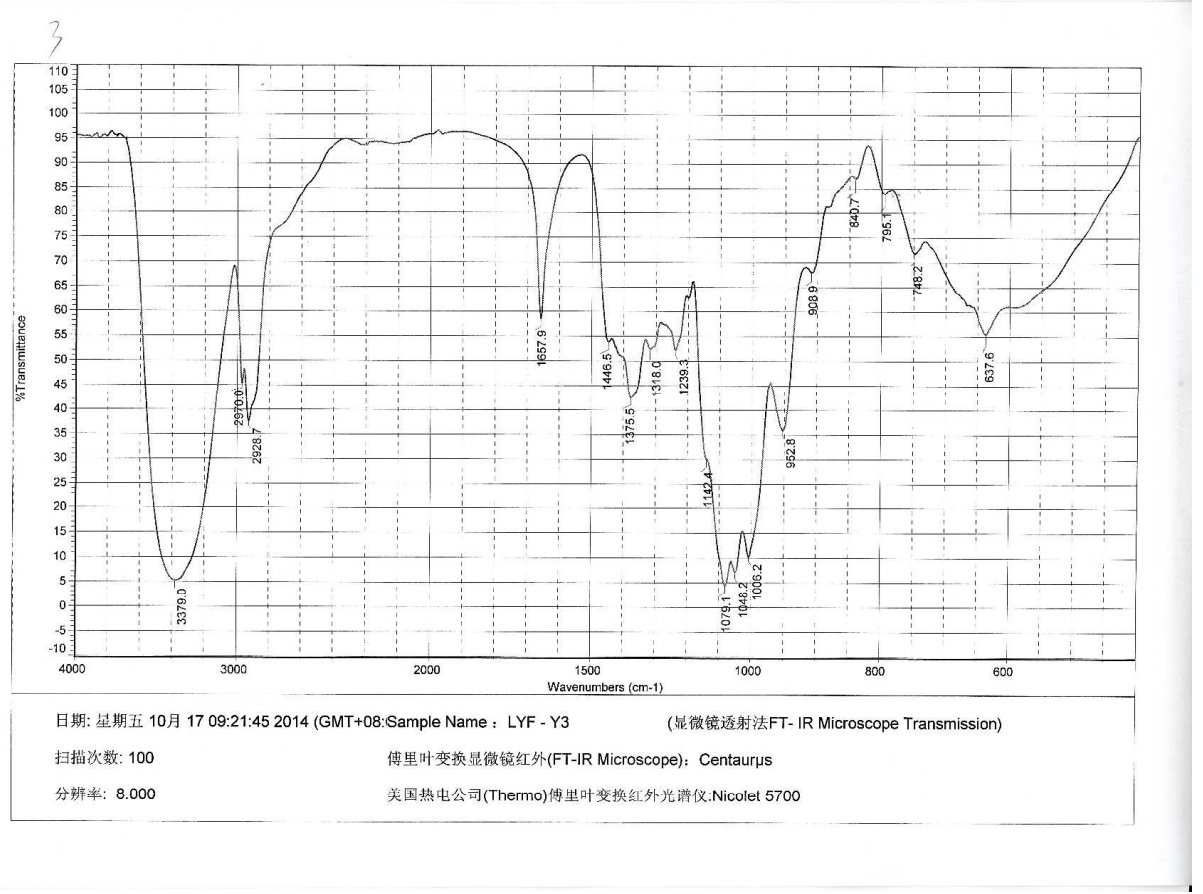

S73. IR Spectrum of compound 9

BRUKER AV-III-500 1H-NMR LYF Y-2 IN MeOD 2014.01.10
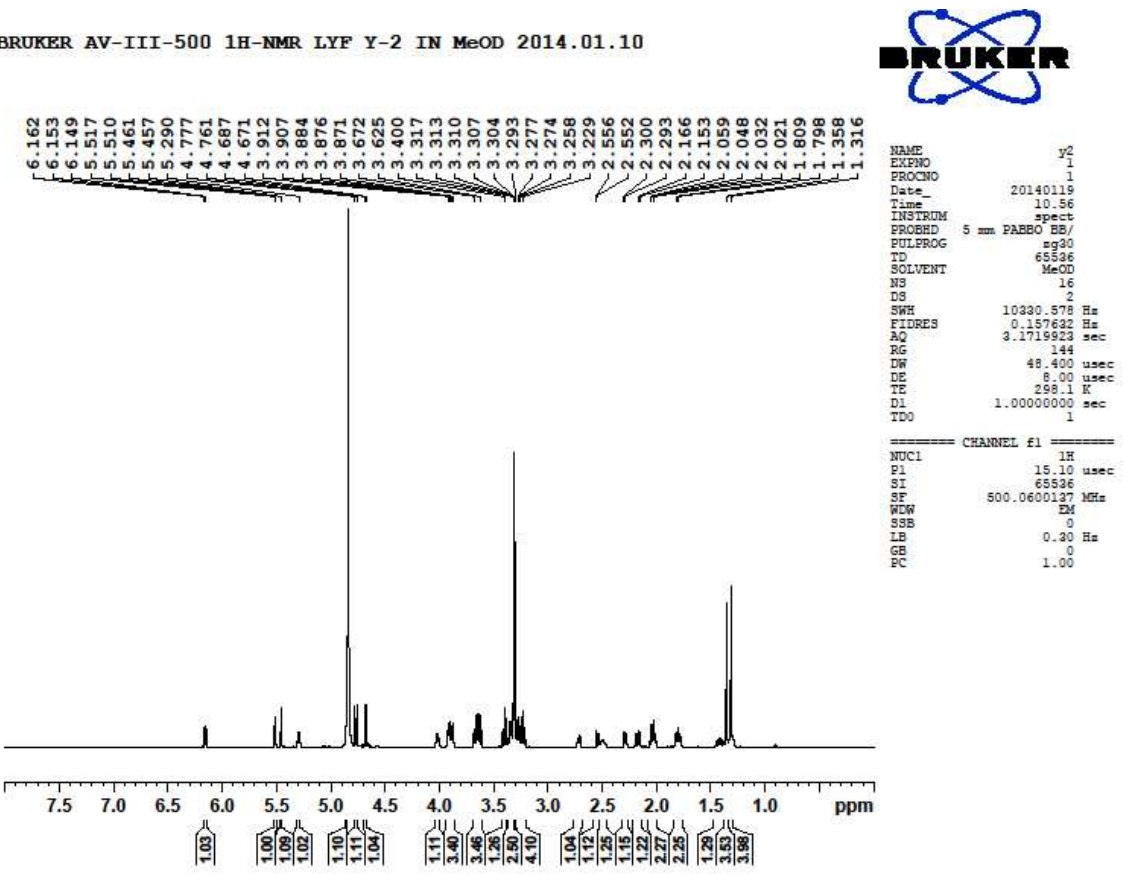

S74. ${ }^{1} \mathrm{H}$ NMR Spectrum of compound $9\left(500 \mathrm{MHz}\right.$, Methanol- $\left.d_{4}\right)$ 


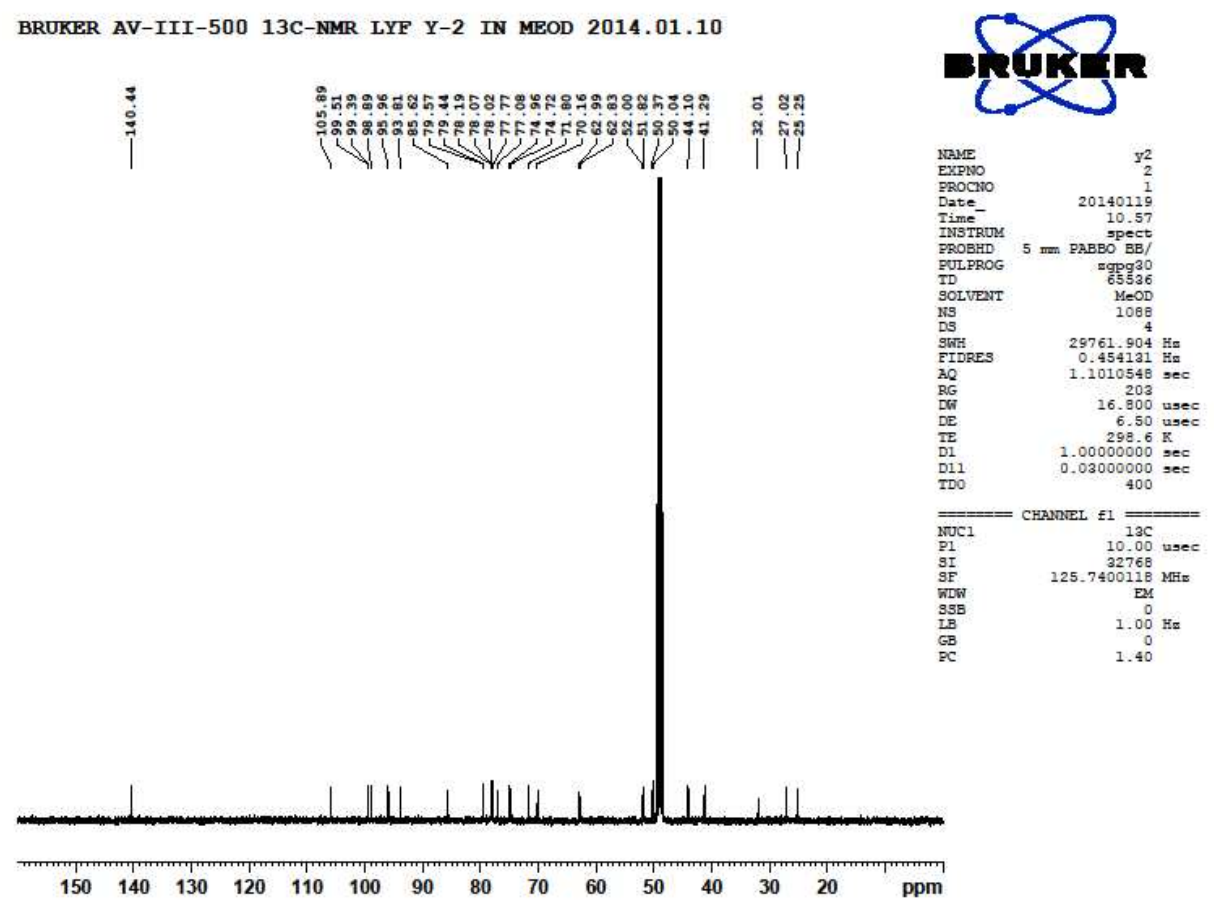

S75. ${ }^{13} \mathrm{C}$ NMR Spectrum of compound 9 (125 MHz, Methanol- $\left.d_{4}\right)$

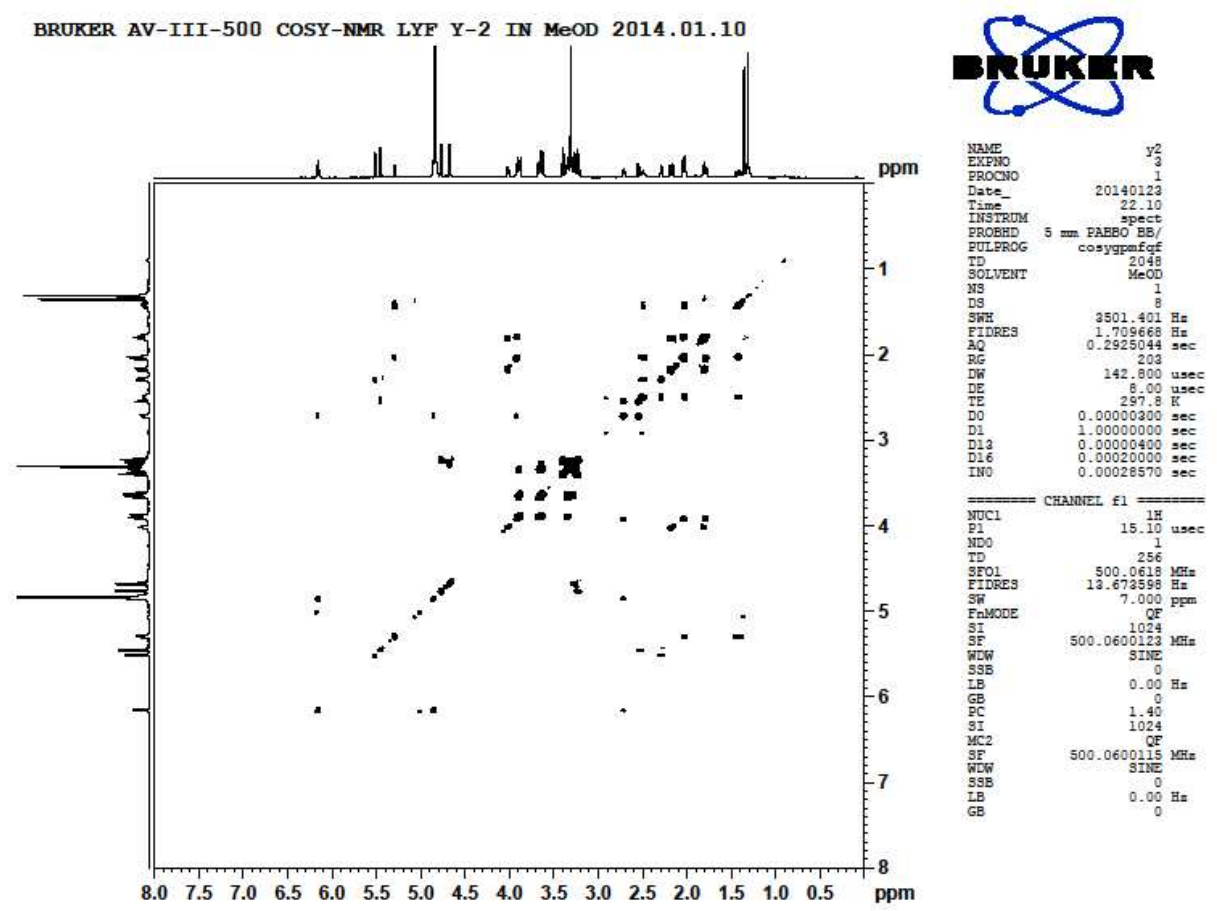

S76. ${ }^{1} \mathrm{H}-{ }^{1} \mathrm{H}$ COSY Spectrum of compound 9 


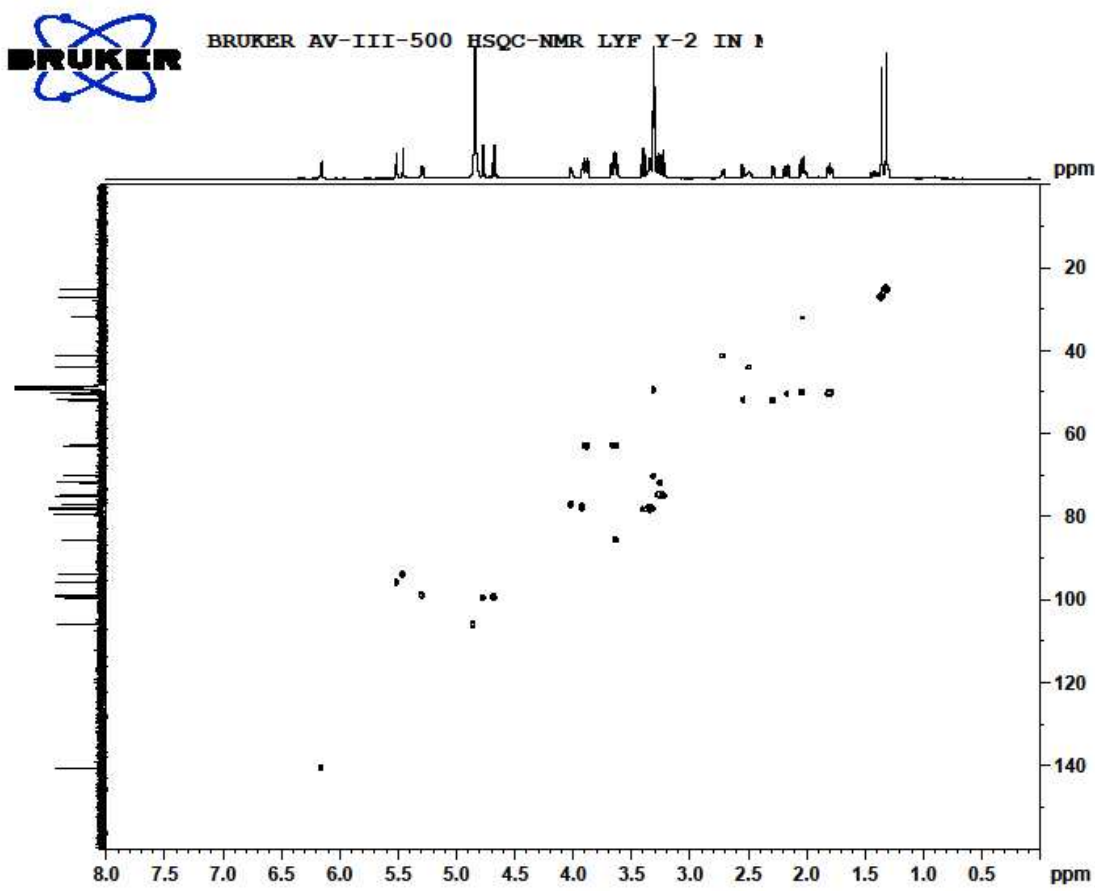

S77. HSQC Spectrum of compound 9

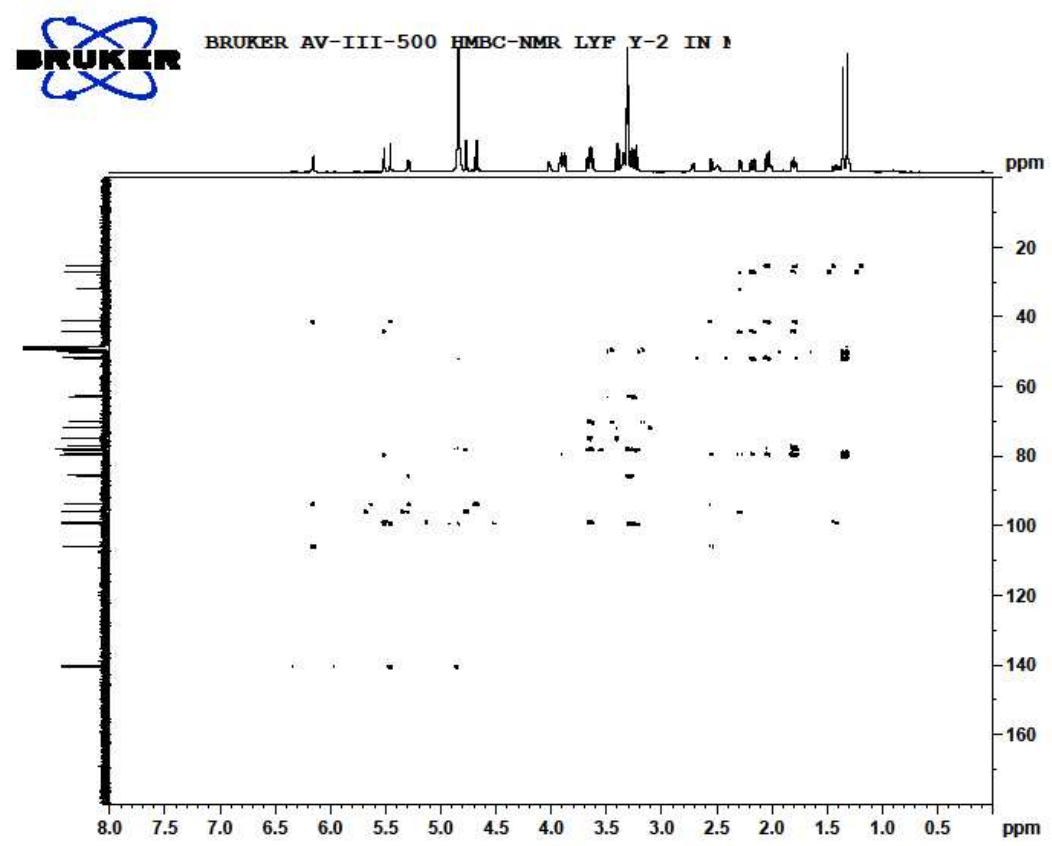

S78. HMBC Spectrum of compound 9 


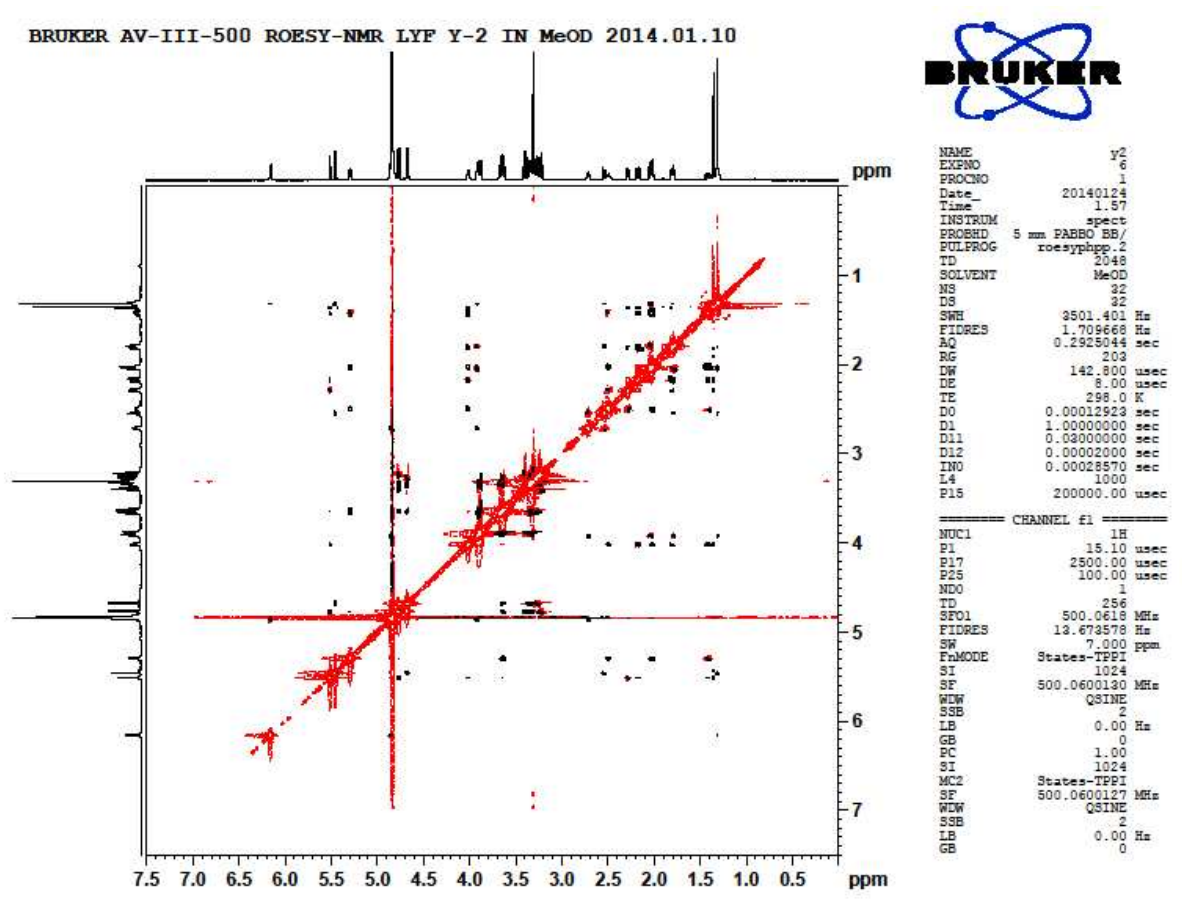

S79. ROESY Spectrum of compound 9

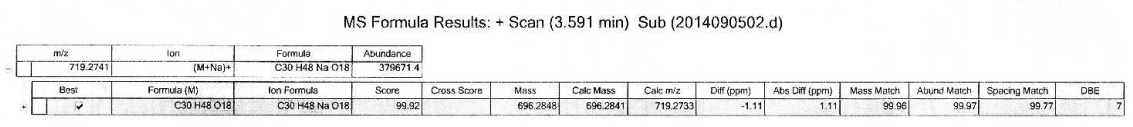

S80. HRESIMS Spectrum of compound 9

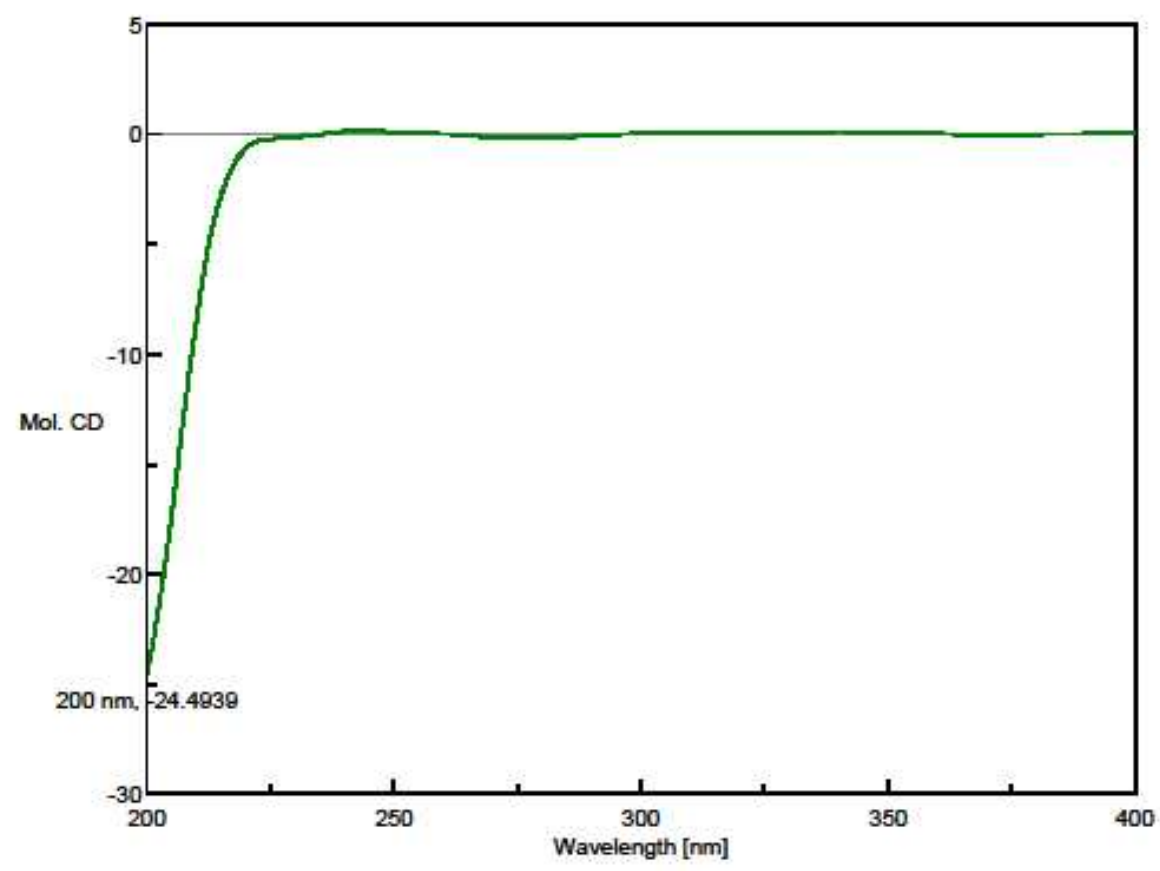

S81. CD Spectrum of compound $9\left(\mathrm{CH}_{3} \mathrm{OH}\right)$ 